NBER WORKING PAPER SERIES

\title{
THE CROSS-SECTION OF RISK AND RETURN
}

\author{
Kent Daniel \\ Lira Mota \\ Simon Rottke \\ Tano Santos \\ Working Paper 24164 \\ http://www.nber.org/papers/w24164 \\ NATIONAL BUREAU OF ECONOMIC RESEARCH \\ 1050 Massachusetts Avenue \\ Cambridge, MA 02138 \\ December 2017, Revised November 2019
}

We thank Mike Chernov, Stefano Giglio, Ravi Jagannathan, Sonia Jimenez-Garcès, Ralph Koijen, Lars Lochstoer, Maurizio Luisi, Luca Mertens, Suresh Sundaresan, Paul Tetlock, Brian Weller, Michael Wolf, Dacheng Xiu, Leifu Zhang, as well as the participants of seminars at Amsterdam, Baruch/CUNY, BI Oslo, CEMFI, Cincinnati, Columbia, Cornell, Georgetown, Hannover, HEC Montreal, Icade, Kellogg/Northwestern, Michigan, NYU, TU München, Münster, UCLA, UT Austin, Washington University, Yale, Zürich, AQR, Barclays, Bloomberg, Deutsche Bank, Goldman Sachs, Kepos Capital, SQA, Stone Ridge, and the participants of conferences at the AFA, AFFI, DGF, EFA, EEA, Fordham, Hoechst, HKUST, Imperial College, "New Methods for the Cross Section of Returns" in Chicago, and Villanova for helpful comments and suggestions, and Dan Mechanic for his support with the computing cluster. Simon Rottke is grateful for financial support from the Fritz Thyssen Stiftung. The views expressed herein are those of the authors and do not necessarily reflect the views of the National Bureau of Economic Research.

At least one co-author has disclosed a financial relationship of potential relevance for this research. Further information is available online at http://www.nber.org/papers/w24164.ack

NBER working papers are circulated for discussion and comment purposes. They have not been peer-reviewed or been subject to the review by the NBER Board of Directors that accompanies official NBER publications.

(C) 2017 by Kent Daniel, Lira Mota, Simon Rottke, and Tano Santos. All rights reserved. Short sections of text, not to exceed two paragraphs, may be quoted without explicit permission provided that full credit, including ( $)$ notice, is given to the source. 
The Cross-Section of Risk and Return

Kent Daniel, Lira Mota, Simon Rottke, and Tano Santos

NBER Working Paper No. 24164

December 2017, Revised November 2019

JEL No. G00,G1,G12,G14

\begin{abstract}
In the finance literature, a common practice is to create characteristic portfolios by sorting on characteristics associated with average returns. We show that the resulting portfolios are likely to capture not only the priced risk associated with the characteristic, but also unpriced risk. We develop a procedure to remove this unpriced risk using covariance information estimated from past returns. We apply our methodology to the five Fama and French (2015) characteristic portfolios. The squared Sharpe ratio of the optimal combination of the resulting characteristic efficient portfolios is 2.16 , compared with 1.16 for the original characteristic portfolios.

Kent Daniel

Graduate School of Business

Columbia University

3022 Broadway, Uris Hall 421

New York, NY 10027

and NBER

kd2371@columbia.edu

Lira Mota

Columbia Business School

3022 Broadway

Uris Hall

New York, NY 10025

LMota20@gsb.columbia.edu

Simon Rottke

University of Amsterdam

Finance Group

Plantage Muidergracht 12

1018 TV Amsterdam

Netherlands

simon.rottke@uva.nl

Tano Santos

Graduate School of Business

Columbia University

3022 Broadway, Uris Hall 414

New York, NY 10027

and NBER

js1786@columbia.edu
\end{abstract}




\section{Introduction}

A common practice in the academic finance literature has been to create characteristic portfolios (CPs) by sorting on characteristics positively associated with expected returns. The resulting set of zero-investment CPs, which go long a portfolio of high characteristic firms and short a portfolio of low characteristic firms, then serve as a model for returns in that asset space. Fama and French $(1993,2015)$ are prominent examples of this approach, but there are numerous others, developed both to explain the equity market anomalies, and also the cross-section of returns in other asset classes 1

Consistent with this, Fama and French (2015, FF) argue that a standard dividend-discount model implies that a combination of firm characteristics based on valuation, profitability and investment should forecast firms' average returns. Based on this they develop a five factor model - consisting of the MktRF, SMB, HML, RMW, and CMA characteristic portfoliosand argue that this model does well in explaining the cross-section of average excess returns for a variety of test portfolios, based on a set of time-series regressions like:

$$
\begin{aligned}
r_{p, t}= & \alpha_{p}+b_{p, m} r_{M k t R F, t}+b_{p, H M L} r_{H M L, t}+b_{p, S M B} r_{S M B, t} \\
& +b_{p, C M A} r_{C M A, t}+b_{p, R M W} r_{R M W, t}+\epsilon_{p, t}
\end{aligned}
$$

SMB, HML, RMW, and CMA are characteristic portfolios, formed by sorting on various combinations of firm size, valuation ratios, profitability and investment respectively. Fama and French (1993, 2015) refer to these characteristic portfolios as "mimicking portfolios" or "factors" 2

Standard projection theory shows that the intercepts $(\alpha s)$ from these regressions will all be zero for all test assets if and only if the mean variance efficient (MVE) portfolio is in the span

\footnotetext{
${ }^{1}$ Examples are: UMD (Carhart,, 1997$)$; LIQ (Pastor and Stambaugh, 2003); BAB (Frazzini and Pedersen. 2014); QMJ (Asness, Frazzini, and Pedersen, 2019); PMU (Novy-Marx, 2013); ISU (Daniel and Titman, 2006) and RX and HML-FX (Lustig, Roussanov, and Verdelhan. 2011). We concentrate on the factors of Fama and French (2015). However, the critique we develop in Section 2 applies to any factors constructed using this method.

${ }^{2}$ As emphasized by Cochrane (2005, p.174), the word "factor" is used with different meanings in the asset pricing literature. In this paper we use "characteristic portfolio" to refer to a zero-investment portfolio formed on the basis of one or more firm characteristics. We use the term "factor" to refer to a latent economic force (see, e.g., equation (2) but not the return on an investment portfolio. Fama and French (1996, p.57) refer to these latent economic forces as risk factors or "state variables of special hedging concern to investors."
} 
of the CPs, or equivalently, if the maximum Sharpe ratio in the economy is the maximum Sharpe ratio achievable with the CPs alone. Despite several critiques of this methodology, it remains popular in the finance literature.

This paper is concerned with the standard procedure employed when constructing these CPs. We show that, if characteristics are a good proxy for expected returns, then forming CPs by sorting on characteristics alone will generally not explain the cross-section of returns in the way proposed in the literature. The argument is based on the early insights of Markowitz (1952) and Roll (1977). Suppose a set of characteristics are positively associated with expected returns, and a corresponding set of long-short CPs are constructed by buying high characteristic stocks and shorting low characteristic stocks. This set of portfolios will explain the returns of portfolios sorted on the same characteristics, but are unlikely to span the mean variance efficient frontier of all assets, because they do not take into account the asset covariance structure.

A simple example with a single characteristic and a single priced factor helps to illustrate this intuition (we describe this example in detail in Section 2.1). Consider an economy with $N$ assets and let $\boldsymbol{\mu}$ be the $N \times 1$ vector of expected excess returns on these assets. Premia are driven by exposure to a single risk factor, which is unobserved. Assume finally that there is a linear relation between expected excess returns and a single characteristic, that is, $\boldsymbol{\mu}=\boldsymbol{x} \lambda_{c}$, where $\boldsymbol{x}$ is the corresponding $N \times 1$ vector of stock characteristics and $\lambda_{c}$ is some constant. Researchers are interested in identifying the underlying risk factor. To do so they construct a CP, a zero investment portfolio that goes long high characteristic stocks and short low characteristic stocks. Since the CP earns a large excess return, it must also have a large exposure to the risk factor. Further, the literature effectively argues that exposure to the $\mathrm{CP}$ should price the cross-section, in the spirit of regressions like the one in equation (1). Of course, this will only be the case if the resulting $\mathrm{CP}$ is mean variance efficient.

We show that, in general, this standard procedure will not produce a mean variance efficient portfolio. The reason is that, while variation in the characteristic does indeed pick up variation in the loading with respect to the priced risk factor, it also captures variation in the loadings with respect to unpriced sources of common variation in returns. As a result, exposure to the $\mathrm{CP}$ commands premium but the volatility of returns is too high because the portfolio also loads on these unpriced sources of common variation. It follows that the Sharpe ratio of the $\mathrm{CP}$ is lower than the Sharpe ratio of the projection of the risk factor on 
the space of returns: the CP is not mean-variance efficient. We show how to improve on the $\mathrm{CP}$ by removing from it unpriced sources of common variation in returns.

We extend these ideas to the empirically relevant case where average excess returns are explained by many characteristics, such as size, book-to-market, profitability, and investment. We introduce the concept of a characteristic efficient portfolio (CEP), which has the smallest return variance amongst the portfolios that has characteristic equal to one for one characteristic and zero to all other characteristics. We further show that the complete set of CEPs spans the mean variance frontier.

The CEPs are the solution to an optimization problem that takes into account the covariance matrix of returns. Were the covariance matrix known, the calculation of the CEP weights would be straightforward. However, there are numerous problems associated with using an estimated covariance matrix to construct portfolios and no accepted way of correcting a sample covariance matrix to fully resolve the problems associated with optimal portfolio construction 3 We instead develop an empirically feasible strategy to get close to the CEPs. Our starting point is a set of CPs - in our empirical implementation we start with the five FF CPs. We then introduce the concept of a hedge portfolio: a characteristic balanced portfolio designed to pick up variation in the loadings with respect to unpriced sources of common variation in returns, and with zero loading on the priced factors. Characteristic balanced here means that the long- and the short-side of the hedge portfolio have identical characteristics, and therefore according to our characteristic model, also have zero expected return. In our theory section, we show how to select the optimal hedge portfolio: It is the characteristic balanced portfolio that maximizes the loading with respect to the CP. Finally we show how an optimal combination of the original CPs and the optimal hedge portfolios delivers the CEPs.

Based on this theoretical development, we construct hedge portfolios for each of the five FF CPs. There are two key empirical challenges: the construction of the optimal hedge portfolios, and the calculation of the optimal hedge ratios. For the construction of the optimal hedge portfolios we build on Daniel and Titman (1997), but improve on their procedure on multiple dimensions. Through the use of higher frequency data and differential windows for calculating volatilities and correlations, we are able to construct hedge portfolios that are

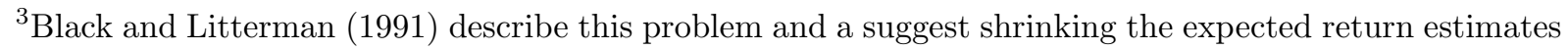
toward an equilibrium-based prior as a partial solution. Ledoit and Wolf (2003, 2004a|b, 2012, 2017) each propose alternative covariance matrix estimators.
} 
highly correlated with the FF CPs, but which have approximately zero expected returns. Importantly, like the FF CPs themselves, our hedge portfolios are highly tradable: we form value-weighted portfolios once per year, at the end of June, and hold their composition fixed for 12 months. Based on robustness considerations, we also calculate the hedge ratios only once per year, also at the end of June, and based only on data that are in the investor's information set at that time. Thus our procedure is out-of-sample in the sense that, given knowledge of the five FF characteristics, an investor could have hedged the FF portfolios in exactly the way we do here.

Empirically, our hedge portfolios behave in a way that is consistent with our theory: except for the size (SMB) hedge portfolio, they all earn economically and statistically significant five-factor alphas 4 We combine each of the original five FF CPs with our hedge portfolios in an ex-ante optimal way, i.e., we forecast the optimal hedge ratio, and generate the five FF CEPs. The optimal combination of the five CEPs yields a squared Sharpe ratio of 2.16 versus 1.16 for the optimal combination of the five FF CPs.

Our procedure has the important advantage that it does not require us to identify the sources of unpriced risk. In fact, we are completely agnostic as to what these unpriced sources of common variation in returns represent. We do argue, though, that one source of unpriced common variation may be industry exposure, and present evidence that the standard FF CPs load on industry returns. We compare the performance of the characteristic efficient FF portfolios with the performance of a strategy in which we only hedge out the industry component of the original five FF CPs. The squared Sharpe ratio of the ex-post optimal combination of the industry-neutral five FF CPs is 1.37, which is lower than what we obtain with our methodology, 2.16: There are unpriced sources of common variation beyond industry and thus the industry-neutral CPs do not span the MVE portfolio.

Our results are important for several reasons. First, they increase the hurdle for standard asset pricing models. Following the logic of Hansen and Jagannathan (1991), the pricing kernel variance that is required to explain the returns of our CEPs is $86 \%$ higher than what is required to explain the returns of the FF CPs.

Second, in order to find economic explanations for the premia associated with characteristics such as size and value, it is important to start out with portfolios that capture the factor

\footnotetext{
${ }^{4}$ Note that over this sample period, the SMB characteristic portfolio has the lowest Sharpe ratio of the five FF CPs.
} 
premia with the minimum possible return variance. In the context of rational models, recall that the ultimate purpose behind this literature is to find the underlying risk factors that are the source of premia. As FF (page 3) suggest, building on the ICAPM logic of Merton (1973), ". . . the factors are just diversified portfolios that provide different combinations of exposures to the unknown state variables" driving the marginal rate of substitution of the marginal investor. CPs then should correlate with proxies for the marginal utility of the representative investor. But if, by construction, as we argue, these CPs load on unpriced sources of common variation this correlation with the marginal rate of substitution is bound to be biased towards zero and thus may lead to the wrong inferences regarding the suitability of the proposed asset pricing model 5

Third, our CEPs are better benchmarks for the performance evaluation of managed portfolios. While the characteristics approach to measure managed portfolio performance (see, e.g., Daniel, Grinblatt, Titman, and Wermers, 1997, DGTW) has gained popularity, the regression based approach initially employed by Jensen (1968) (and later by Carhart (1997), Fama and French (2010) and numerous others) remains the more popular. A good reason for this is that the characteristics approach can only be used to estimate the alpha of a portfolio when the holdings of the managed portfolio are known, and frequently sampled. In contrast, the Jensen-style regression approach can be used in the absence of holdings data, as long as time series of portfolio returns are available.

However, as pointed out originally by Roll (1977), the regression approach requires that the benchmark used in the regression test be efficient; otherwise the conclusions of the regression test will be invalid. What we show in this paper is that, with the historical return data, efficiency of the proposed CPs can be rejected. However, our CEPs incorporate the information both from the characteristics and from the historical covariance structure and thus improve on their FF counterparts. Thus, if the CEPs are used as benchmarks and loadings can be estimated accurately, alphas equivalent to what would be obtained with the DGTW characteristics-approach can be generated with the regression approach without the need for portfolio holdings data.

\footnotetext{
${ }^{5}$ We thank our discussant, Ralph Koijen, for emphasizing this point to us. Indeed, a recent literature studies the connection between characteristic premia and risk. See Lewellen, Nagel, and Shanken (2010), and Daniel and Titman (2012) for summaries of the literature. One example is the study by Golubov and Konstantinidi (2019), which focuses on the value premium.
} 
Finally, our paper connects to the recent vintage of papers that revisits the question of how to combine characteristics into tradable portfolios (see $\mathrm{Gu}$, Kelly, and Xiu, 2018; Huang, Li, and Zhou, 2018; Freyberger, Neuhierl, and Weber, 2018; Kozak, Nagel, and Santosh, 2019; Liu, Tsyvinski, and Wu, 2019). These papers all take as their starting point a set of characteristics that explain average excess returns. Our focus instead is on improving the efficiency of the characteristic portfolios by using individual asset loadings on the CPs. Our work also connects to another set of papers which identify the priced components of book-tomarket CPs (see Gerakos and Linnainmaa, 2018; Golubov and Konstantinidi, 2019), but our point is much broader and refers to the general procedure used to construct characteristic portfolios.

\section{Theory and examples}

Fama and French (1993) and numerous subsequent studies construct characteristic portfolios as a proxy for the priced risk associated with characteristic premia. ${ }^{6}$ These papers construct a zero-investment CP by going long a unit-investment portfolio of high characteristic assets, and short a unit-investment portfolio of low characteristic assets (where average returns are positively correlated with the characteristic). Then, each paper proceeds to examine whether the returns of a set of test assets are explained by a combination of well-known benchmark portfolios and the new $\mathrm{CP}$, often using regressions like the one in equation (1). The implicit argument here is that the such a characteristic portfolio, in combination with the other benchmark portfolios, will span the mean variance efficient portfolio.

This paper makes two contributions. We first show that the standard characteristic portfolio construction procedure is unlikely to yield the mean variance efficient (MVE) portfolio, because the so-constructed CP will load on unpriced risk. Second, we show how to improve on this standard procedure by constructing a hedge portfolio which captures the unpriced risk in the $\mathrm{CP}$.

To illustrate, we start with a simple example. The example makes two key assumptions: excess returns are described by a two-factor structure and expected excess returns are linear in a single characteristic. Section 2.1 .2 further illustrates our results in the context of the popular HML portfolio. Section 2.2 generalizes the simple example to the empirically relevant

\footnotetext{
${ }^{6}$ See footnote 1 for examples.
} 
case in which multiple characteristics are needed to fully describe the cross-section of average excess returns.

\subsection{A simple example}

\subsubsection{Characteristic portfolios and mean variance efficiency}

We consider a single period economy with $N$ assets. Realized excess returns are determined by a two-factor structure, so for asset $i$ :

$$
r_{i}=\beta_{i}(f+\lambda)+\gamma_{i} g+\varepsilon_{i}
$$

where $\mathbb{E}[f]=\mathbb{E}[g]=\mathbb{E}\left[\varepsilon_{i}\right]=0$ for all $i=1,2, \cdots, N$. Further, suppose that $\operatorname{var}(f)=\sigma_{f}^{2}$, $\operatorname{var}(g)=\sigma_{g}^{2}, \operatorname{var}\left(\varepsilon_{i}\right)=\sigma_{\varepsilon}^{2}$ for all $i=1,2, \cdots, N$, and that $f, g$, and $\varepsilon_{i}$ are mutually orthogonal for all $i \neq j$.

Let $r$ denote the $(N \times 1)$ column vector of individual excess returns,

$$
\boldsymbol{r}^{\top} \equiv\left[\begin{array}{llll}
r_{1} & r_{2} & \cdots & r_{N}
\end{array}\right]
$$

where $T$ denotes transpose. Taking expectations of equation (2) gives:

$$
\mu \equiv \mathbb{E}[r]=\beta \lambda
$$

where $\beta$ is the $(N \times 1)$ column vector of individual assets' exposures to $f$.

The standard interpretation of $f$ is that it is a proxy for shocks to the marginal rate of substitution; the two canonical examples are that $f$ is (some function of) consumption growth or that $(f+\lambda)$ is the return on the market portfolio (Cochrane, 2005, page 78). $g$ is the unpriced source of common variation. That there is only one factor that is the source of premia is without loss of generality: For any factor structure there is always a rotation of the factor space in which there is only one priced factor. Accurately determining $f$ is important in assessing macroeconomic theories. Its projection onto the space of returns has the maximal Sharpe ratio, so financial economists attempt to identify $f$ by constructing portfolios with the highest possible Sharpe ratios. 
Studies in this literature begin with the observation that expected excess returns in the cross-section are a function of a set of characteristics. For instance, Fama and French (1993, page 4), state that "two empirically determined variables, size and book-to-market equity, do a good job explaining the cross-section of average returns on NYSE, Amex, and NASDAQ stocks for the 1963-1990 period," and then build the characteristic portfolios SMB and HML based on the these characteristics.

We follow the literature but go a step further. We assume that expected excess returns are perfectly described by a linear function of characteristics. To make this example as simple as possible we assume that expected excess returns are described by a single characteristic, $\boldsymbol{x}$, an $N \times 1$ column vector and that this characteristic lines up perfectly with expected excess returns,

$$
\boldsymbol{\mu}=\boldsymbol{x} \lambda_{c}
$$

where $\lambda_{c}$ is the characteristic premium.

In order for equations (3) and (4) to hold simultaneously, it must be the case that:

$$
\beta=\left(\frac{\lambda_{c}}{\lambda}\right) x
$$

In this simple setting the characteristic is a perfect proxy for the exposure to the priced factor. Thus, sorting on the characteristic will pick up variation in $\beta$. This is the motivation for the standard procedure in the literature, first developed in Fama and French (1993), of constructing a zero investment portfolio that goes long stocks with a high value of the characteristic $x$ and short stocks with low value of the characteristic.

A portfolio is defined by an $N$-dimensional column vector of portfolio weights,

$$
\boldsymbol{w}^{\top} \equiv\left[\begin{array}{llll}
w_{1} & w_{2} & \cdots & w_{N}
\end{array}\right]
$$

where $w_{i}$ is asset $i$ 's weight in the portfolio for $i=1,2, \cdots, N$.

To continue, suppose that there are only six stocks $(N=6)$ with equal market capitalizations. The six stocks have characteristics and loadings on the priced and unpriced factors as illustrated in Figure 1. Notice that assets 1 and 2 have identical loadings and characteristics. The same holds for assets 5 and 6 . 


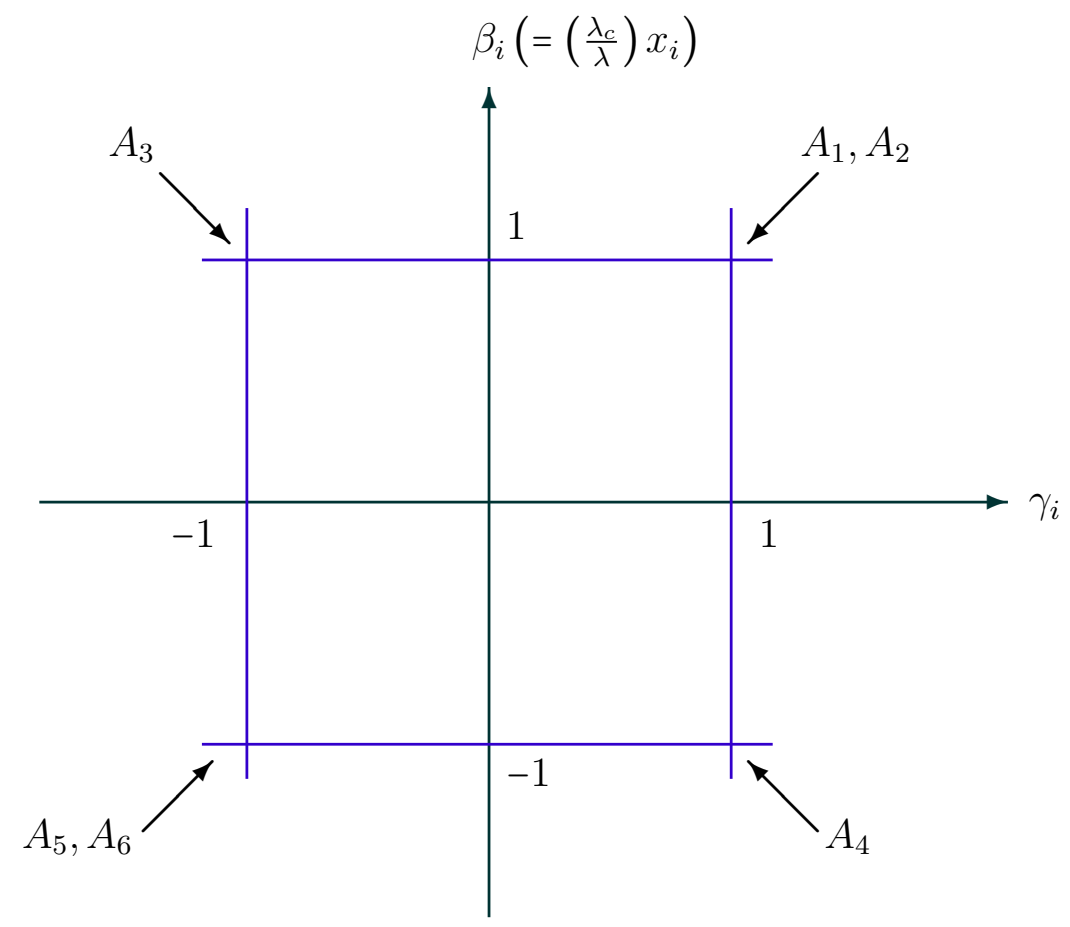

Figure 1: Six assets in the space of loadings on priced and unpriced factors.

We now construct a specific characteristic portfolio, or CP, which we label $c$, on the basis of characteristic $x$, by going long a value-weighted portfolio of the high characteristic stocks $A_{1}, A_{2}$, and $A_{3}$, and short a value-weighted portfolio of the low characteristic stocks $A_{4}, A_{5}$, and $A_{6} \mathrm{~b}^{7}$ Specifically, the weights on individual stocks in the characteristic portfolio $c$ are given by:

$$
\boldsymbol{w}_{c}^{\top}=\left[\begin{array}{llllll}
\frac{1}{3} & \frac{1}{3} & \frac{1}{3} & -\frac{1}{3} & -\frac{1}{3} & -\frac{1}{3}
\end{array}\right],
$$

and the return of portfolio $c$ is:

$$
r_{c}=\boldsymbol{w}_{c}^{\top} \boldsymbol{r}=\frac{1}{3} \times\left[\sum_{j=1}^{3} r_{j}-\sum_{j=4}^{6} r_{j}\right]=2(f+\lambda)+\frac{2}{3} g+\frac{1}{3}\left[\sum_{j=1}^{3} \varepsilon_{j}-\sum_{j=4}^{6} \varepsilon_{j}\right] .
$$

The CP's return $r_{c}$ does indeed capture the common source of variation in expected excess returns, since it loads on $f$. However, our point here is that CPs so constructed are likely to also load on unpriced factors, and will therefore not be mean-variance efficient. This is the case in this example: because of the cross-sectional correlation between the characteristic and the loading on the unpriced factor - i.e., the fact that most high characteristic firms also have a high loading on the unpriced factor - the constructed CP also loads on the unpriced

\footnotetext{
7 Because in this simple example all stocks have equal weight there is no difference between equal and value weighting. The usual Fama-French construction uses value-weighted portfolios.
} 
source of common variation $g$. 8 Specifically, the CP loads on the factor $f$ with $\beta_{c}=2$ and on $g$ with $\gamma_{c}=\frac{2}{3}$. The value of the characteristic for this portfolio is $x_{c}=2 \frac{\lambda}{\lambda_{c}}$ and thus expected excess return is $\mathbb{E}\left[r_{c}\right]=2 \lambda$. The variance of the returns is given by

$$
\sigma_{c}^{2}=4 \sigma_{f}^{2}+\frac{4}{9} \sigma_{g}^{2}+\frac{2}{3} \sigma_{\varepsilon}^{2}
$$

giving the $\mathrm{CP}$ a Sharpe ratio of

$$
\mathrm{SR}_{c}=\frac{2 \lambda}{\sqrt{4 \sigma_{f}^{2}+\frac{4}{9} \sigma_{g}^{2}+\frac{2}{3} \sigma_{\varepsilon}^{2}}} .
$$

If $\sigma_{\varepsilon}^{2}$ is small relative to the variance of the systematic factors $f$ and $g$, then it is clear that the CP is not MVE because it is exposed to both priced and unpriced risk. In this example then a single characteristic lines up perfectly with expected excess returns and still the CP fails to deliver the mean variance efficient portfolio. Can we improve on the CP?

Consider the following portfolio $h$ with weights:

$$
\boldsymbol{w}_{h}^{\top}=\left[\begin{array}{llllll}
-\frac{1}{4} & -\frac{1}{4} & \frac{1}{2} & -\frac{1}{2} & \frac{1}{4} & \frac{1}{4}
\end{array}\right]
$$

This portfolio goes long stocks with low loadings on $g$ and short stocks with high loadings on $g$. The return of portfolio $h$ is given by

$$
r_{h}=\frac{1}{2}\left[r_{3}+\frac{r_{5}}{2}+\frac{r_{6}}{2}\right]-\frac{1}{2}\left[\frac{r_{1}}{2}+\frac{r_{2}}{2}+r_{4}\right]=-2 g+\frac{1}{2}\left[\varepsilon_{3}+\frac{\varepsilon_{5}}{2}+\frac{\varepsilon_{6}}{2}\right]-\frac{1}{2}\left[\frac{\varepsilon_{1}}{2}+\frac{\varepsilon_{2}}{2}+\varepsilon_{4}\right] .
$$

The loading of the $h$ portfolio on $g$ is $\gamma_{h}=-2$. Notice that this portfolio is characteristic balanced in that $x_{h}=\boldsymbol{w}_{h}^{\top} \boldsymbol{x}=0$, so $\beta_{h}=0$ and $\mathbb{E}\left[r_{h}\right]=0$ (see (4)).

We can use the portfolio $h$ to improve on the CP by reducing its variance without changing its expected excess returns. For this reason we refer to $h$ as a hedge portfolio. Indeed, given that the characteristic and hedge portfolios have loadings on $g$ of $\gamma_{c}=\frac{2}{3}$ and $\gamma_{h}=-2$, respectively, we can form a portfolio for which for every dollar invested long in portfolio $c$ we also invest $\$ \frac{1}{3}$ (long) in the hedge portfolio $h$. This combined portfolio has the same

\footnotetext{
${ }^{8}$ Note that a cross-sectional correlation between the characteristic and the loading on the unpriced factor of exactly zero constitutes the knife-edge case, i.e., it is extremely unlikely.
} 
expected return as the CP (which is $2 \lambda$ ) but its exposure to $g$ is eliminated. The variance of this portfolio is

$$
4 \sigma_{f}^{2}+\frac{3}{4} \sigma_{\varepsilon}^{2}
$$

and thus it has a Sharpe ratio of

$$
\frac{2 \lambda}{\sqrt{4 \sigma_{f}^{2}+\frac{3}{4} \sigma_{\varepsilon}^{2}}},
$$

which is higher than the Sharpe ratio of the CP, $\mathrm{SR}_{c}$ (see equation (10), whenever diversification is large enough so that idiosyncratic risk vanishes 9

We can do better by combining the hedge portfolio with the characteristic portfolio in order to maximize the Sharpe ratio. Given that the hedge portfolio has zero expected excess return this is equivalent to finding the combination of the characteristic portfolio and the hedge portfolio that minimizes the variance of the resulting portfolio, that is,

$$
\min _{\delta} \operatorname{var}\left(r_{c}+\delta r_{h}\right) \quad \Rightarrow \quad \delta^{*}=\rho_{c, h} \frac{\sigma_{c}}{\sigma_{h}}
$$

where $\sigma_{h}$ is the standard deviation of the returns of the hedge portfolio, $h$, and $\rho_{c, h}$ is the correlation coefficient between the returns of the characteristic portfolio, $c$, and the hedge portfolio, $h$. We refer to $\delta^{*}$ as the optimal hedge ratio. It can be shown that this procedure improves the Sharpe ratio of the characteristic portfolio by

$$
\frac{\mathrm{SR}^{\prime}}{\mathrm{SR}_{c}}=\frac{1}{\sqrt{1-\rho_{c, h}^{2}}}
$$

where SR' is the Sharpe ratio of the improved characteristic portfolio.

Notice that there are several ways of constructing the hedge portfolio $h$ so as to remove exposure to $g$ from the characteristic portfolio $c$. Equation (15) shows though that the optimal hedge portfolio is the one that is maximally correlated with the CP. In Section 2.2 we extend these insights to the empirically relevant case in which a full description of the cross-section of expected excess returns requires multiple characteristics. Before showing these result formally, we illustrate the ideas of the example in the context of a popular characteristic portfolio, the HML portfolio of Fama and French (1993).

\footnotetext{
${ }^{9}$ For a well-diversified portfolio for which residual variance is zero, this problem is the same as setting the loading on the unpriced factor to zero; with residual risk it is not. In this example the Sharpe ratio is higher as long as $\sigma_{g}^{2}>\left(\frac{3}{16}\right) \sigma_{\varepsilon}^{2}$.
} 


\subsubsection{The simple example in practice: Industry portfolios as $g$}

Book-to-market is one characteristic that has been shown to align with average returns in the cross-section and HML is a popular characteristic portfolio 10 Asness, Porter, and Stevens (2000), Cohen and Polk (1995) and others'11 have shown that if book-to-market ratios are decomposed into an across-industry component and a within-industry component, then only the within-industry component - that is, the difference between a firm's book-tomarket ratio and the book-to-market ratio of its corresponding industry portfolio-forecasts future returns. This literature then suggests that the exposure of HML to industry returns is unpriced, that is, that industry is one unpriced source of common variation, $g$. Therefore, if the industry exposure of HML was hedged out, it would result in a characteristic portfolio with lower risk, but the same expected return, i.e., with a higher Sharpe ratio. But, does HML really load on industries?

Figure 2 plots the $R^{2}$ from 126-day rolling regressions of daily HML returns on the twelve daily Fama and French (1997) value-weighted industry excess returns. The time period is 1963/07 - 2019/0612 The plot shows that, while there are short periods where the realized $R^{2}$ dips below $50 \%$, there are also several periods where it exceeds $90 \%$. The $R^{2}$ fluctuates considerably but the average is well above 70\%. The upper Panel of Figure 3 plots, for the same set of daily, 126-day rolling regressions, the regression coefficients for each of the 12 industries. As it is apparent, these coefficients display considerable variation: sometimes the HML portfolio loads more heavily on some industries than on others.

The behavior of the 'Money' industry during and after the Great Recession of 2008 is a striking example of the large industry effect on HML. The lower Panel of Figure 3 shows that the regression coefficient associated with 'Money' increased dramatically between 2007 and early 2009, as stock prices for firms in this segment collapsed and those firms quickly became classified as value, 13 As shown in Figure 4, the volatility of returns also increased dramatically. As a result of these two effects, 'Money' explained a substantial amount of the

\footnotetext{
$1 0 \longdiv { \text { Fama and French } } [ 1 9 9 3 , 2 0 1 5 )$ refer to HML as well as to the other portfolios, as factors or factor portfolios. We instead use the expression characteristic portfolios throughout, in order to further distinguish between the underlying factor, $f$, and the portfolio formed on characteristic sorts.

${ }^{11}$ See also Lewellen (1999), Cohen, Polk, and Vuolteenaho (2003), and Golubov and Konstantinidi (2019).

12 The industry classification follows Ken French's data library at http://mba.tuck.dartmouth.edu/ pages/faculty/ken.french/Data_Library.

${ }^{13}$ As shown in Laeven and Huizinga (2009) banks during the crisis used accounting discretion to avoid writing down the value of distressed assets. As a result the value of bank equity was overstated. The market knew better and as a result the book-to-market ratio of bank stocks shot up during the crisis.
} 
variation of HML returns during those years. Indeed Figure 5 plots the $R^{2}$ of a regression of the return on HML on the 'Money' industry excess returns alone. Between late 2008 and late 2010 , the $R^{2}$ was well above $60 \%$. The reason for this was that as of December 2007, the top 4 firms by market capitalization in the 'Money' industry were J.P. Morgan, Bank of America, Citigroup and Wells Fargo. Three of these four were in the large value portfolio portfolio (Big/High-BEME to use the standard terminology). While the market capitalization of these firms fell dramatically through 2008, they remained large and, particularly as the volatility of the returns on the 'Money' industry increased, these firms and others like them drove the returns both of the HML portfolio and the 'Money' industry portfolio.

However, there were firms in the 'Money' industry that did not have high book-to-market ratios, even in the depths of the financial crisis. For example, in 2008 American Express (AXP) and UnitedHealth Group (UNH) were both "L" (low book-to-market) firms. Yet both AXP and UNH had large positive loadings on HML at this point in time (see Table 1). The reason is that, at this time, both AXP and UNH covaried strongly with the returns on the 'Money' industry, as did HML. We can exploit this variation within the 'Money' industry to construct a characteristic balanced hedge portfolio $\boldsymbol{w}_{h}$ as illustrated in the example in the previous section. The short side of the characteristic balanced portfolio features firms with high loadings on HML and low and high book-to-market, such as American Express and Citi, respectively. Loosely speaking, in the example in Figure 1, Citi would be like $A_{1}$ (i.e., a value stock in the finance industry), and American Express would be like asset $A_{4}$ (a growth stock in the finance industry). The characteristic balanced hedge portfolio goes long both value and growth stocks with low loadings on HML, and goes short value and growth firms with high loadings, such as Citi and Amex ${ }^{14}$

\subsection{The general case}

We now show that the insights of the previous section extend to the more general case in which there are multiple factors and characteristics that drive excess returns.

As in the example in Section 2.1, we consider a single period economy with a large number of assets $N$ but in which now realized excess returns are determined by a factor structure

\footnotetext{
${ }^{14}$ By maximizing the negative loading on HML, subject to the constraint that the the portfolio be bookto-market neutral, we pick up the unpriced part of the HML-exposure. In this simple example the unpriced component of HML is money-industry return.
} 
in which the number of factors is $K$. Recall that for any multifactor representation there is always a rotation with only one priced factor $f$ and a vector of $(K-1)$ unpriced factors $\boldsymbol{g}$. We can then write realized excess returns as

$$
r_{i}=\beta_{i}(f+\lambda)+\gamma_{i} g+\varepsilon_{i}
$$

where $\mathbb{E}[f]=\mathbb{E}\left[g_{k}\right]=\mathbb{E}\left[\varepsilon_{i}\right]=0$ for all $k=1,2, \cdots, K-1$ and $i=1,2, \cdots, N$. Further, suppose that $\operatorname{var}(f)=\sigma_{f}^{2}, \operatorname{var}(\boldsymbol{g})=\Sigma_{g}, \operatorname{cov}(f, \boldsymbol{g})=\mathbf{0}, \operatorname{cov}\left(\varepsilon_{i}, f\right)=0, \operatorname{cov}\left(\varepsilon_{i}, \boldsymbol{g}\right)=\mathbf{0}$ for $i=1,2, \cdots, N$ and $\operatorname{cov}\left(\varepsilon_{i}, \varepsilon_{j}\right)=0$ for all $i \neq j . \gamma_{i}$ is the $(1 \times(K-1))$ vector of asset $i$ 's exposure to the unpriced factors $g$.

As before we assume that there is a linear relation between expected excess returns and characteristics

$$
\mu=X \lambda_{c}
$$

where $\boldsymbol{\mu}$ is again an $(N \times 1)$ vector of expected excess returns, $X$ is now an $(N \times M)$ matrix of characteristics, and $\boldsymbol{\lambda}_{c}$ is an $(M \times 1)$ vector of characteristic premia.

Assumption (A1) is consistent with model (16) as long as

$$
\beta=\frac{1}{\lambda} X \lambda_{c}
$$

where $\beta$ is an $(N \times 1)$ vector of loadings on $f$. Thus, under assumption (A1), asset $i$ 's exposure to $f$ is a linear combination of the $M$ characteristics that describe expected excess returns.

This setting captures, in somewhat simplified form, the current state of the asset pricing literature, where a set of characteristics explains average returns. The asset pricing tests in the literature (e.g., Fama and French, 1993, 2015) construct a set of CPs, one for each of the characteristics that are shown to capture variation in average excess returns in the cross-section, and then examine whether the cross-section of returns is explained by the CPs' returns, for example using time-series regressions like that in equation (11). The hope is that the projection of $f$ on the space of returns (the MVE portfolio) will be in the span of those CPs. If this were the case, then the factor model with the CPs as factors would be a valid multi-factor asset pricing model. We now examine when, for CPs constructed in this way, the MVE portfolio will indeed be in the span of the CPs. 
Our starting point is the set of $M$ CPs, one for each characteristic. The $(N \times 1)$ vector of weights for the $m$-th $\mathrm{CP}, \boldsymbol{w}_{c, m}$, will have positive values for firms with a high value of the $m$-th characteristic, and negative values for firms with a negative characteristic. The return of the $m$-th CP is then:

$$
r_{c, m} \equiv \boldsymbol{w}_{c, m}^{\top} \boldsymbol{r} \quad \text { for } \quad m=1,2, \cdots, M
$$

We further define the $(N \times M)$ matrix of $\mathrm{CP}$ weights as:

$$
W_{c}=\left[\begin{array}{llll}
\boldsymbol{w}_{c, 1} & \boldsymbol{w}_{c, 2} & \cdots & \boldsymbol{w}_{c, m}
\end{array}\right]
$$

This paper is concerned with, first, whether the CPs span the MVE frontier, and, second, if they do not, whether and how we can improve on the CPs. A key concept in what follows is that of characteristic efficient portfolios or CEPs.

Definition 2.1 (Characteristic efficient portfolios) The weight-vector of the $m$-th characteristic efficient portfolio is the solution to the program

$$
\min _{\boldsymbol{w}_{c, m}} \boldsymbol{w}_{c, m}^{\top} \Sigma \boldsymbol{w}_{c, m} \quad \text { subject to } \quad \boldsymbol{w}_{c, m}^{\top} X=\boldsymbol{e}_{m}
$$

In program $\left(\mathcal{P}_{m}\right), \Sigma$ is the $(N \times N)$ return covariance matrix and $\boldsymbol{e}_{m}$ is an $(M \times 1)$ vector with the $m$-th entry equal to 1 and all others equal to 0 . Intuitively the $m$-th CEP selects among the portfolios that have the $m$-th characteristic equal to one and all other characteristics equal to zero, the one with the minimum variance possible.

Our main results are that, first, the $M$ CEPs span the mean variance efficient frontier and, second, that the asset loadings with respect to CEPs line up perfectly with asset characteristics. Finally we show how to adjust any set of CPs to transform them into CEPs.

\subsubsection{Characteristic efficient portfolios}

As shown in the Appendix B.1, the solution to program $\left(\mathcal{P}_{m}\right)$ is

$$
\boldsymbol{w}_{c, m}^{*}=\Sigma^{-1} X\left(X^{\top} \Sigma^{-1} X\right)^{-1} \boldsymbol{e}_{m}
$$


Let

$$
W_{c}^{*} \equiv\left[\begin{array}{llll}
\boldsymbol{w}_{c, 1}^{*} & \boldsymbol{w}_{c, 2}^{*} & \cdots & \boldsymbol{w}_{c, M}^{*}
\end{array}\right]=\Sigma^{-1} X\left(X^{\top} \Sigma^{-1} X\right)^{-1},
$$

be the $(N \times M)$ matrix of CEP weights.

Let $B^{*}$, an $(N \times M)$ matrix, be the projection coefficient of $\boldsymbol{r}$ on $\boldsymbol{r}_{c}^{*}$, where each column $\boldsymbol{b}_{m}^{*}$ corresponds to the vector of individual stocks' loadings on the $m$-th CEP, that is, $B^{*} \equiv$ $\left[\begin{array}{llll}\boldsymbol{b}_{1}^{*} & \boldsymbol{b}_{2}^{*} & \cdots & \boldsymbol{b}_{M}^{*}\end{array}\right]$. Armed with this we can prove the following:

Proposition 2.2 Under assumption (A1)

1. The returns of the CEPs span the mean-variance-efficient portfolio, that is,

$$
S R^{* 2}=\boldsymbol{\mu}_{c}^{* \top} \Sigma_{c}^{*-1} \boldsymbol{\mu}_{c}^{\star}=\boldsymbol{\mu}^{\top} \Sigma^{-1} \boldsymbol{\mu}
$$

where

$$
\boldsymbol{\mu}_{c}^{*} \equiv W_{c}^{* \top} \boldsymbol{\mu}=\boldsymbol{\lambda}_{c} \quad \text { and } \quad \Sigma_{c}^{*} \equiv \operatorname{var}\left(W_{c}^{* \top} \boldsymbol{r}\right)=\left(X^{\top} \Sigma^{-1} X\right)^{-1} .
$$

2. Asset loadings with respect to the CEPs line up with the characteristics

$$
B^{*}=X
$$

Proof: See Appendix B.2.

Proposition 2.2 says that given (A1), there is an optimal way of constructing portfolios linked to the characteristics so that they span the mean variance efficient frontier. One property of these portfolios is that the loadings of any test portfolio on the CEPs will equal the vector of portfolio characteristics for that test portfolio. That is, if the portfolios are the CEPs there is no distinction between characteristics and covariances.

Notice that any rotation of the CEPs, $\widehat{W}_{c}^{*}=W_{c}^{*} A$ where $A$ is $(M \times M)$ and full rank, will also span the MVE portfolio of excess returns. But for any such rotation the loadings will no longer be the corresponding characteristic but a linear combination of them 15

\footnotetext{
${ }^{15}$ That the loadings are a linear function of the characteristics follows from the fact that the loadings with respect to any rotation of the CEPs are given by

$$
\widehat{B}^{*}=\Sigma W_{c}^{*} A\left(A^{\top} W_{c}^{* \top} \Sigma W_{c}^{*} A\right)^{-1}=X\left(A^{\top}\right)^{-1},
$$

where the last equality uses 21 .
} 
We are interested in constructing CEPs rather than CPs. However, $\Sigma$ is difficult to estimate, which may justify the implicit choice in the literature to use simple characteristic sorting procedures to construct CPs, but in general these CPs will not span the same space as the CEPs.

There is though a particular case of interest in which the CPs span the mean variance

efficient frontier. It is when $K=M$, that is, when the number of characteristics equals the number of factors that explain the covariance matrix. In this case, adding the hedge portfolios would not increase the maximum Sharpe ratio achievable with the CPs. Our view though is that this case is of limited practical interest. The number of factors that capture common variation in stock returns is likely large (at least the number of industries!) whereas the number of characteristics that have been found to explain the cross-section of expected excess returns is smaller. In particular, it is easy to show that as long as $K>>M$ and the characteristics are correlated with the loadings on the unpriced factors $\gamma$ in the cross-section, the CPs will not span the MVE portfolio. We proceed next by showing how to recover CEPs from the CPs.

\subsubsection{Characteristic portfolios and hedge portfolios}

Our starting point is a set of CPs, for example the five portfolios in Fama and French (2015). Let $B$, an $(N \times M)$ matrix, be the matrix of projection coefficients of $\boldsymbol{r}$ on $\boldsymbol{r}_{c}$, where each column $\boldsymbol{b}_{m}$ corresponds to the vector of loadings of individual assets on the $m$-th CP, that is, $B \equiv\left[\begin{array}{llll}\boldsymbol{b}_{1} & \boldsymbol{b}_{2} & \cdots & \boldsymbol{b}_{M}\end{array}\right]$. The empirical counterpart of $B$ is a matrix of a multivariate time series regression coefficients of each asset's excess return on $\boldsymbol{r}_{c}$.

We show next that there exists a set of optimal hedge portfolios, with weights given by the columns of the $(N \times M)$ matrix $W_{h}^{*}$, that can be combined with the original CPs to obtain (a rotation of) the CEPs. That is,

$$
W_{c}^{*} A=W_{c}-W_{h}^{*} \Delta^{*}
$$

where $A$ is an $(M \times M)$ rotation matrix, and $\Delta^{*}$ is an $(M \times M)$ matrix of optimal hedge ratios. 
Definition 2.3 (Optimal hedge portfolio) The weight-vector of the $m$-th characteristic hedge portfolio is the solution to the program

$$
\max _{\boldsymbol{w}_{h, m}} \boldsymbol{w}_{h, m}^{\top} \boldsymbol{b}_{m} \quad \text { subject to } \quad \boldsymbol{w}_{h, m}^{\top} X=\mathbf{0} \quad \text { and } \frac{1}{2} \boldsymbol{w}_{h, m}^{\top} \Sigma \boldsymbol{w}_{h, m}=\overline{\sigma^{2}} \quad\left(\mathcal{P}_{h, m}\right)
$$

Program $\left(\mathcal{P}_{h, m}\right)$ delivers a portfolio weight-vector $\boldsymbol{w}_{h, m}^{*}$ so as to maximize the correlation of the returns of the hedge portfolio, $r_{h, m} \equiv \boldsymbol{w}_{h, m}^{* \top} \boldsymbol{r}$, with the returns of the corresponding CP, $r_{c, m}$, conditional on having zero characteristic exposure. Define

$$
W_{h}^{*}=\left[\begin{array}{llll}
\boldsymbol{w}_{h, 1}^{*} & \boldsymbol{w}_{h, 2}^{*} & \cdots & \boldsymbol{w}_{h, M}^{*}
\end{array}\right] .
$$

\section{Proposition 2.4}

1. The weights of the optimal hedge portfolios are given by

$$
W_{h}^{*}=\left(W_{c}-W_{c}^{*} X^{\top} W_{c}\right) \Sigma_{c}^{-1} E^{-1}
$$

where $E$ is an $(M \times M)$ diagonal matrix specified in the Appendix B.3 and $W_{c}^{*}$ is given by (21).

2. $A$ and $\Delta^{*}$ in expression (25) are given by

$$
A=X^{\top} W_{c} \quad \text { and } \quad \Delta^{*}=E \Sigma_{c}
$$

Proof: See Appendix B.3

To understand the intuition of Proposition 2.4 start by noticing that $W_{c}^{*} A$ is a rotation of the CEPs' weights such that these rotated CEPs have the same characteristic as the original CPs. The corresponding optimal hedge portfolios have zero expected excess returns,

$$
\mathbb{E} \boldsymbol{r}_{h}=\mathbf{0} \quad \text { where } \quad \boldsymbol{r}_{h}=W_{h}^{* \top} \boldsymbol{r}
$$


Finally, there is the interpretation of the optimal hedge ratios. A bit of algebra, reported in the Appendix B.4, shows that 16

$$
\Delta^{*}=\Sigma_{h}^{-1} W_{h}^{* \top} \Sigma W_{c}
$$

that is, for each CP, the optimal hedge ratios are the coefficients of a multivariate regression of its return $r_{c, m}$ on the returns of all the optimal hedge portfolios. The intuition of this result is straightforward. The hedge portfolios command zero premia, but their returns are correlated with $\boldsymbol{r}_{c}$. Hence, the optimal hedge ratios are such that the return of the CEP is orthogonal to $\boldsymbol{r}_{h}$. That is, consistent with exactly the intuition in the example in Section 2.1, each $\mathrm{CEP}$ is the residual from a projection of the $\mathrm{CP}$ on the set of hedge portfolios, meaning that each CEP is equal to the corresponding CP, orthogonalized to the set of hedge portfolios.

In sum, the optimal hedge portfolios do not remove any of the premia from the CPs but remove sources of variation that do not command any premium. In other words, each of the optimal hedge portfolios has zero expected excess return, and hence zero loading on the priced risk factor $f$. The only reason that the optimal hedge portfolios load on the CPs is because they all load on the unpriced risk factors.17 All optimal hedge portfolios together then form a basis for the unpriced components in the CPs and can be used to hedge out all the exposure to unpriced risk factors. This is the source of the improvement in the Sharpe ratio when going from CPs to CEPs.

An important implication of this analysis is that whenever we have a set of characteristics that explain expected excess returns, we can always find a set of portfolios that span the MVE portfolio. These portfolios lack economic content and thus so do the loadings with respect to those portfolios, which are simply the characteristics (see Proposition 2.2). These CEPs though can help in discriminating amongst alternative economic models: if a particular economic variable is uncorrelated with the CEPs, then it cannot be a candidate for a state variable that drives the marginal rate of substitution of the marginal investor. But the validity of such an inference depends on using the CEPs rather than the CPs; the correlation of an economic variable with a CP could result from a correlation of the variable with the priced factor, or with the unpriced factors on which the CP loads.

\footnotetext{
${ }^{16}$ The reason why we write $\Delta^{*}$, rather than $\Delta$, is because, as it was the case in the example (see $\sqrt{14}$ ), the optimal hedge ratios are the solution of an optimization problem that results in an optimal combination of the CPs and the optimal hedge portfolios.

${ }^{17}$ We assume that $N$ is large enough and we can ignore idiosyncratic risk.
} 


\section{Empirical results}

\subsection{Hedge portfolio construction}

Recall that our starting point is any given set of CPs on which we want to improve. To do so our methodology involves two steps. First, we construct the hedge portfolios. Second we find the optimal hedge ratios.

In our empirical exercise, we focus on the FF five-factor model and we follow these authors in the construction of their CPs. The empirical goal is to construct the best possible hedge portfolios, as introduced in $\left(\mathcal{P}_{h, m}\right)$. The empirical procedure to construct the hedge portfolios builds on Daniel and Titman (1997). The idea is to use ex-ante forecasts for the loadings for each stock $i$ on the returns of the CPs, $r_{c, m}$, in order to construct hedge portfolios with maximum loadings on the CPs. At the same time, these hedge portfolios are constructed in such a way that they have characteristics as close as possible to zero.

More precisely, our empirical approach is based on the first order conditions of the pro$\operatorname{gram}\left(\mathcal{P}_{h, m}\right)$. We show in the Appendix B.3 that the weights of each optimal hedge portfolio are given by

$$
\boldsymbol{w}_{h, m}^{*}=\frac{1}{\kappa_{2, m}} \Sigma^{-1}\left(\boldsymbol{b}_{m}-X \boldsymbol{\kappa}_{1, m}^{\top}\right),
$$

the $m$-th column of $W_{h}$ in (26). In (30) $\kappa_{1, m}$, which is $(1 \times M)$, and $\kappa_{2, m}>0$ are the Lagrange multipliers associated with the first and second constraints in program $\left(\mathcal{P}_{h, m}\right)$.

Roughly, equation (30) says, holding fixed the characteristics, the hedge portfolio goes long stocks with high loadings and short stocks with low loadings with respect to the CP. Intuitively, one can think about stocks' loadings with respect to the CPs as a combination of exposure to priced and unpriced risk. When we control for the characteristics, we control for cross-sectional variation in the exposure to the CEPs, the sole source of variation in premia. Thus, holding characteristics constant, sorting on CP loadings captures the remaining variation: the one with respect to the unpriced sources of common variation.

Empirically, we construct the optimal hedge portfolios by sorting individual stocks into characteristic bins and then within each bin sort again on the forecast loading with respect to a particular CP. We form the portfolio with maximum negative loading, as in Daniel and 
Titman (1997), rather than what is prescribed in equation (30). This is without any effect on the interpretation of the results.

There are two challenges in constructing optimal hedge portfolios. First, our theory requires that we control for all characteristics. Roughly, within each characteristic bin stocks have the same characteristic values. But if there are, for example, five characteristics and we sort stocks into three bins for each of them, this would result in 243 portfolios. Some of these portfolios would surely contain very few stocks and thus would not be sufficiently diversified. It turns out that, empirically, controlling for size and one additional characteristic at a time is enough to deliver hedge portfolios that have close to zero exposure to all characteristics, while obtaining well-diversified portfolios. We return to this issue when we discuss the characteristic properties of the hedge portfolios.

Second, notice that construction of the optimal hedge portfolios requires use of the full covariance matrix $(\Sigma$; see equation (30)). We instead construct an approximation to the optimal hedge portfolio by, for a set of firms with roughly equal characteristics, going long a value-weighted portfolio of stocks with low loadings and short a value-weighted portfolio of stocks with high loadings with respect to the CPs. This results in a hedge portfolio that we can combine with the CPs to get close to the CEPs. Indeed, because we are not using the theoretically optimal hedge portfolios we cannot exactly recover the CEPs from Definition 2.1. We still refer to these "approximate CEPs" as CEPs in order to avoid the need to introduce additional terminology. Finally, value-weighting stocks in each of the portfolios sorted on characteristics and loadings guarantees that our portfolios do not overweight small stocks; this avoids the inherent difficulties in trading small stocks because of a lack of liquidity.

We describe next the exact procedure to construct the hedge portfolios based on the example of HML. We first calculate book-to-market (BEME) and market capitalization (ME) break points at the marks of $33.3 \%$ and $66.7 \%$ based on NYSE firms. For BEME we use data from the end of December of the previous year and for ME we use data from the end of June of each year. Then, at the end of June of a given year, all NYSE, AMEX and NASDAQ stocks are placed into one of the nine resulting bins. Next, within these nine bins, each of the stocks is sorted into one of three additional bins formed based on the stocks' forecast future loading on the HML CP. This last sort results in portfolios of stocks with similar characteristics 
(BEME and ME) but different loadings on HML ${ }^{18}$ The firms remain in those portfolios between July and June of the following year. Finally, we construct our hedge portfolio for HML by going long a combination of all low loading portfolios and short a combination of all high loading portfolios, where each portfolio receives a weight of $\frac{1}{9}$.

The hedge portfolios for RMW and CMA are constructed in exactly the same way, simply by replacing BEME with operating profitability (OP) and investment (INV). For SMB, we follow $\mathrm{FF}$ and construct three different hedge portfolios: the first sorts are based on BEME and ME, and then within these $3 \times 3$ bins, we conditionally sort on the loading on SMB. The second and third versions use OP and INV instead of BEME in the first sort. Then, an equal weighted portfolio of the three different SMB hedge portfolios is used as the hedge portfolio for SMB. We do exactly the same for the hedge portfolio for the market (MktRF), using forecast loadings on MktRF instead of forecast loadings on SMB.

Clearly a key ingredient of the last step of the sorting procedure is the estimation of the future loading on the corresponding characteristic portfolio. Our purpose is to obtain forecasts of loadings in the five-factor FF model 19

$$
\begin{aligned}
r_{i, t}=\alpha_{p} & +b_{i, M k t R F} r_{M k t R F, t}+b_{i, H M L} r_{H M L, t}+b_{i, S M B} r_{S M B, t} \\
& +b_{i, C M A} r_{C M A, t}+b_{i, R M W} r_{R M W, t}+\epsilon_{p, t}
\end{aligned}
$$

For each stock, we instrument future loadings with pre-formation loading forecasts. The resulting estimation method is intuitive and is close to the method proposed by Frazzini and Pedersen (2014) to estimate individual-firm market loadings. These authors build on the observation that correlations are more persistent than variances ${ }^{20}$ and propose estimating correlations and variances separately. They then combine these estimates to produce the pre-formation loadings. Specifically, correlations are estimated using a five-year window with overlapping log-return observations aggregated over three trading days, to account for nonsynchronicity of trading. Variances of characteristic portfolios and stocks are estimated on daily log-returns over a one-year horizon. Furthermore, we introduce an additional intercept in the pre-formation regressions for returns in the six months preceding portfolio formation,

\footnotetext{
${ }^{18} \mathrm{~A}$ potential concern with independently triple-sorted portfolios is sparse portfolio population. The number of traded firms has varied substantially over time, reaching a "listing peak" in 1996 when it started declining (see Doidge, Karolyi, and Stulz, 2017). We show in Appendix D.1 that even in periods of relatively few listed firms, the resulting portfolios are sufficiently diversified.

${ }^{19}$ We write, say, $r_{H M L, t}$ instead of $r_{c, B E M E, t}$ to simplify the notation.

${ }^{20}$ See, e.g., De Santis and Gerard (1997)
} 
i.e., from January to June of the rank-year (see Figure 1 in Daniel and Titman (1997) for an illustration). Further, we use constant-allocation and constant-weight pre-formation characteristic portfolio returns, as in Daniel and Titman (1997) 21

The accuracy of loading forecast impacts the efficacy of the hedge portfolios. Intuitively, if our forecasts of future loadings are very noisy, then sorting on the basis of forecast loadings will not capture variation in the actual post-formation loadings of the sorted portfolios. In contrast, if the forecasts are accurate, then our hedge portfolio - which goes long the lowforecast-loading portfolio and short the high-forecast-loading portfolio - will indeed have very negative loading with respect to the corresponding FF CP. Notice that this relates to statistical power of rejecting the benchmark asset pricing model. Under the null hypothesis, $\alpha$ s are equal to zero for all stocks. Given our theory, the alternative hypothesis is that the hedge portfolios have zero expected returns and strong negative loadings, which translates into large positive $\alpha$ s. The more negative the ex-port loadings, the higher is the power of the test designed to reject the null hypothesis that the benchmark model is true. We show in the Appendix D.2 that using a low power methodology that follows Daniel and Titman (1997) and Davis, Fama, and French (2000) leads to different results than the ones presented in the next section. Indeed, with hedge portfolios constructed using the low power method we are not able to reject the FF five-factor model.

\subsection{Description of the sorted portfolios}

Table 2 presents average monthly excess returns for the portfolios sorted on characteristics and forecast-loadings, which we combine to form our hedge portfolios. Each panel presents a set of sorts with respect to size and one characteristic - either book-to-market, profitability or investment - and the loading on HML (Panel A), RMW (Panel B), CMA (Panel C), MktRF (Panels D-F), or SMB (Panels G-I).

For each of the 27 portfolios in each subpanel, we report value-weighted monthly excess returns. The column labeled "Avg." gives the average across the 9 portfolios for a given characteristic. First, note that the average returns in the "Avg." column are consistent with empirical regularities well-known in the literature: the average returns of value portfolios

\footnotetext{
${ }^{21}$ See Appendix C.2 for details.
} 
are higher than those of growth, historically robust profitability firms beat weak profitability firms, and historically conservative investment firms beat aggressive investment firms.

In Table 3 we present the post-formation loadings and $\alpha$ s. These are the coefficients from regressing the monthly excess returns of the BEME/OP/INV $\times \mathrm{ME} \times$ loading sorted portfolios on the excess returns of the five FF CPs, in the sample period from 1963/07 to 2019/06. We see that there are large differences between the post-formation loadings of the lowforecast-loading ("1") and high-forecast-loading ("3") portfolios For the value, profitability, and investment sorts, the average post-formation differences in loading of the " 3 " and " 1 " portfolios are $0.79,0.69$, and 0.96 respectively. Given these large differences in loadings, it is remarkable that the difference in the average monthly returns for the high- and low-loading portfolios are 8, 6, and -4 basis points per month for the value, profitability and investmentloading sorts, respectively (see the last rows, labeled "Avg." of Panels A-C in Table 2).22 This is consistent with the Daniel and Titman (1997) conjecture that average returns are a function of characteristics, and are unrelated to the loadings on the FF-CPs after controlling for the characteristics.

In Figures 6, 7 and 8 we analyze the average characteristics of the sorted portfolios. Each dot in these plots represents one of the 27 portfolios from the $3 \times 3 \times 3, \mathrm{BEME} / \mathrm{OP} / \mathrm{INV} \times \mathrm{ME} \times$ loading sort. The dotted lines connect all portfolios within the same BEME/OP/INV $\times$ ME bucket. The $\mathrm{x}$-axis is the respective post-formation loading and the $\mathrm{y}$-axis the average characteristic value. Figure 6 shows the portfolios sorted on HML loadings (Panel A), the portfolios sorted on RMW loadings (Panel B) and the portfolios sorted on CMA loadings (Panel C). Figure 7 shows portfolios that form the market hedge portfolio and Figure 8 shows portfolios that form the SMB hedge portfolio.

Ideally, all the dotted lines in Figures 6, 7 and 8 should be horizontal straight line. This would mean that, within each characteristic bucket, forecast loadings were uncorrelated with any characteristic. However, our method uses coarse characteristic sorts and therefore we do not expect the characteristics of the high and low loading portfolios to be identical. Rather, we expect that the loading with respect to the CP will be correlated with the characteristic used to construct it. For example, $b_{H M L}$ is correlated with BEME in the cross-section. This correlation translates into differences in the average characteristics of the low $b$ and the high $b$ portfolios. Last, we do not control for the two other characteristics, when sorting on a

\footnotetext{
${ }^{22}$ For comparison, the average excess returns of the HML, RMW, and CMA portfolios over the same period are 31,27 , and $22 \mathrm{bp} /$ month, respectively.
} 
particular loading. For example, when we form BEME $\times \mathrm{ME} \times b_{H M L}$ sorted portfolios, we do not control for OP or INV. To the extent that OP and/or INV are cross-sectionally correlated with $b_{H M L}$, we might also pick up variation in those characteristics.

One way to assess the magnitude of the deviation of our sorted portfolios from the ideal "characteristic balanced" case, is to compare the spread in characteristics within and across characteristic buckets. The former constitutes the vertical distance between red and green dots, that are connected with a dotted line, which we call the "unintended characteristic spread". The latter is the vertical distance across the dotted lines for the cases where the characteristic on the y-axis corresponds to the one used to form the CP (i.e. HML with BEME, RMW with OP, and CMA with INV). This is the "intended spread" in the characteristic between high and low characteristic portfolios used to form the CP. This gives us an idea of the magnitude of a large spread in the characteristic.

As one can see from the figures, in general, the unintended spreads are relatively small, compared to the intended spreads. For example, in the case of portfolios sorted on $b_{h m l}$, the unintended BEME spread within characteristic buckets is at most about 0.24 (among the small-value stocks). When we compare that to the intended spread in BEME between small value and small growth stocks, which amounts to 1.13, we can conclude that the unintended spread is relatively small.

We view these results as evidence that even a sorting procedure as simple and coarse as ours does a reasonable job in forming hedge portfolios that are close to being characteristic balanced. Furthermore, the small observed return differences presented in Table 2 may be related to the characteristic spread observed above. In fact, our theory predicts that the characteristic spreads across low loading and high loading portfolios should relate to the expected returns in the hedge portfolios. For example, among the firms in the small-cap, low BEME bucket in Panel A of Figure 6, there is considerable variation in OP. This could partially explain the 19 bp difference in returns between the high and low $b_{H M L}$ portfolios, as documented in the top row in Panel A of Table 2.

Finally, from Figures 6, 7 and 8 we can also see that we forecast future loadings quite well. Ideally, the low forecast loading stocks also have a low post-formation loading on the CPs. Therefore, the red dots should always be the farthest to the left, whereas the green dots (the high forecast loading stocks) should end up to the right of those, within each characteristic bucket. Indeed we observe this pattern for all portfolios. Moreover, the spread 
between the red and the green dots, within a given characteristic bucket, should be as large as possible. Indeed the spread generated here is far bigger, as compared to, e.g., the one that is generated using a loading forecast methodology following Daniel and Titman (1997) or Davis et al. (2000) 23

\subsection{Pricing results}

In this subsection we describe the two key empirical results of this paper. First, we show that we can reject the FF five-factor model using the hedge portfolios as test assets. Second we show how to improve the Sharpe ratios of the FF CPs by combining them optimally with the hedge portfolios. We argue that such CEPs have a better chance of spanning the mean variance efficient frontier than the standard CPs proposed in the literature.

\subsubsection{Pricing the hedge portfolios}

We run a single time series regression of the monthly excess returns of the hedge portfolios $r_{h, m}, m \in\{H M L, R M W, C M A, S M B, M k t R F\}$, on the excess returns of the five FF CPs. Table 4 reports the average excess returns, alphas and loadings as well as the corresponding $t$-statistics.

Two attributes are important to determine the ability of the hedge portfolios in hedging unpriced risk: They must have zero expected excess returns and have large negative loadings with respect to the corresponding $\mathrm{CP}$.

We first assess the hedge portfolios' expected excess returns. Column "Avg" in Table 4 reports the monthly average excess returns of all hedge portfolios. Ideally, all of these numbers should be exactly zero. For all 5 hedge portfolios, average excess returns are slightly negative but statistically indistinguishable from zero. This result mirrors the fact that the hedge portfolios have close to zero characteristic exposures. The fact that the excess returns are all slightly negative, albeit insignificantly so, reflects the earlier insight, that characteristics and corresponding loadings are inherently cross-sectionally correlated. A coarse sort (such as 3 buckets) is thus always at risk of picking up some variation in the corresponding

\footnotetext{
${ }^{23}$ We present evidence on this in Appendix D.2
} 
characteristic. Hence, going long low (short high) loading stocks mechanically also tends to slightly tilt towards low (high) characteristic values, as pointed out in Section 3.2 .

We then turn to the hedge portfolios' ability to hedge out unpriced risk by looking at their post-formation loading on their corresponding CP. As expected, each hedge portfolio exhibits a strong significantly negative loading on their corresponding CP. For example, the hedge portfolio for HML has a loading on HML of -0.79 with a $t$-statistic of -27.8 .

This directly translates into pricing implications, as indicated by the alphas. The five FF CPs fail to price four out of five long-short hedge portfolios, three of them (MktRF, RMW, and CMA) at a significance level of 5\%.24 The last lines of the Table constructs equalweight combinations of these portfolios. The alphas for all of them are strongly statistically significant. For instance, when we consider the equal-weight combination of four hedge portfolios (the ones corresponding to HML, RMW, CMA and MktRF), the monthly alpha is 0.18 with a $t$-statistic of 5.93 .

\subsubsection{Ex-ante determination of the optimal hedge-ratio}

Having studied the hedge portfolios, the next step is to construct characteristic efficient portfolios, i.e.,

$$
r_{c, m, t}^{*}=r_{c, m, t}-\boldsymbol{r}_{h, t} \hat{\boldsymbol{\delta}}_{m, t-1}
$$

where $m \in\{H M L, R M W, C M A, S M B, M k t R F\} 2$

The optimal hedge ratio $\hat{\boldsymbol{\delta}}_{m, t-1}$ is determined ex-ante, in the spirit of equation (14). We employ the same loading forecast techniques as described before to forecast loadings, i.e., we first calculate five years of constant-weight and constant-allocation pre-formation returns of $r_{c, m, t}$ and $\boldsymbol{r}_{h, t}$. We then calculate correlations over the whole five years of 3-day overlapping return observations and variances by utilizing only the most recent 12 months of daily observations. Note that this is done in a multi-variate framework, i.e., we consider the covariance of each CP with all five hedge portfolios, to account for the correlation structure

\footnotetext{
${ }^{24}$ The only one for which the FF model cannot be rejected, even at the $10 \%$ level, is the SMB hedge portfolio. The fact that the FF model succeeds in pricing the SMB hedge portfolio is consistent with the notion that there is little to price there, as we know that the size premium has historically been relatively weak.

${ }^{25}$ To be consistent with our notation, the returns of, for example, the HML portfolio at time $t$ should be denoted by $r_{c, B E M E, t}$. We simplify the notation by calling it $r_{H M L, t}$.
} 
among the hedge portfolios. Consequently, both $\hat{\boldsymbol{\delta}}_{m, t-1}$ and $\boldsymbol{r}_{h, t}$ are $M$-dimensional vectors, where $M=5$ in the case of the FF model examined here. Note further, that the returns of the CEPs $r_{m, t}^{*}$ are (approximately) orthogonal to the returns of the hedge portfolios $\boldsymbol{r}_{h, t}$. The reason why they are only approximately orthogonal is because the $\hat{\boldsymbol{\delta}}_{m, t-1}$ is estimated ex-ante, i.e., up to $t-1$.

\subsubsection{Characteristic efficient Fama and French portfolios}

The first column of Table 5 reports key statistics on the returns of each of the CPs $\left(r_{c}\right)$ : the annualized average returns in percentages, the annualized volatility of returns and the squared annualized Sharpe ratio. The second column reports the same three quantities for the CEPs, $r_{c}^{*}$. These portfolios are constructed exactly as in expression (32).

When we move from $r_{c, m}$ to $r_{c, m}^{*}$, we see that the mean return of all characteristic portfolios decreases, but that the volatility decreases substantially more. This leads to an increase in the Sharpe ratio for each of the individual Fama and French CPs. For example, the squared Sharpe ratio of the improved version of CMA is 0.29 , where the squared Sharpe ratio of the original CMA is 0.16 .

The right-side panel of Table 5 presents $p$-values for the differences in means based on a $t$-test, and for the volatilities using a Levene (1961) test for equality of variances. To test for differences in Sharpe-Ratios, we use a test based on Jensen (1968)'s alpha. Specifically, to assess whether the portfolio performance increases when we move from the CP to the CEP, we run a time-series regression of the returns of the CEP on the $\mathrm{CP}$, and obtain a $p$-value for the regression intercept. Consistent with the interpretation of Jensen (1968) we are testing whether there is a statistically significant performance differential between the $\mathrm{CP}$ and the CEP.

While the result that we improve on each characteristic portfolio individually is promising, the ultimate goal of the exercise was to construct a set of portfolios that gets closer to spanning the mean variance efficient portfolio, as compared to the CPs. Hence, in the second-to-last panel of Table 5, we compute the in-sample optimal combination of both the original FF CPs (column $r_{c, m}$ ) and the CEPs $\left(r_{c, m}^{*}\right)$. The maximum achievable squared Sharpe ratio with FF CPs in the sample period covered in this paper $(1963 / 07$ - 2019/06) is 1.16. The squared Sharpe ratio of the optimal combination of the CEPs is instead 2.16. 
Notice that each individual CEP is perfectly tradable, as all information used to construct them is known to an investor ex-ante. Only the weights of optimal combinations of the five CPs as well as CEPs, as reported in the bottom panel of Table 5, are calculated insample. Additionally, we want to emphasize that the way we construct our portfolios is very conservative, in that we only rebalance once every year - in order to be consistent with the rules of the game set by Fama and French.

We reiterate that our empirical approach does not in general deliver the theoretical CEPs. Computation of the optimal hedge portfolios (see equation (30) and optimal hedge ratios (described in equation (29) ) requires knowledge of $\Sigma$, which is difficult to estimate, as well as of the post-formation loadings. Nevertheless, the CEPs deliver a large improvement over the CPs. Moreover, our empirical method is robust and, at same time, delivers tradable hedge portfolios.

\subsubsection{Redundancy of HML}

FF find that $H M L$ is redundant, in that it is spanned by the other CPs. Table 6 shows that we can replicate this result based on our extended sample. The weight of $H M L$ in the ex-post optimal combination, based on Markowitz optimization, is - $1.0 \%$ when we use the original FF CPs (column $r_{c}$ ). However, if we use the CEPs (column $r_{c}^{*}$ ), the weight on $H M L$ increases to $8.0 \%$, close to the weight on $M k t R F$.

We can confirm this result by running spanning regressions in Table 7. The return of $H M L$, $r_{H M L}$ is indeed spanned by the other four CPs (column 1). It is similarly subsumed by the other four CEPs (column 2). The return of the CEP version of $H M L, r_{H M L}^{*}$ (column 3), is not fully spanned by the returns of the other four FF CPs: removing unpriced sources of variation from $H M L$ makes it an unspanned portfolio, relative to the other four original FF CPs. The alpha of a regression of the $H M L$ CEP on the other CEPs has a $t$-statistic of 1.53. We can thus reject redundancy of $H M L^{\star}$ at the $10 \%$ significance level.

An important additional empirical finding is that the correlation between $H M L^{*}$ and $R M W^{*}$ is now strongly negative, -.52 , whereas it was positive but very small for $H M L$ and $R M W$, .09 (see Table 8). This fact suggests that both CPs, $H M L$ and $R M W$, load on an unpriced source of common variation. The implication is that an investor can capture the premium 
associated with exposure to $H M L^{*}$ and $R M W^{*}$ while lowering the total variance of the portfolio.

\subsection{Industry-neutral characteristic portfolios}

In Section 2.1.2, we argued that industry was one potential source of common variation that was likely to be unpriced. Since we know that there are periods in which the FF CPs strongly load on industry portfolios, a natural exercise is to construct CPs that are industry-neutral. In this section, we construct industry-neutral versions of CPs and compare their performance with the performance of the CEPs constructed in this paper.

To construct industry-neutral CPs we ex-ante hedge any exposure to the $12 \mathrm{FF}$ industries out of the FF CPs, except for the market26 Define the returns of the industry-neutral portfolio, $r_{c-i n d, m, t}$, as:

$$
r_{c-i n d, m, t}=r_{c, m, t}-\boldsymbol{r}_{i n d, t} \widehat{\boldsymbol{\delta}}_{c, m, t-1}^{i n d}
$$

where $m \in\{H M L, R M W, C M A, S M B, M k t R F\}, \boldsymbol{r}_{i n d, t}$ is a $(1 \times 12)$ vector with excess returns of all 12 industries, $\boldsymbol{\delta}_{c, m, t-1}^{\text {ind }}$ is the ex-ante optimal industry hedge-ratio. Analogous to the previous exercises, $\boldsymbol{\delta}_{c, m, t-1}^{i n d}$ is estimated every June 30th, using correlations over the previous five years of 3-day overlapping return observations and variances by using only the most recent 12 months of daily observations 27

Table 5 reports the mean, volatility and squared Sharpe ratios for all $r_{c-i n d, m}$ and the insample optimal combination of the industry-neutral characteristic portfolios. Hedging out industry risk leads to an improvement in the squared Shape ratio for HML, CMA and SMB, consistent with the hypothesis that it is generally unpriced risk. However, the CEPs outperform the industry-hedged CPs in the case of RMW and CMA, i.e., the use of our hedge portfolio results in a greater Sharpe ratio improvement than simply hedging out industry exposure. In contrast, for HML the industry-neutral version has a higher Sharpe ratio than CEP. A possible explanation is that, in theory, unlike our procedure, the industry-hedging can change the characteristic of the resulting portfolio and as a consequence the exposure to the priced factor. Recall that our CEPs have the same characteristics as the CPs, but lower

\footnotetext{
${ }^{26}$ The market is a linear combination of all industries and thus, hedging out industries from the market using the method described is not feasible.

${ }^{27}$ We also employ constant-weight, constant-allocation (as of June 30th) pre-formation returns of the factor- and industry-portfolios.
} 
variance and therefore a higher squared Sharpe ratio. Instead, industry-neutral portfolios do not need to have the same characteristic as the original CPs and our theory does not have a prediction for this case.

Nevertheless, improving the squared Sharpe ratios for each of the CPs is not the goal. Rather it is to construct CEPs that span the MVE portfolio. Indeed, the ex-post optimal combination of the CEPs shows a far more dramatic improvement over the original FF CPs compared to the ex-post optimal combination of industry-hedged portfolios. Based on our Jensen (1968) test, the CEPs' optimal combination significantly outperforms the industryneutral one ${ }^{28}$ Since the market could not be included in the industry-hedging, we repeat the ex-post optimal combination exercise excluding MktRF in the last panel of Table 5 . The CEPs also achieve a higher Sharpe ratio compared to the industry-neutral CPs in this specification, and that difference is also statistically significant.

These results suggest that simply hedging out industry exposure is not optimal for two potential reasons. First, some component of the industry factors might be priced. Second, there can be other sources of common variation that are not related to industries and do not command a premium. Our procedure is designed to only hedge out unpriced sources of common variation and does not require us to identify those sources.

\section{Conclusions}

This paper makes two contributions to the asset pricing literature. First, we examine the standard procedure employed for constructing characteristic portfolios (CPs): zeroinvestment portfolios for which the long side is a portfolio of high characteristic stocks, and the short side consists of a portfolio of low characteristic stocks. This procedure, which has become standard since Fama and French (1993), does not guarantee that the set of portfolios will span the mean variance efficient frontier. The reason is that, when sorting on a characteristic, the resulting portfolios are likely to load on an unpriced sources of common variation. Our second contribution is to show how to construct hedge portfolios that capture the unpriced risk in these portfolios, and which can be combined with the CPs to form

\footnotetext{
${ }^{28}$ Note that we test whether Jensen's $\alpha$ of regressing the CEP on the industry-neutral portfolio is statistically larger than zero. For CPs where the point estimate of that $\alpha$ is negative (such as HML and SMB), we report a "-".
} 
characteristic efficient portfolios (CEPs) that are free of exposure to these unpriced sources of common variation. Our hedge portfolios are constructed to have maximum loading on the CPs, subject to having zero characteristic. We show in particular that if the model linking characteristics and average excess returns is correct, the CEPs will span the mean variance efficient portfolio.

We illustrate the empirical relevance of our ideas in the context of the five-factor model of Fama and French (2015). We take the five characteristic portfolios from that model and construct hedge portfolios for each. Then we construct empirical counterparts to the CEPs, one for each of the characteristics (market, size, market-to-book, profitability and investment) by optimally combining the original CPs with our hedge portfolios. The insample squared Sharpe ratio of the optimal combination of the FF CPs is 1.16 whereas it is 2.16 for the CEPs. Removing unpriced sources of common variation from the original CPs is both empirically and economically relevant.

This paper sheds light on some of the debates in the cross-sectional asset pricing literature. First, an important, if somewhat implicit, assumption in the literature is that there is a model linking average excess return to characteristics. The existence of this model is also our starting point. Our contribution is then to show how to construct the CEPs from the CPs so that they span the MVE portfolio. It is a representation theorem: If a complete model of average excess returns and characteristics is available, then average excess returns can be fully described with a "factor model" in which the "factors" are the CEPs.

Economic theory is interested in understanding the economic forces that are the sources of premia in asset returns. The CEPs we construct are important when discriminating between alternative economic models of the marginal rate of substitution of the representative investor. The reason is that only the return of the optimal combination of the CEPs - which is the maximum Sharpe ratio portfolio - is maximally correlated with shocks to the marginal rate of substitution of the representative investor. The returns of the CPs are not, as these portfolios also load on unpriced sources of common variation. CEPs then provide a lens through which we can learn about the economic shocks that matter for the representative investor.

Second, the loadings of any portfolio on the CEPs equal the portfolio characteristics. This clarifies the characteristics versus covariance debate. To put it sharply: In the context of the asset pricing models that spring from Fama and French (1993) there is no distinction 
between characteristics and covariances when the portfolios that serve as factors are the CEPs.

Third, we emphasize the distinction between priced and unpriced sources of common variation. A full description of the covariance matrix of returns requires at the very least the CEPs and the hedge portfolios, but only the CEPs are needed for pricing. This speaks to the theoretical distinction between the APT of Ross (1976) and the ICAPM of Merton (1973). The first is a model of the covariance matrix of returns whereas the second is a model of sources of premia, that is, of expected excess returns. Keeping in mind this distinction when building asset pricing models out of characteristics is key to guaranteeing that the resulting portfolios span the MVE portfolio. 


\section{References}

Asness, C. S., A. Frazzini, and L. H. Pedersen. 2019. Quality Minus Junk. Review of Accounting Studies 24:34-112.

Asness, C. S., R. B. Porter, and R. Stevens. 2000. Predicting stock returns using industryrelative firm characteristics. SSRN working paper \# 213872.

Black, F., and R. Litterman. 1991. Global Portfolio Optimization. Financial Analysts' Journal 48:28-43.

Carhart, M. M. 1997. On Persistence in Mutual Fund Performance. Journal of Finance $52: 57-82$.

Cochrane, J. H. 2005. Asset pricing: Revised edition. Princeton university press.

Cohen, R. B., C. Polk, and T. Vuolteenaho. 2003. The value spread. Journal of Finance 58:609-642.

Cohen, R. B., and C. K. Polk. 1995. An Investigation of the Impact of Industry Factors in Asset-Pricing Tests. University of Chicago working paper.

Daniel, K. D., M. Grinblatt, S. Titman, and R. Wermers. 1997. Measuring Mutual Fund Performance with Characteristic-Based Benchmarks. Journal of Finance 52:1035-1058.

Daniel, K. D., and S. Titman. 1997. Evidence on the Characteristics of Cross-Sectional Variation in Common Stock Returns. Journal of Finance 52:1-33.

Daniel, K. D., and S. Titman. 2006. Market Reactions to Tangible and Intangible Information. Journal of Finance 61:1605-1643.

Daniel, K. D., and S. Titman. 2012. Testing Factor-Model Explanations of Market Anomalies. Critical Finance Review 1:103-139.

Davis, J., E. F. Fama, and K. R. French. 2000. Characteristics, Covariances, and Average Returns: 1929-1997. Journal of Finance 55:389-406.

De Santis, G., and B. Gerard. 1997. International asset pricing and portfolio diversification with time-varying risk. Journal of Finance 52:1881-1912.

Doidge, C., G. A. Karolyi, and R. M. Stulz. 2017. The U.S. listing gap. Journal of Financial Economics 123:464-487.

Fama, E. F., and K. R. French. 1993. Common risk factors in the returns on stocks and bonds. Journal of Financial Economics 33:3-56.

Fama, E. F., and K. R. French. 1996. Multifactor Explanations of Asset Pricing Anomalies. Journal of Finance 51:55-84.

Fama, E. F., and K. R. French. 1997. Industry Costs of Equity. Journal of Financial Economics 43:153-193. 
Fama, E. F., and K. R. French. 2010. Luck versus Skill in the Cross-Section of Mutual Fund Returns. Journal of Finance 65:1915-1947.

Fama, E. F., and K. R. French. 2015. A five-factor asset pricing model. Journal of Financial Economics 116:1-22.

Frazzini, A., and L. H. Pedersen. 2014. Betting Against Beta. Journal of Financial Economics 111:1-25.

Freyberger, J., A. Neuhierl, and M. Weber. 2018. Dissecting Characteristics Nonparametrically. Review of Financial Studies forthcoming.

Gerakos, J., and J. T. Linnainmaa. 2018. Decomposing value. Review of Financial Studies $31: 1825-1854$.

Golubov, A., and T. Konstantinidi. 2019. Where is the risk in value? Evidence from a market-to-book decomposition. Journal of Finance forthcoming.

Gu, S., B. T. Kelly, and D. Xiu. 2018. Empirical Asset Pricing via Machine Learning. Yale SOM working paper.

Hansen, L. P., and R. Jagannathan. 1991. Implications of Security Market Data for Models of Dynamic Economies. Journal of Political Economy 99:225-262.

Huang, D., J. Li, and G. Zhou. 2018. Shrinking Factor Dimension: A Reduced-Rank Approach. Washington University-Olin School working paper.

Jensen, M. C. 1968. The Performance of Mutual Funds in the Period 1945-1964. Journal of Finance 23:389-416.

Kozak, S., S. Nagel, and S. Santosh. 2019. Shrinking the Cross Section. Journal of Finance forthcoming.

Laeven, M. L., and H. Huizinga. 2009. Accounting discretion of banks during a financial crisis. IMF working paper 9-207.

Ledoit, O., and M. Wolf. 2003. Improved estimation of the covariance matrix of stock returns with an application to portfolio selection. Journal of empirical finance 10:603-621.

Ledoit, O., and M. Wolf. 2004a. Honey, I shrunk the sample covariance matrix. The Journal of Portfolio Management 30:110-119.

Ledoit, O., and M. Wolf. 2004b. A well-conditioned estimator for large-dimensional covariance matrices. Journal of multivariate analysis 88:365-411.

Ledoit, O., and M. Wolf. 2012. Nonlinear shrinkage estimation of large-dimensional covariance matrices. The Annals of Statistics 40:1024-1060.

Ledoit, O., and M. Wolf. 2017. Nonlinear shrinkage of the covariance matrix for portfolio selection: Markowitz meets Goldilocks. Review of Financial Studies 30:4349-4388. 
Levene, H. 1961. Robust tests for equality of variances. Contributions to probability and statistics. Essays in honor of Harold Hotelling pp. 279-292.

Lewellen, J. 1999. The time-series relations among expected return, risk, and book-to-market. Journal of Financial Economics 54.

Lewellen, J., S. Nagel, and J. Shanken. 2010. A skeptical appraisal of asset pricing tests. Journal of Financial Economics 96:175-194.

Liu, Y., A. Tsyvinski, and X. Wu. 2019. Common Risk Factors in Cryptocurrency. URL https://dx.doi.org/10.2139/ssrn.3379131. Yale University Working Paper.

Lustig, H. N., N. L. Roussanov, and A. Verdelhan. 2011. Common Risk Factors in Currency Markets. Review of Financial Studies 24:3731-3777.

Markowitz, H. M. 1952. Portfolio Selection. Journal of Finance 7:77-91.

Merton, R. C. 1973. An Intertemporal Capital Asset Pricing Model. Econometrica 41:867887.

Novy-Marx, R. 2013. The other side of value: The gross profitability premium. Journal of Financial Economics 108:1-28.

Pastor, L., and R. F. Stambaugh. 2003. Liquidity Risk and Expected Stock Returns. Journal of Political Economy 111:642-685.

Roll, R. W. 1977. A Critique of the Asset Pricing Theory's Tests. Journal of Financial Economics 4:129-176.

Ross, S. A. 1976. The Arbitrage Theory of Capital Asset Pricing. Journal of Economic Theory 13:341-360. 


\section{Figures}

Figure 2: Rolling regression $R^{2} \mathbf{s}-\mathrm{HML}$ returns on industry returns This figure shows the $R^{2}$ from 126-day rolling regressions of daily HML returns on the twelve daily Fama and French (1997) industry excess returns. The time period is 1963/07 - 2019/06.

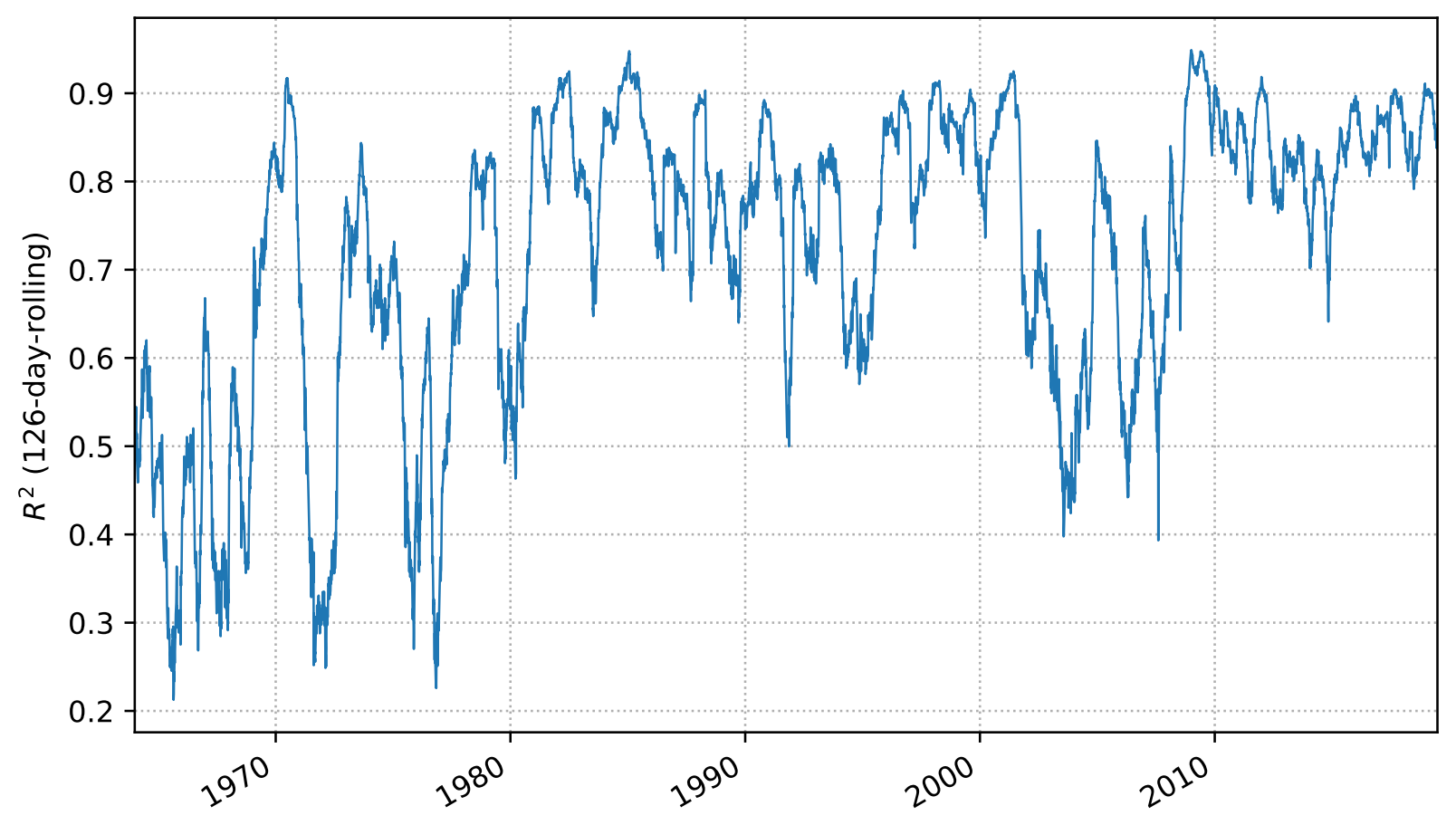


Figure 3: HML loadings on industry-portfolios. The upper panel of this figure plots the loadings from rolling 126-day regressions of the daily returns to the HML characteristic portfolio on the twelve daily Fama and French (1997) industry excess returns over the 1963/07 - 2019/06 time period. The lower panel plots only the loading on the Money industry portfolio (including the $95 \%$ confidence interval) and hides the other 11 industrv-portfolio loadings.
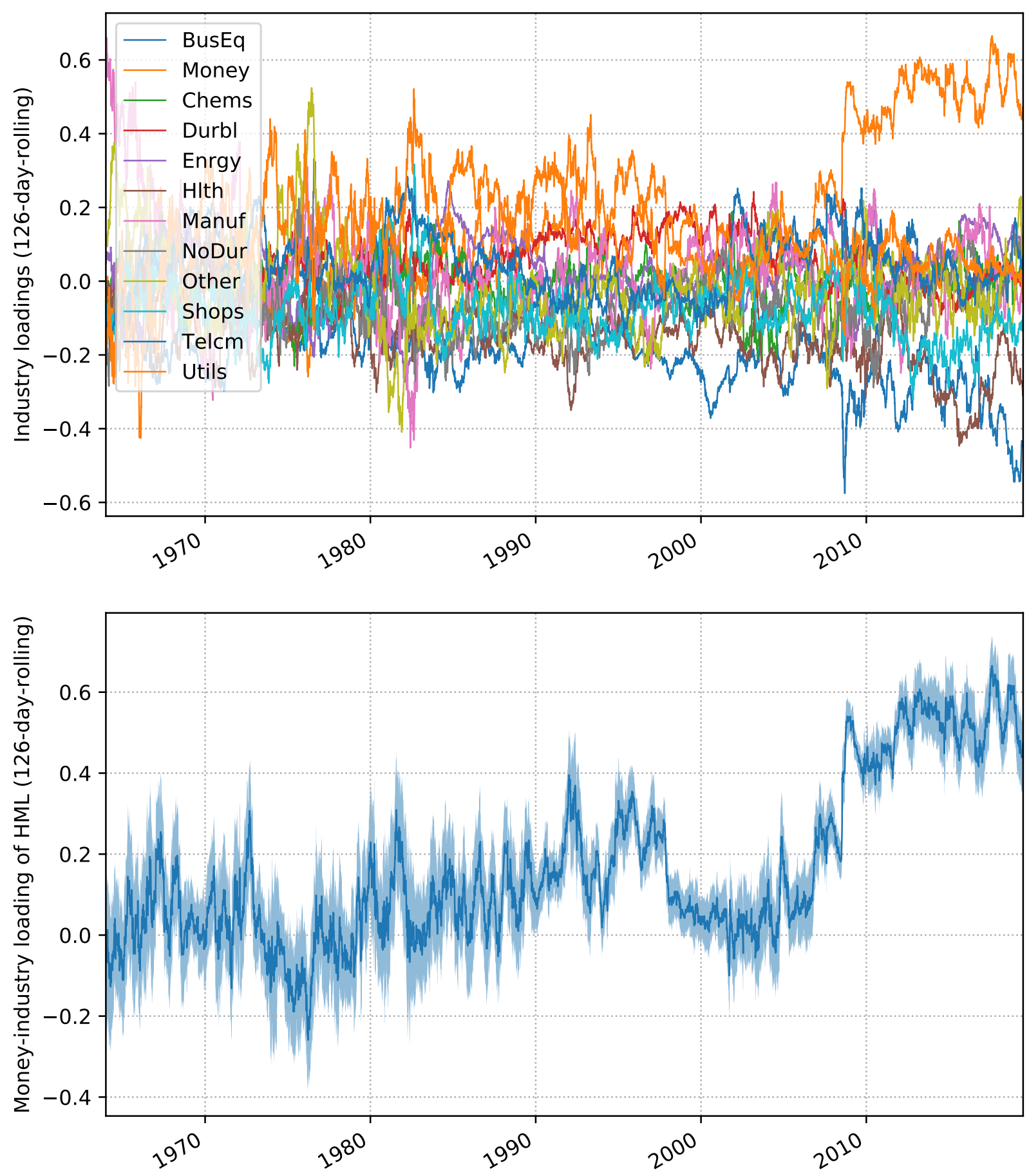
Figure 4: Volatility of the money industry-portfolios. This figure shows 126-day volatility of the daily returns to the Money portfolio over the 1963/07 - 2019/06 time period.

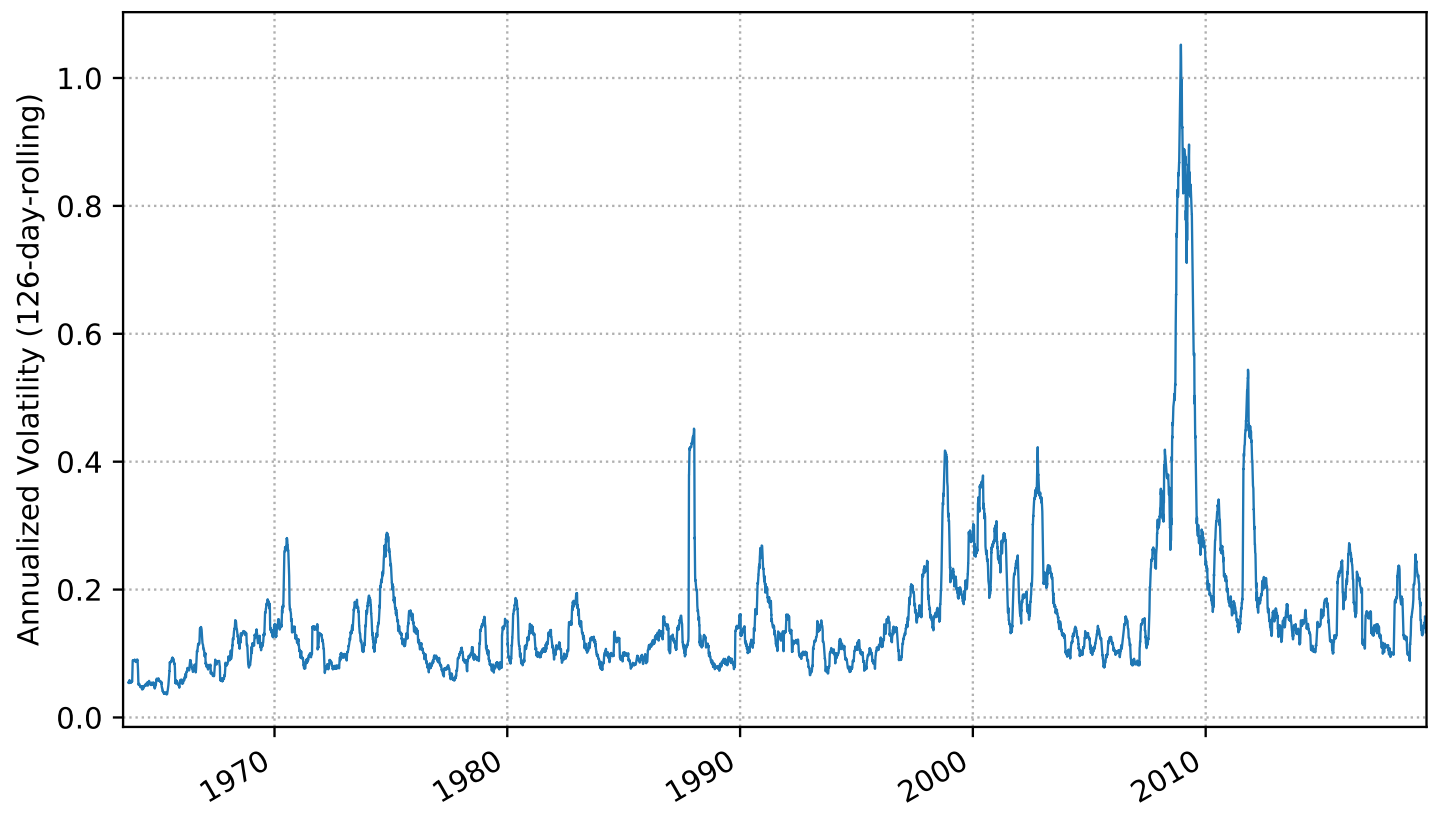

Figure 5: Rolling regression $R^{2} \mathrm{~s}-\mathrm{HML}$ returns on Money industry returns. This figure shows the $R^{2}$ from 126-day rolling regressions of daily HML returns on daily Money industry excess returns from the 12 Fama and French (1997) industry returns. The time period is 2000/01 - 2019/06.

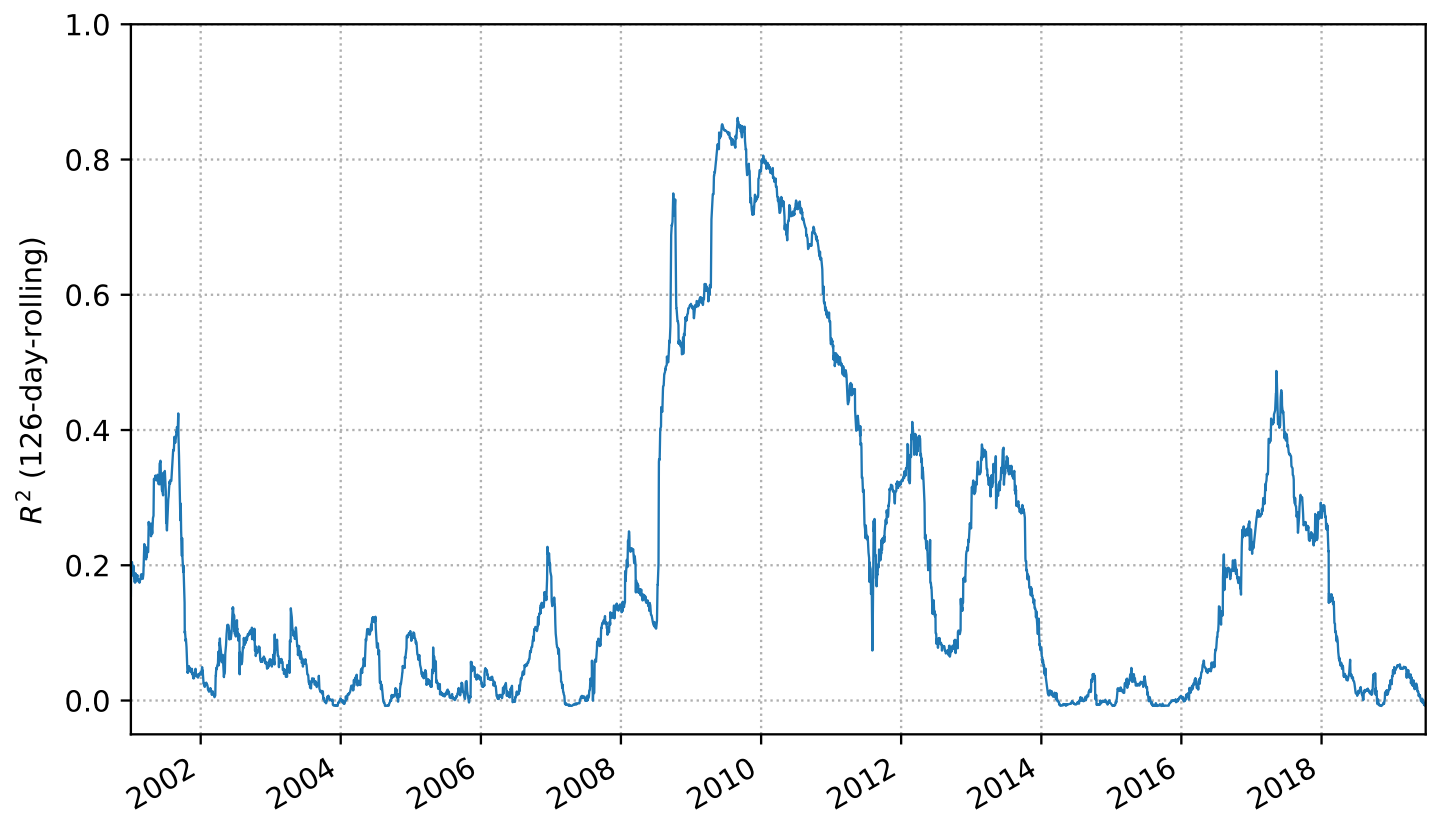


Figure 6: Ex-post HML/RMW/CMA loadings vs. characteristics. This figure shows the time-series average of post-formation characteristic portfolio loading on the $\mathrm{x}$-axis and the time-series average of each characteristic on the y-axis for each of the 27 portfolios formed on size, characteristic (bookto-market/operating profitability/investment) and HML/RMW/CMA-loading. The first column uses sorts on book-to-market and HML-loading, the second one operating profitability and RMW-loading and the last one investment and CMA-loading.

Panel A: HML
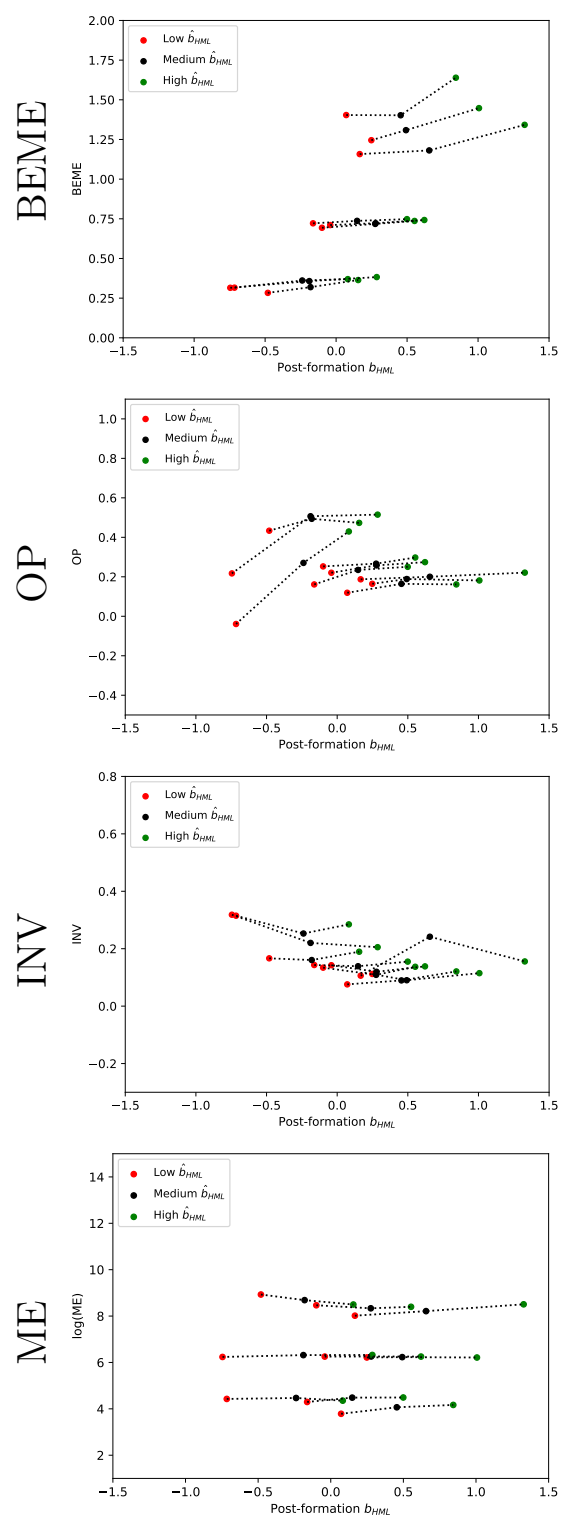

Panel B: RMW
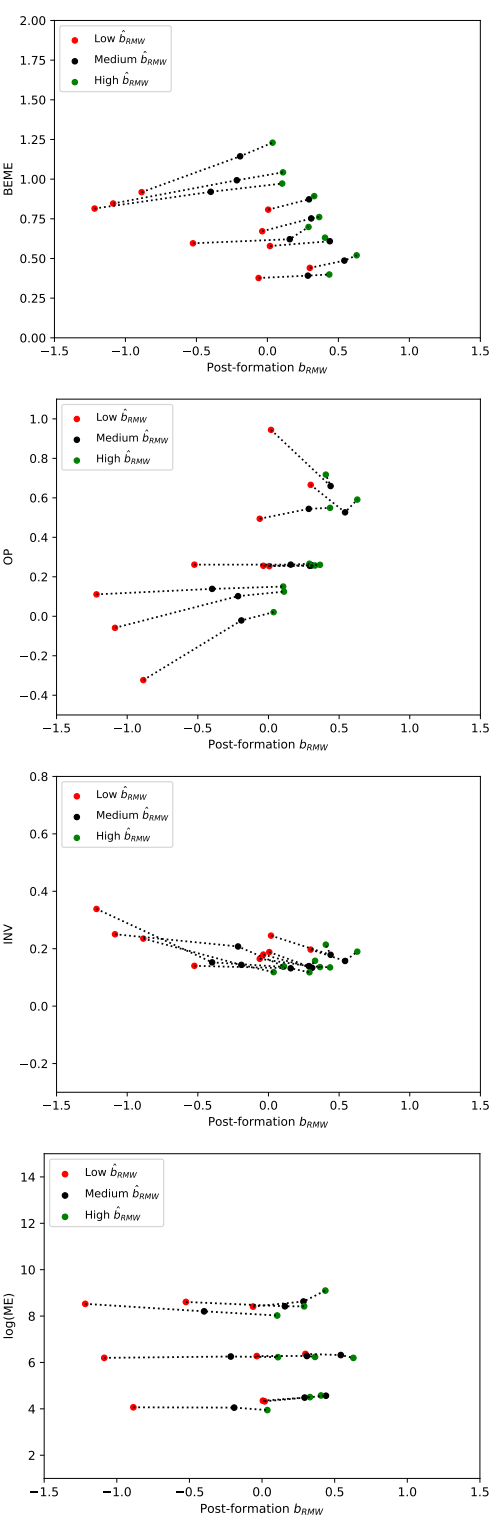

Panel C: CMA
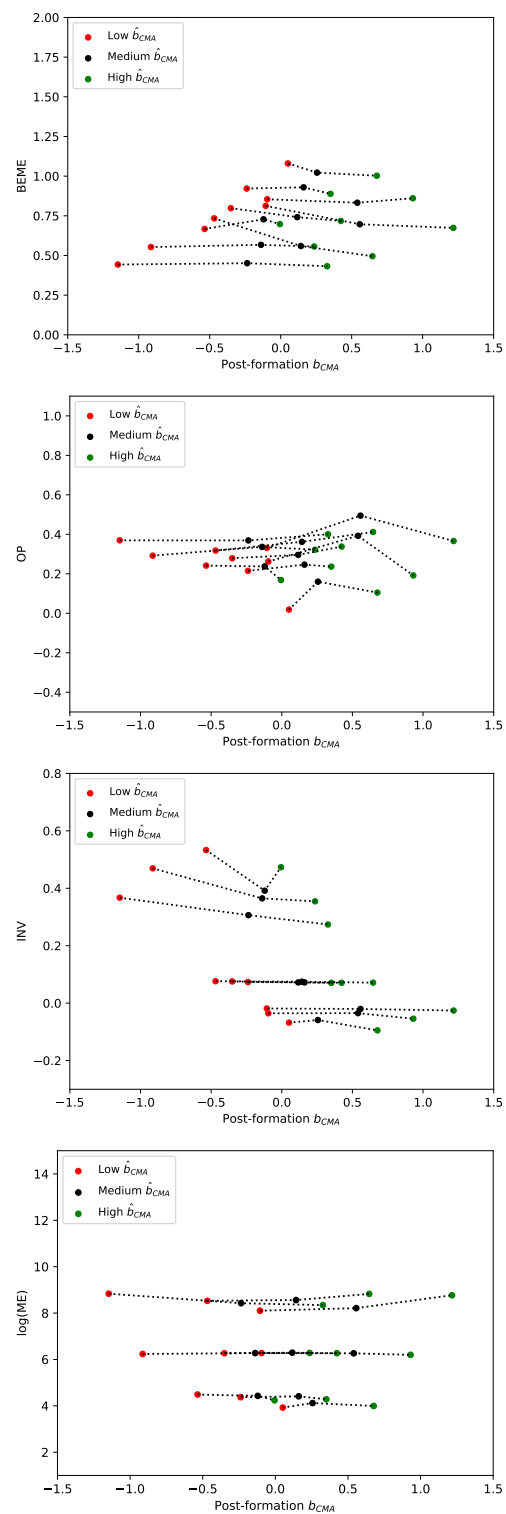
Figure 7: Ex-post MktRF loadings vs. characteristics. This figure shows the timeseries average of post-formation characteristic portfolio loading on the $\mathrm{x}$-axis and the time-series average of each characteristic on the y-axis for each of the 27 portfolios formed on size, characteristic (book-tomarket/operating profitability/investment) and MktRF-loading. The first column uses sorts on book-tomarket and MktRF-loading, the second one operating profitability and MktRF-loading and the last one investment and MktRF-loading.

Panel A: MktRF $(\mathrm{ME} \times \mathrm{BEME}) \quad$ Panel B: MktRF $(\mathrm{ME} \times \mathrm{OP})$
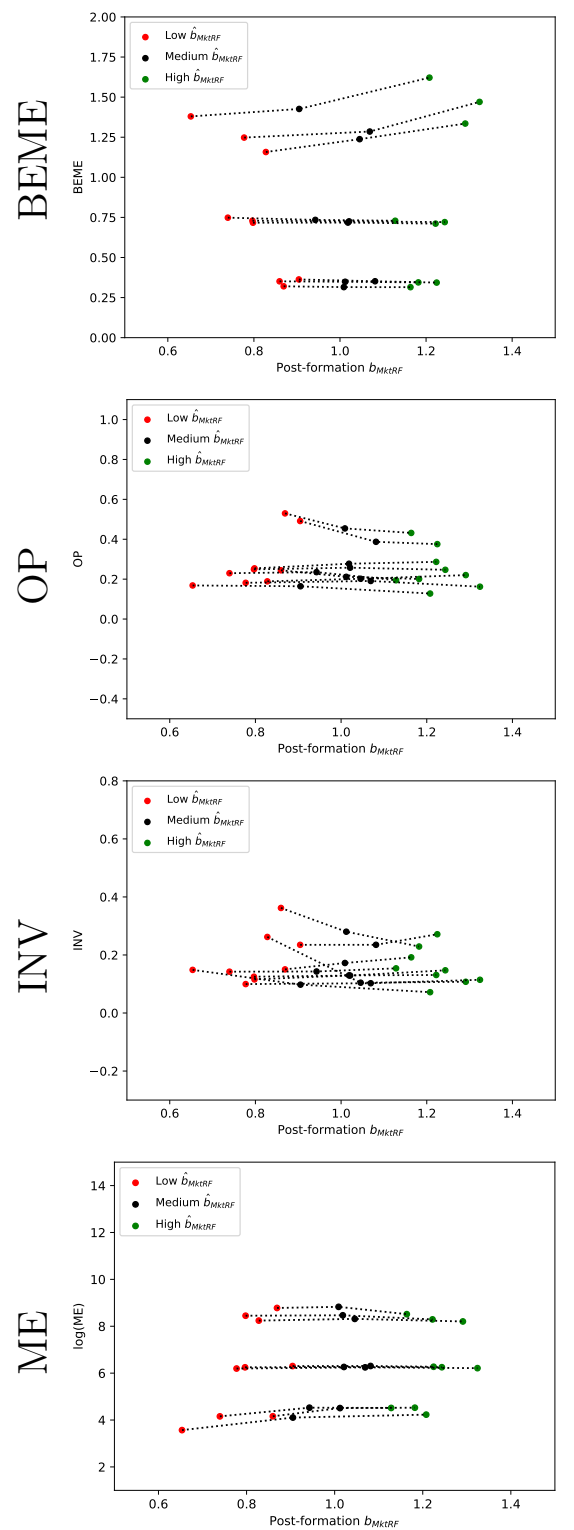
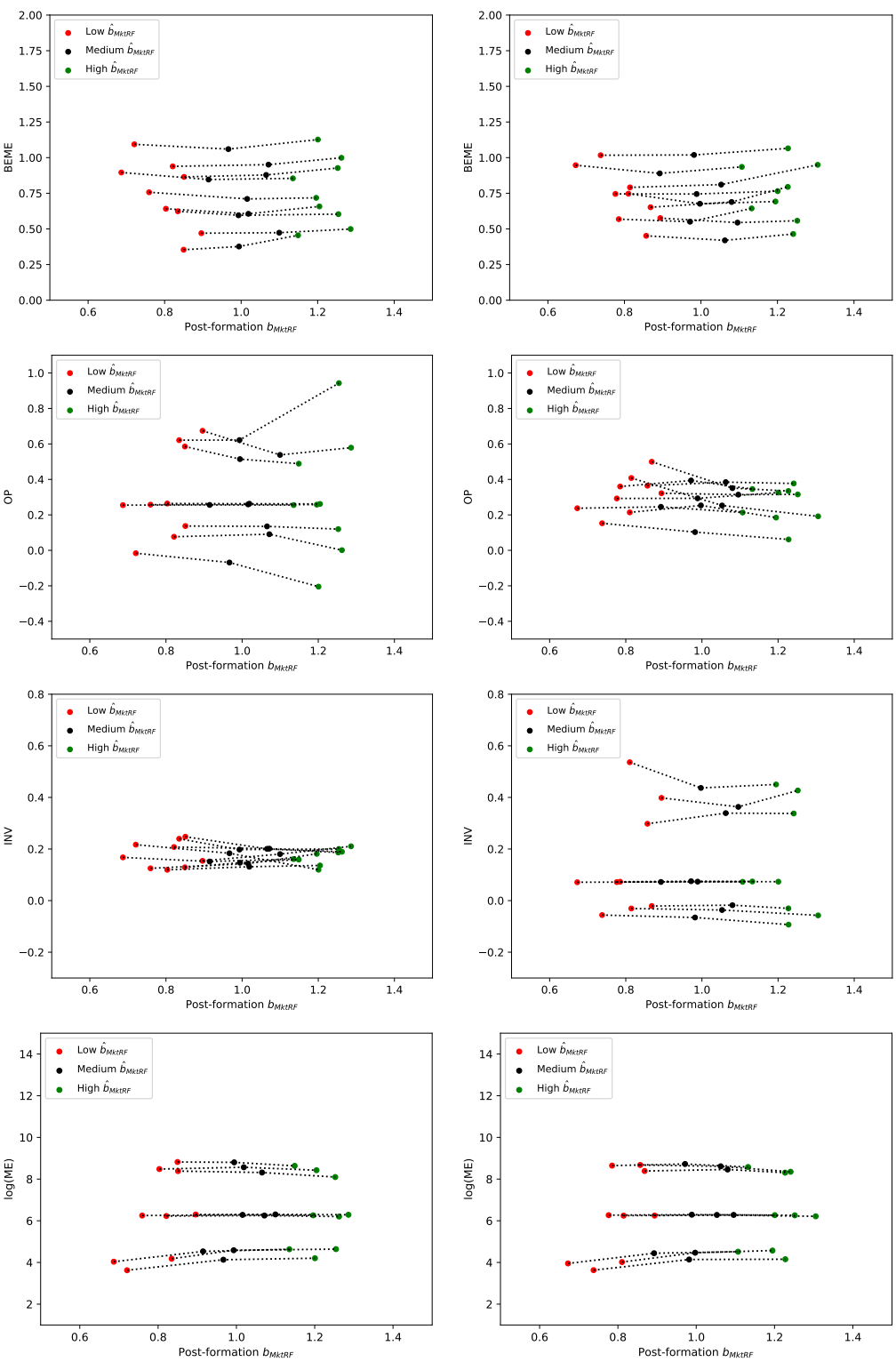
Figure 8: Ex-post SMB loadings vs. characteristics. This figure shows the time-series average of post-formation characteristic portfolio loading on the $\mathrm{x}$-axis and the time-series average of each characteristic on the y-axis for each of the 27 portfolios formed on size, characteristic (book-to-market/operating profitability/investment) and SMB-loading. The first column uses sorts on book-to-market and SMB-loading, the second one operating profitability and SMB-loading and the last one investment and SMB-loading.
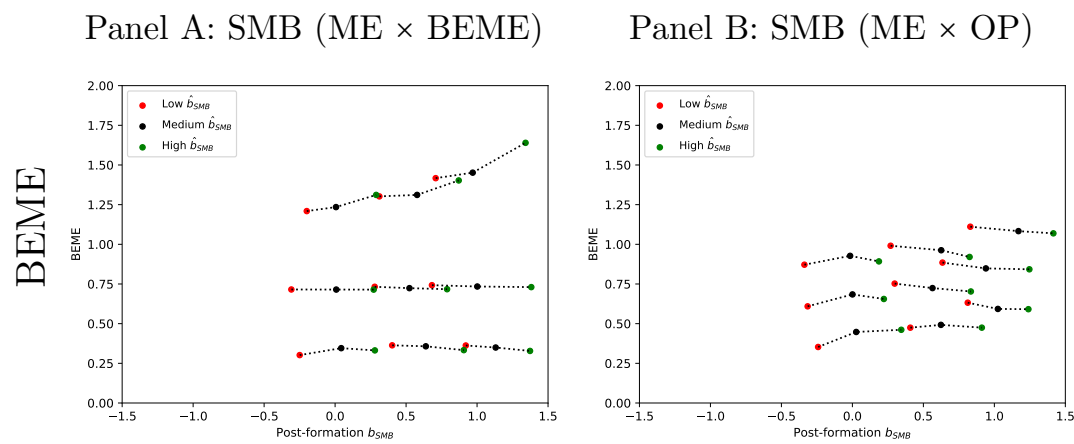

Panel C: SMB $(\mathrm{ME} \times \mathrm{INV})$
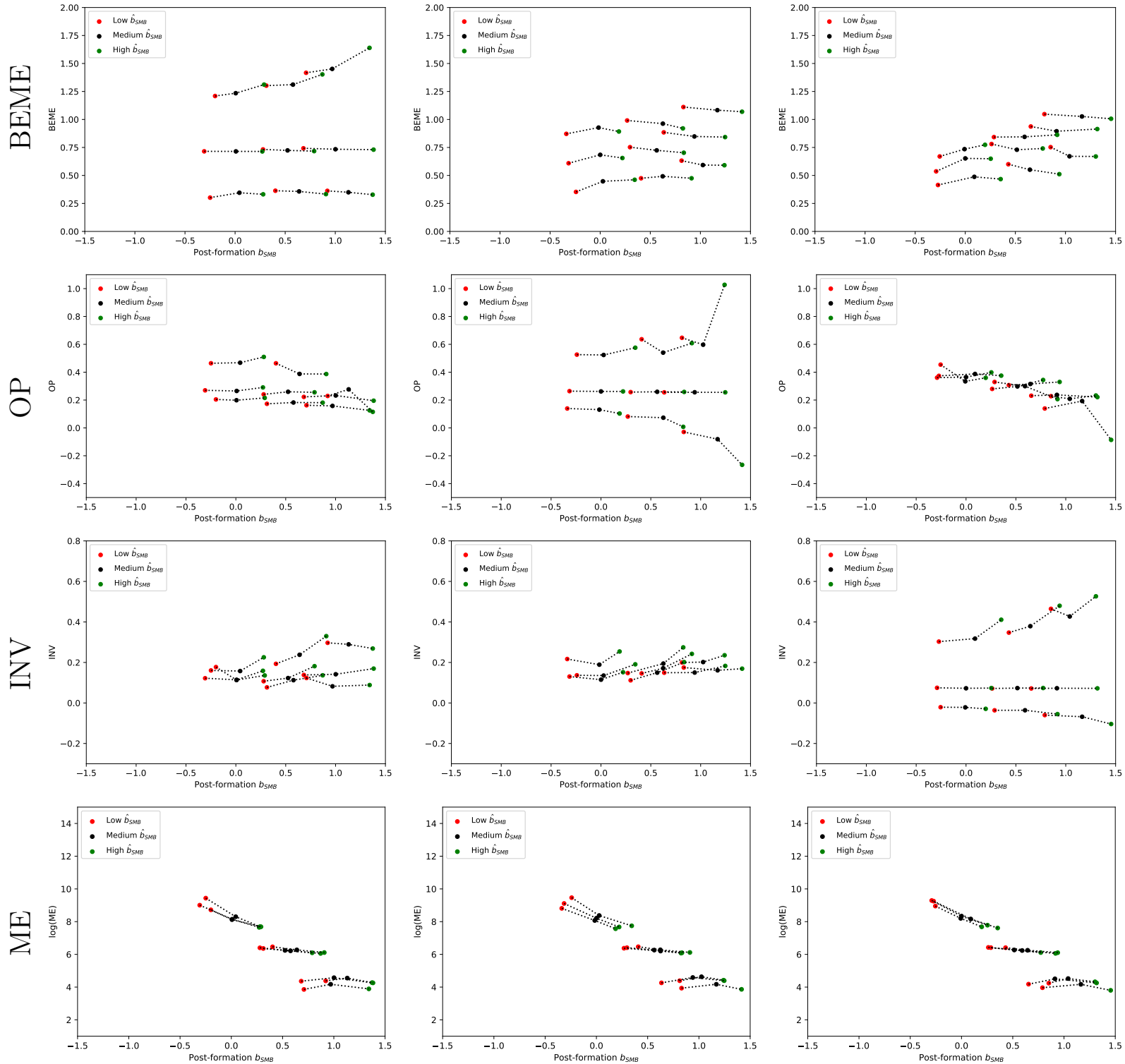


\section{Tables}

Table 1: Low book-to-market stocks in the Money industry as of June 2008. The first column reports the largest fifteen stocks in the Money industry in the low book-to-market bin, sorted by market capitalization. The second column reports the book-to-market and the third reports the HML loading-portfolio to which the stock belongs as of June 30th, 2008.

\begin{tabular}{l|rr}
\hline Firm & BE/ME & $\beta_{H M L}$-portfolio \\
\hline American Express & 0.19 & 3 \\
United Health & 0.27 & 3 \\
Aflac & 0.29 & 3 \\
Charles Schwab & 0.13 & 3 \\
Franklin Resources & 0.27 & 3 \\
Cme Group & 0.34 & 3 \\
Aetna & 0.36 & 2 \\
Express Scripts Holding & 0.04 & 1 \\
Northern Trust & 0.27 & 3 \\
Price T. Rowe & 0.17 & 3 \\
TD Ameritrade & 0.18 & 2 \\
Cigna & 0.34 & 1 \\
Navient & 0.36 & 3 \\
Humana & 0.32 & 2 \\
Nasdaq & 0.32 & 2 \\
\hline
\end{tabular}


Table 2: Average monthly excess returns for the sorted portfolios.

Stocks are sorted into 3 portfolios based on the respective characteristic - book-to-market (BEME), operating profitability (OP) or investment (INV) - and independently into 3 size (ME) groups. These are depicted row-wise and indicated in the first two columns. Last, within each bucket, stocks are sorted into 3 further portfolios based on the loading forecast. These portfolios are displayed column-wise and in Panels A-C for HML, RMW, CMA, and Panels D-F for MktRF, and Panels G-I for SMB. The last column shows average returns of all 9 respective characteristic-portfolios. The last row shows averages of all 9 respective loading-portfolios. The sample period is 1963/07 - 2019/06.

Panel A: HML

\begin{tabular}{|c|c|c|c|c|c|}
\hline \multicolumn{2}{|c|}{ Char-Portfolio } & \multicolumn{3}{|c|}{$\hat{b}_{H M L}$-Portfolio } & \multirow{2}{*}{$\frac{\text { Avg. }}{0.58}$} \\
\hline & $\mathrm{ME}$ & & 2 & 3 & \\
\hline \multirow[t]{2}{*}{1} & 1 & 0.49 & 0.65 & 0.68 & \\
\hline & $\begin{array}{l}2 \\
3\end{array}$ & $\begin{array}{l}0.51 \\
0.47\end{array}$ & $\begin{array}{l}0.61 \\
0.55\end{array}$ & $\begin{array}{l}0.75 \\
0.54\end{array}$ & \\
\hline \multirow[t]{2}{*}{2} & 1 & 0.85 & 0.9 & 0.91 & 0.74 \\
\hline & $\begin{array}{l}2 \\
3\end{array}$ & $\begin{array}{l}0.71 \\
0.56\end{array}$ & $\begin{array}{l}0.77 \\
0.58\end{array}$ & $\begin{array}{l}0.85 \\
0.57\end{array}$ & \\
\hline \multirow[t]{2}{*}{3} & 1 & 1 & 0.98 & 1.02 & 0.87 \\
\hline & $\begin{array}{l}2 \\
3\end{array}$ & $\begin{array}{r}0.9 \\
0.75\end{array}$ & $\begin{array}{l}0.88 \\
0.66\end{array}$ & & \\
\hline Avg. & & 0.69 & 0.73 & 0.77 & \\
\hline
\end{tabular}

Panel B: RMW

\begin{tabular}{|c|c|c|c|c|c|}
\hline \multicolumn{2}{|c|}{$\mathrm{Cl}$ b $\mathrm{D}=\mathrm{s}$} & \multicolumn{3}{|c|}{$\hat{b}_{R M W}$-Portfolio } & \multirow{3}{*}{$\frac{\mathrm{Avg}}{0.61}$} \\
\hline $\mathrm{OP}$ & ME & 1 & 2 & 3 & \\
\hline \multirow[t]{2}{*}{1} & 1 & 0.64 & 0.81 & 0.78 & \\
\hline & 2 & 0.58 & 0.72 & 0.79 & \\
\hline \multirow[t]{3}{*}{2} & $\begin{array}{l}3 \\
1\end{array}$ & $\begin{array}{l}0.20 \\
0.89\end{array}$ & $\begin{array}{l}0.49 \\
0.93\end{array}$ & $\begin{array}{l}0.49 \\
0.82\end{array}$ & 0.7 \\
\hline & 2 & 0.72 & 0.79 & 0.76 & \\
\hline & 3 & & 0.4 & & \\
\hline \multirow[t]{3}{*}{3} & 1 & & 1.02 & 0.95 & \\
\hline & 2 & 0.76 & 0.84 & 0.93 & \\
\hline & 3 & 0.59 & 0.59 & 0.57 & \\
\hline
\end{tabular}

Panel E: MktRF $(\mathrm{ME} \times \mathrm{OP})$

\begin{tabular}{|c|c|c|c|c|c|}
\hline \multicolumn{2}{|c|}{ Char-Portfolio } & \multicolumn{3}{|c|}{$\hat{b}_{M k t R F}$-Portfolio } & \multirow{3}{*}{$\begin{array}{r}\text { Avg. } \\
0.6\end{array}$} \\
\hline $\mathrm{OP}$ & $\mathrm{ME}$ & 1 & 2 & 3 & \\
\hline \multirow[t]{3}{*}{1} & 1 & 0.54 & 0.75 & 0.83 & \\
\hline & 2 & 0.56 & 0.74 & 0.74 & \\
\hline & 3 & 36 & 0.42 & 0.46 & \\
\hline \multirow[t]{2}{*}{2} & $\begin{array}{l}1 \\
2\end{array}$ & $\begin{array}{r}0.83 \\
0.7\end{array}$ & 0.94 & 0.86 & \\
\hline & 3 & 0.44 & 0.5 & 0.54 & \\
\hline \multirow[t]{2}{*}{3} & 1 & 1.02 & 0.97 & 0.93 & \\
\hline & 2 & 0.81 & 0.84 & 0.87 & \\
\hline & & 0.05 & $\begin{array}{l}0.01 \\
0.72\end{array}$ & 0.74 & \\
\hline
\end{tabular}

Panel H: SMB $(\mathrm{ME} \times \mathrm{OP})$

\begin{tabular}{|c|c|c|c|c|c|}
\hline \multicolumn{2}{|c|}{ Char-Portfolio } & \multicolumn{3}{|c|}{$\hat{b}_{S M B}$-Portfolio } & \multirow{3}{*}{$\begin{array}{c}\text { Avg. } \\
0.62\end{array}$} \\
\hline $\mathrm{OP}$ & $\mathrm{ME}$ & 1 & 2 & 3 & \\
\hline \multirow[t]{2}{*}{1} & 1 & 0.65 & 0.76 & 0.72 & \\
\hline & 2 & 0.65 & 0.7 & 0.67 & \\
\hline \multirow[t]{3}{*}{2} & 1 & $\begin{aligned} 0.29 \\
0.8\end{aligned}$ & $\begin{array}{l}0.41 \\
0.92\end{array}$ & $\begin{array}{l}0.66 \\
0.89\end{array}$ & \\
\hline & 2 & & 0.78 & 0.8 & \\
\hline & 3 & 0.42 & 0.62 & 0.66 & \\
\hline \multirow[t]{2}{*}{3} & 1 & 0.96 & 1.02 & 0.89 & 0.8 \\
\hline & $\begin{array}{l}2 \\
3\end{array}$ & 0.77 & 0.85 & 0.94 & \\
\hline & & 0.64 & 0.75 & 0.78 & \\
\hline
\end{tabular}

Panel C: CMA

\begin{tabular}{|c|c|c|c|c|c|}
\hline \multicolumn{2}{|c|}{ Char-Portfolio } & \multicolumn{3}{|c|}{$b_{C M A}$-Portfolio } & \multirow{3}{*}{ Avg. } \\
\hline INV & $\mathrm{ME}$ & 1 & 2 & 3 & \\
\hline \multirow[t]{3}{*}{1} & 1 & 0.98 & 0.97 & 0.9 & \\
\hline & 2 & & 0.86 & 0.72 & \\
\hline & 3 & & 0.63 & 0.59 & \\
\hline \multirow[t]{3}{*}{2} & 1 & & 0.92 & 0.97 & 0.78 \\
\hline & 2 & 0.97 & 0.86 & 0.74 & \\
\hline & 3 & 0.55 & 0.5 & 0.59 & \\
\hline & 1 & 0.59 & 0.76 & 0.58 & 0.62 \\
\hline & 2 & 0.61 & 0.73 & 0.71 & \\
\hline & 3 & 0.51 & 0.54 & 0.54 & \\
\hline vg. & & 0.74 & 0.75 & 0.7 & \\
\hline
\end{tabular}

Panel F: MktRF $($ ME $\times$ INV)

\begin{tabular}{|c|c|c|c|c|c|}
\hline \multicolumn{2}{|c|}{ Char-Portfolio } & \multicolumn{3}{|c|}{$\hat{b}_{M k t R F}$-Portfolio } & \multirow{3}{*}{$\begin{array}{c}\mathrm{Avg} \\
0.79\end{array}$} \\
\hline INV & ME & 1 & 2 & 3 & \\
\hline \multirow[t]{3}{*}{1} & 1 & 0.74 & 0.99 & 1.03 & \\
\hline & 2 & 0.72 & 0.7 & 0.92 & \\
\hline & 3 & 0.62 & 0.67 & 0.68 & \\
\hline \multirow[t]{3}{*}{2} & 1 & 0.84 & 0.94 & 1.02 & 0.78 \\
\hline & 2 & 0.79 & 0.83 & 0.95 & \\
\hline & 3 & 0.47 & 0.51 & 0.64 & \\
\hline \multirow[t]{3}{*}{3} & 1 & 0.69 & 0.7 & 0.56 & 0.62 \\
\hline & 2 & 0.6 & 0.77 & 0.66 & \\
\hline & 3 & 0.56 & 0.5 & 0.53 & \\
\hline$\overline{A v g}$ & & 0.67 & 0.74 & 0.78 & \\
\hline
\end{tabular}

Panel I: SMB $(\mathrm{ME} \times \mathrm{INV})$

\begin{tabular}{|c|c|c|c|c|c|}
\hline \multicolumn{2}{|c|}{ Char-Portfolio } & \multirow{2}{*}{\multicolumn{3}{|c|}{$\hat{b}_{S M B}$-Portfolio }} & \multirow{3}{*}{$\begin{array}{r}\text { Avg } \\
0.82\end{array}$} \\
\hline INV & $\mathrm{ME}$ & & & 3 & \\
\hline \multirow[t]{3}{*}{1} & 1 & 0.89 & 0.93 & 1 & \\
\hline & 2 & 0.69 & 0.81 & 0.96 & \\
\hline & 3 & 0.54 & 0.74 & 0.79 & \\
\hline \multirow[t]{3}{*}{2} & 1 & 0.89 & 0.97 & 0.99 & 0.81 \\
\hline & 2 & 0.78 & 0.83 & 1.01 & \\
\hline & 3 & 0.47 & 0.6 & 0.76 & \\
\hline \multirow[t]{3}{*}{3} & 1 & 0.6 & 0.7 & 0.58 & 0.63 \\
\hline & 2 & 0.62 & 0.7 & 0.74 & \\
\hline & 3 & 0.46 & 0.63 & 0.67 & \\
\hline Avg. & & 0.66 & 0.77 & 0.83 & \\
\hline
\end{tabular}


Table 3: Alphas and loadings.

The table shows alphas and loadings from time-series regressions of monthly excess returns of the loadingsorted portfolios on the five Fama and French characteristic portfolios from 1963/07 - 2019/06. The column labeled ' $1-3$ ' shows the alphas/loadings of long low-loading short high-loading hedge-portfolios. The last row shows averages of all 9 loading-portfolios.

Panel A: HML

\begin{tabular}{|c|c|c|c|c|c|c|c|c|c|}
\hline \multicolumn{2}{|c|}{ Char-Portfolio } & \multicolumn{8}{|c|}{ pre-formation $\hat{b}_{\mathrm{HML}}$-sorted portfolios } \\
\hline \multirow[t]{2}{*}{ BEME } & ME & 1 & 2 & 3 & $1-3$ & 1 & 2 & 3 & $1-3$ \\
\hline & & \multicolumn{4}{|c|}{$\alpha$} & \multicolumn{4}{|c|}{$t(\alpha)$} \\
\hline \multirow[t]{3}{*}{1} & 1 & 0.01 & -0.03 & -0.16 & 0.17 & 0.14 & -0.41 & -2.33 & 1.43 \\
\hline & 2 & 0.10 & -0.10 & -0.13 & 0.23 & 1.24 & -1.64 & -1.78 & 2.07 \\
\hline & 3 & 0.04 & 0.04 & -0.02 & 0.06 & 0.67 & 0.73 & -0.27 & 0.55 \\
\hline \multirow[t]{3}{*}{2} & 1 & 0.11 & 0.09 & -0.02 & 0.13 & 1.67 & 1.69 & -0.36 & 1.47 \\
\hline & 2 & -0.11 & -0.08 & -0.03 & -0.07 & -1.52 & -1.22 & -0.48 & -0.75 \\
\hline & 3 & -0.06 & -0.14 & -0.13 & 0.07 & -0.70 & -1.88 & -1.62 & 0.60 \\
\hline \multirow[t]{3}{*}{3} & 1 & 0.19 & 0.10 & -0.07 & 0.26 & 2.76 & 2.01 & -1.20 & 2.76 \\
\hline & 2 & -0.01 & -0.02 & 0.01 & -0.02 & -0.07 & -0.33 & 0.15 & -0.14 \\
\hline & 3 & 0.02 & -0.15 & -0.12 & 0.14 & 0.24 & -1.85 & -1.21 & 0.90 \\
\hline \multirow[t]{2}{*}{ Avg. } & & 0.03 & -0.03 & -0.07 & 0.11 & 0.95 & -1.13 & -2.14 & 1.80 \\
\hline & & \multicolumn{4}{|c|}{ post-formation $b_{H M L}$} & \multicolumn{4}{|c|}{$t\left(b_{H M L}\right)$} \\
\hline \multirow[t]{3}{*}{1} & 1 & -0.72 & -0.24 & 0.08 & -0.80 & -15.28 & -7.29 & 2.59 & -14.12 \\
\hline & 2 & -0.75 & -0.19 & 0.29 & -1.03 & -19.29 & -6.63 & 8.45 & -19.76 \\
\hline & 3 & -0.48 & -0.18 & 0.16 & -0.64 & -16.60 & -7.20 & 5.12 & -12.66 \\
\hline \multirow[t]{3}{*}{2} & 1 & -0.16 & 0.15 & 0.50 & -0.66 & -5.22 & 5.90 & 19.16 & -15.79 \\
\hline & 2 & -0.04 & 0.28 & 0.62 & -0.66 & -1.25 & 9.51 & 18.94 & -14.51 \\
\hline & 3 & -0.10 & 0.28 & 0.55 & -0.65 & -2.48 & 8.04 & 14.26 & -11.31 \\
\hline \multirow[t]{3}{*}{3} & 1 & 0.07 & 0.45 & 0.84 & -0.77 & 2.15 & 20.18 & 30.90 & -17.15 \\
\hline & 2 & 0.25 & 0.49 & 1.01 & -0.76 & 6.36 & 16.64 & 23.48 & -11.83 \\
\hline & 3 & 0.17 & 0.66 & 1.33 & -1.16 & 3.91 & 17.26 & 27.88 & -15.41 \\
\hline Avg. & & -0.20 & 0.19 & 0.60 & -0.79 & -11.38 & 14.24 & 36.53 & -27.80 \\
\hline
\end{tabular}

Panel B: RMW

\begin{tabular}{|c|c|c|c|c|c|c|c|c|c|}
\hline \multicolumn{2}{|c|}{ Char-Portfolio } & \multicolumn{8}{|c|}{ pre-formation $\hat{b}_{\mathrm{RMW}}$-sorted portfolios } \\
\hline \multirow[t]{2}{*}{$\mathrm{OP}$} & ME & 1 & 2 & 3 & $1-3$ & 1 & 2 & 3 & $1-3$ \\
\hline & & \multicolumn{4}{|c|}{$\alpha$} & \multicolumn{4}{|c|}{$t(\alpha)$} \\
\hline \multirow[t]{3}{*}{1} & 1 & 0.04 & 0.05 & -0.14 & 0.19 & 0.55 & 0.96 & -2.43 & 1.84 \\
\hline & 2 & 0.23 & 0.06 & -0.13 & 0.36 & 2.25 & 0.84 & -1.95 & 2.94 \\
\hline & 3 & 0.12 & 0.00 & -0.22 & 0.33 & 1.31 & 0.06 & -2.81 & 2.51 \\
\hline \multirow[t]{3}{*}{2} & 1 & 0.10 & 0.04 & -0.15 & 0.25 & 1.49 & 0.75 & -2.66 & 2.84 \\
\hline & 2 & 0.02 & -0.03 & -0.13 & 0.15 & 0.31 & -0.43 & -2.08 & 1.70 \\
\hline & 3 & 0.17 & -0.14 & -0.21 & 0.38 & 2.23 & -2.22 & -3.08 & 3.25 \\
\hline \multirow[t]{3}{*}{3} & 1 & 0.06 & 0.05 & -0.08 & 0.14 & 0.72 & 0.81 & -1.09 & 1.25 \\
\hline & 2 & -0.07 & -0.09 & -0.10 & 0.02 & -1.08 & -1.43 & -1.19 & 0.22 \\
\hline & 3 & 0.16 & 0.02 & -0.02 & 0.17 & 2.42 & 0.38 & -0.24 & 1.62 \\
\hline \multirow[t]{2}{*}{ Avg. } & & 0.09 & -0.00 & -0.13 & 0.22 & 2.56 & -0.12 & -3.97 & 3.91 \\
\hline & & \multicolumn{4}{|c|}{ post-formation $b_{R M W}$} & \multicolumn{4}{|c|}{$t\left(b_{R M W}\right)$} \\
\hline \multirow[t]{3}{*}{1} & 1 & -0.89 & -0.19 & 0.04 & -0.92 & -22.24 & -7.74 & 1.28 & -18.70 \\
\hline & 2 & -1.09 & -0.22 & 0.11 & -1.20 & -22.15 & -6.64 & 3.34 & -20.08 \\
\hline & 3 & -1.22 & -0.40 & 0.10 & -1.32 & -28.15 & -11.47 & 2.77 & -20.45 \\
\hline \multirow[t]{3}{*}{2} & 1 & 0.01 & 0.29 & 0.33 & -0.32 & 0.18 & 10.39 & 11.71 & -7.55 \\
\hline & 2 & -0.04 & 0.31 & 0.36 & -0.40 & -1.14 & 10.63 & 11.58 & -9.04 \\
\hline & 3 & -0.52 & 0.16 & 0.29 & -0.81 & -14.10 & 5.14 & 8.73 & -14.33 \\
\hline \multirow[t]{3}{*}{3} & 1 & 0.02 & 0.44 & 0.41 & -0.39 & 0.47 & 14.72 & 11.55 & -7.28 \\
\hline & 2 & 0.30 & 0.54 & 0.63 & -0.33 & 9.02 & 17.87 & 16.05 & -6.58 \\
\hline & 3 & -0.06 & 0.29 & 0.44 & -0.50 & -1.93 & 10.55 & 14.39 & -9.53 \\
\hline Avg. & & -0.39 & 0.14 & 0.30 & -0.69 & -22.41 & 9.87 & 18.70 & -24.90 \\
\hline
\end{tabular}




\section{Panel C: CMA}

\begin{tabular}{|c|c|c|c|c|c|c|c|c|c|}
\hline \multicolumn{2}{|c|}{ Char-Portfolio } & \multicolumn{8}{|c|}{ pre-formation $\hat{b}_{\mathrm{CMA}}$-sorted portfolios } \\
\hline \multirow[t]{2}{*}{ INV } & $\mathrm{ME}$ & 1 & 2 & 3 & $1-3$ & 1 & 2 & 3 & $1-3$ \\
\hline & & \multicolumn{4}{|c|}{$\alpha$} & \multicolumn{4}{|c|}{$t(\alpha)$} \\
\hline \multirow[t]{3}{*}{1} & 1 & 0.14 & 0.12 & 0.02 & 0.12 & 2.18 & 2.37 & 0.22 & 1.22 \\
\hline & 2 & 0.05 & 0.02 & -0.22 & 0.27 & 0.67 & 0.32 & -2.64 & 2.44 \\
\hline & 3 & 0.18 & -0.12 & -0.23 & 0.41 & 2.33 & -1.77 & -3.15 & 3.44 \\
\hline \multirow[t]{3}{*}{2} & 1 & 0.08 & 0.08 & 0.14 & -0.05 & 1.34 & 1.39 & 2.11 & -0.57 \\
\hline & 2 & 0.26 & 0.07 & -0.14 & 0.40 & 3.54 & 1.24 & -1.93 & 3.90 \\
\hline & 3 & 0.13 & -0.08 & -0.10 & 0.23 & 1.69 & -1.33 & -1.60 & 1.99 \\
\hline \multirow[t]{3}{*}{3} & 1 & -0.22 & -0.04 & -0.19 & -0.03 & -3.08 & -0.80 & -2.99 & -0.35 \\
\hline & 2 & -0.01 & -0.09 & -0.00 & -0.01 & -0.16 & -1.42 & -0.07 & -0.08 \\
\hline & 3 & 0.34 & -0.00 & -0.16 & 0.50 & 3.85 & -0.03 & -2.24 & 3.66 \\
\hline \multirow[t]{2}{*}{ Avg. } & & 0.11 & -0.01 & -0.10 & 0.20 & 2.91 & -0.19 & -2.93 & 3.33 \\
\hline & & \multicolumn{4}{|c|}{ post-formation $b_{C M A}$} & \multicolumn{4}{|c|}{$t\left(b_{C M A}\right)$} \\
\hline \multirow[t]{3}{*}{1} & 1 & 0.05 & 0.26 & 0.68 & -0.63 & 1.06 & 6.90 & 11.43 & -8.32 \\
\hline & 2 & -0.10 & 0.54 & 0.93 & -1.03 & -1.84 & 11.03 & 14.73 & -12.39 \\
\hline & 3 & -0.11 & 0.56 & 1.22 & -1.32 & -1.85 & 11.28 & 22.16 & -14.86 \\
\hline \multirow[t]{3}{*}{2} & 1 & -0.24 & 0.16 & 0.35 & -0.59 & -5.07 & 3.99 & 7.15 & -8.33 \\
\hline & 2 & -0.35 & 0.12 & 0.42 & -0.77 & -6.39 & 2.82 & 8.11 & -10.23 \\
\hline & 3 & -0.47 & 0.14 & 0.65 & -1.11 & -8.37 & 3.21 & 14.13 & -13.21 \\
\hline \multirow[t]{3}{*}{3} & 1 & -0.54 & -0.12 & -0.01 & -0.53 & -10.00 & -3.07 & -0.12 & -7.46 \\
\hline & 2 & -0.91 & -0.14 & 0.24 & -1.15 & -13.68 & -2.98 & 4.66 & -13.44 \\
\hline & 3 & -1.15 & -0.24 & 0.33 & -1.47 & -17.24 & -5.31 & 6.20 & -14.42 \\
\hline Avg. & & -0.42 & 0.14 & 0.53 & -0.96 & -15.70 & 6.92 & 21.37 & -21.01 \\
\hline
\end{tabular}

Panel D: MktRF $(\mathrm{ME} \times \mathrm{BEME})$

\begin{tabular}{|c|c|c|c|c|c|c|c|c|c|}
\hline \multicolumn{2}{|c|}{ Char-Portfolio } & \multicolumn{8}{|c|}{ pre-formation $\hat{b}_{\mathrm{MktRF}}$-sorted portfolios } \\
\hline \multirow[t]{2}{*}{ BEME } & $\mathrm{ME}$ & 1 & 2 & 3 & $1-3$ & 1 & 2 & 3 & $1-3$ \\
\hline & & \multicolumn{4}{|c|}{$\alpha$} & \multicolumn{4}{|c|}{$t(\alpha)$} \\
\hline \multirow[t]{3}{*}{1} & 1 & -0.10 & 0.02 & -0.16 & 0.06 & -1.28 & 0.27 & -1.80 & 0.48 \\
\hline & 2 & 0.01 & -0.05 & -0.11 & 0.12 & 0.17 & -0.84 & -1.27 & 1.05 \\
\hline & 3 & 0.19 & 0.03 & -0.13 & 0.32 & 3.02 & 0.49 & -1.70 & 2.65 \\
\hline \multirow[t]{3}{*}{2} & 1 & 0.01 & 0.06 & 0.03 & -0.02 & 0.24 & 1.06 & 0.48 & -0.17 \\
\hline & 2 & -0.01 & -0.05 & -0.15 & 0.15 & -0.11 & -0.85 & -2.04 & 1.44 \\
\hline & 3 & -0.06 & -0.05 & -0.25 & 0.19 & -0.74 & -0.70 & -2.85 & 1.47 \\
\hline \multirow[t]{3}{*}{3} & 1 & 0.30 & 0.10 & -0.13 & 0.43 & 4.72 & 2.05 & -1.94 & 4.51 \\
\hline & 2 & 0.12 & -0.00 & -0.16 & 0.29 & 1.79 & -0.02 & -1.72 & 2.21 \\
\hline & 3 & -0.07 & -0.05 & -0.13 & 0.05 & -0.77 & -0.64 & -1.16 & 0.31 \\
\hline \multirow[t]{2}{*}{ Avg. } & & 0.04 & -0.00 & -0.13 & 0.18 & 1.12 & -0.02 & -2.91 & 2.31 \\
\hline & & \multicolumn{4}{|c|}{ post-formation $b_{M k t R F}$} & \multicolumn{4}{|c|}{$t\left(b_{M k t R F}\right)$} \\
\hline \multirow[t]{3}{*}{1} & 1 & 0.86 & 1.01 & 1.18 & -0.32 & 43.48 & 54.91 & 53.22 & -10.44 \\
\hline & 2 & 0.90 & 1.08 & 1.22 & -0.32 & 54.31 & 70.29 & 57.10 & -11.18 \\
\hline & 3 & 0.87 & 1.01 & 1.16 & -0.29 & 55.34 & 78.21 & 62.24 & -9.85 \\
\hline \multirow[t]{3}{*}{2} & 1 & 0.74 & 0.94 & 1.13 & -0.39 & 49.30 & 69.98 & 70.29 & -15.94 \\
\hline & 2 & 0.80 & 1.02 & 1.24 & -0.45 & 48.87 & 64.27 & 66.33 & -17.64 \\
\hline & 3 & 0.80 & 1.02 & 1.22 & -0.42 & 39.48 & 56.96 & 56.76 & -13.46 \\
\hline \multirow[t]{3}{*}{3} & 1 & 0.65 & 0.91 & 1.21 & -0.55 & 40.82 & 72.04 & 75.01 & -23.42 \\
\hline & 2 & 0.78 & 1.07 & 1.32 & -0.55 & 45.51 & 65.71 & 56.10 & -17.01 \\
\hline & 3 & 0.83 & 1.05 & 1.29 & -0.46 & 34.30 & 52.00 & 47.88 & -11.24 \\
\hline Avg. & & 0.80 & 1.01 & 1.22 & -0.42 & 81.41 & 152.40 & 108.62 & -22.10 \\
\hline
\end{tabular}


Panel E: MktRF $(\mathrm{ME} \times \mathrm{OP})$

\begin{tabular}{|c|c|c|c|c|c|c|c|c|c|}
\hline \multicolumn{2}{|c|}{ Char-Portfolio } & \multicolumn{8}{|c|}{ pre-formation $\hat{b}_{\mathrm{MktRF}}$-sorted portfolios } \\
\hline \multirow[t]{2}{*}{$\mathrm{OP}$} & $\mathrm{ME}$ & 1 & 2 & 3 & $1-3$ & 1 & 2 & 3 & $1-3$ \\
\hline & & \multicolumn{4}{|c|}{$\alpha$} & \multicolumn{4}{|c|}{$t(\alpha)$} \\
\hline \multirow[t]{3}{*}{1} & 1 & -0.07 & 0.00 & -0.04 & -0.03 & -0.98 & 0.04 & -0.51 & -0.27 \\
\hline & 2 & 0.04 & 0.14 & -0.03 & 0.06 & 0.48 & 1.96 & -0.28 & 0.46 \\
\hline & 3 & 0.00 & 0.06 & -0.09 & 0.09 & 0.00 & 0.80 & -0.93 & 0.60 \\
\hline \multirow[t]{3}{*}{2} & 1 & 0.15 & 0.05 & -0.17 & 0.32 & 2.29 & 0.83 & -2.78 & 3.45 \\
\hline & 2 & 0.05 & -0.04 & -0.14 & 0.19 & 0.72 & -0.71 & -1.85 & 1.80 \\
\hline & 3 & 0.00 & 0.01 & -0.18 & 0.19 & 0.06 & 0.12 & -2.23 & 1.47 \\
\hline \multirow[t]{3}{*}{3} & 1 & 0.19 & 0.03 & -0.17 & 0.36 & 2.58 & 0.58 & -2.09 & 3.11 \\
\hline & 2 & 0.04 & -0.09 & -0.21 & 0.25 & 0.66 & -1.40 & -2.48 & 2.30 \\
\hline & 3 & 0.23 & -0.03 & -0.02 & 0.25 & 3.51 & -0.53 & -0.30 & 2.04 \\
\hline \multirow[t]{2}{*}{ Avg. } & & 0.07 & 0.02 & -0.12 & 0.19 & 1.80 & 0.63 & -2.66 & 2.48 \\
\hline & & \multicolumn{4}{|c|}{ post-formation $b_{M k t R F}$} & \multicolumn{4}{|c|}{$t\left(b_{M k t R F}\right)$} \\
\hline \multirow[t]{3}{*}{1} & 1 & 0.72 & 0.97 & 1.20 & -0.48 & 42.01 & 75.71 & 63.27 & -18.26 \\
\hline & 2 & 0.82 & 1.07 & 1.26 & -0.44 & 44.05 & 58.81 & 51.98 & -13.07 \\
\hline & 3 & 0.85 & 1.07 & 1.25 & -0.40 & 40.72 & 53.72 & 54.05 & -11.13 \\
\hline \multirow[t]{3}{*}{2} & 1 & 0.69 & 0.91 & 1.14 & -0.45 & 41.36 & 62.45 & 74.06 & -19.17 \\
\hline & 2 & 0.76 & 1.02 & 1.20 & -0.44 & 47.76 & 68.76 & 63.76 & -17.00 \\
\hline & 3 & 0.80 & 1.02 & 1.20 & -0.40 & 42.96 & 66.70 & 58.94 & -12.55 \\
\hline \multirow[t]{3}{*}{3} & 1 & 0.83 & 0.99 & 1.25 & -0.42 & 44.33 & 66.13 & 61.85 & -14.37 \\
\hline & 2 & 0.90 & 1.10 & 1.29 & -0.39 & 58.27 & 67.40 & 61.56 & -14.52 \\
\hline & 3 & 0.85 & 0.99 & 1.15 & -0.30 & 52.44 & 76.67 & 59.05 & -9.74 \\
\hline Avg. & & 0.80 & 1.02 & 1.22 & -0.41 & 81.88 & 165.52 & 111.23 & -21.99 \\
\hline
\end{tabular}

Panel F: MktRF $(\mathrm{ME} \times \mathrm{INV})$

\begin{tabular}{|c|c|c|c|c|c|c|c|c|c|}
\hline \multicolumn{2}{|c|}{ Char-Portfolio } & \multicolumn{8}{|c|}{ pre-formation $\hat{b}_{\mathrm{MktRF}}$-sorted portfolios } \\
\hline \multirow[t]{2}{*}{ INV } & $\mathrm{ME}$ & 1 & 2 & 3 & $1-3$ & 1 & 2 & 3 & $1-3$ \\
\hline & & \multicolumn{4}{|c|}{$\alpha$} & \multicolumn{4}{|c|}{$t(\alpha)$} \\
\hline \multirow[t]{3}{*}{1} & 1 & 0.08 & 0.13 & 0.02 & 0.05 & 1.15 & 2.57 & 0.30 & 0.48 \\
\hline & 2 & 0.03 & -0.05 & -0.13 & 0.15 & 0.39 & -0.86 & -1.40 & 1.23 \\
\hline & 3 & -0.00 & -0.08 & -0.17 & 0.16 & -0.03 & -1.17 & -1.96 & 1.30 \\
\hline \multirow[t]{3}{*}{2} & 1 & 0.16 & 0.09 & 0.06 & 0.11 & 2.38 & 1.43 & 0.82 & 1.03 \\
\hline & 2 & 0.13 & 0.04 & 0.00 & 0.13 & 2.16 & 0.57 & 0.04 & 1.37 \\
\hline & 3 & -0.01 & -0.07 & -0.06 & 0.05 & -0.11 & -1.23 & -0.85 & 0.46 \\
\hline \multirow[t]{3}{*}{3} & 1 & 0.01 & -0.11 & -0.31 & 0.32 & 0.17 & -1.83 & -4.73 & 2.98 \\
\hline & 2 & -0.03 & 0.03 & -0.14 & 0.11 & -0.44 & 0.40 & -1.55 & 0.91 \\
\hline & 3 & 0.31 & 0.04 & -0.07 & 0.39 & 4.61 & 0.59 & -0.87 & 2.96 \\
\hline \multirow[t]{2}{*}{ Avg. } & & 0.08 & 0.00 & -0.09 & 0.16 & 2.00 & 0.08 & -2.06 & 2.22 \\
\hline & & \multicolumn{4}{|c|}{ post-formation $b_{M k t R F}$} & \multicolumn{4}{|c|}{$t\left(b_{M k t R F}\right)$} \\
\hline \multirow[t]{3}{*}{1} & 1 & 0.74 & 0.98 & 1.23 & -0.49 & 44.14 & 75.09 & 59.68 & -17.68 \\
\hline & 2 & 0.81 & 1.05 & 1.31 & -0.49 & 47.91 & 65.92 & 58.36 & -15.97 \\
\hline & 3 & 0.87 & 1.08 & 1.23 & -0.36 & 48.30 & 63.73 & 57.69 & -11.38 \\
\hline \multirow[t]{3}{*}{2} & 1 & 0.67 & 0.89 & 1.11 & -0.43 & 39.07 & 57.69 & 64.22 & -16.64 \\
\hline & 2 & 0.78 & 0.99 & 1.20 & -0.42 & 50.57 & 56.19 & 71.09 & -17.84 \\
\hline & 3 & 0.79 & 0.97 & 1.13 & -0.35 & 44.43 & 69.39 & 62.61 & -11.88 \\
\hline \multirow[t]{3}{*}{3} & 1 & 0.81 & 1.00 & 1.19 & -0.38 & 43.50 & 69.38 & 72.92 & -14.19 \\
\hline & 2 & 0.89 & 1.10 & 1.25 & -0.36 & 54.73 & 66.40 & 56.72 & -12.07 \\
\hline & 3 & 0.86 & 1.06 & 1.24 & -0.38 & 50.28 & 70.01 & 59.08 & -11.75 \\
\hline Avg. & & 0.80 & 1.01 & 1.21 & -0.41 & 83.85 & 169.24 & 113.40 & -22.03 \\
\hline
\end{tabular}


Panel G: SMB (ME × BEME)

\begin{tabular}{|c|c|c|c|c|c|c|c|c|c|}
\hline \multicolumn{2}{|c|}{ Char-Portfolio } & \multicolumn{8}{|c|}{ pre-formation $\hat{b}_{\mathrm{SMB}}$-sorted portfolios } \\
\hline \multirow[t]{2}{*}{ BEME } & $\mathrm{ME}$ & 1 & 2 & 3 & $1-3$ & 1 & 2 & 3 & $1-3$ \\
\hline & & \multicolumn{4}{|c|}{$\alpha$} & \multicolumn{4}{|c|}{$t(\alpha)$} \\
\hline \multirow[t]{3}{*}{1} & 1 & -0.15 & -0.07 & -0.04 & -0.11 & -2.08 & -0.99 & -0.36 & -0.92 \\
\hline & 2 & -0.08 & -0.02 & -0.01 & -0.07 & -1.33 & -0.39 & -0.11 & -0.81 \\
\hline & 3 & 0.04 & 0.06 & 0.03 & 0.02 & 1.04 & 1.05 & 0.36 & 0.18 \\
\hline \multirow[t]{3}{*}{2} & 1 & -0.00 & -0.06 & 0.11 & -0.12 & -0.01 & -1.20 & 1.52 & -1.13 \\
\hline & 2 & -0.09 & -0.10 & -0.02 & -0.06 & -1.32 & -1.68 & -0.35 & -0.68 \\
\hline & 3 & -0.11 & -0.08 & -0.12 & 0.01 & -1.56 & -1.11 & -1.61 & 0.10 \\
\hline \multirow[t]{3}{*}{3} & 1 & 0.17 & -0.02 & 0.02 & 0.15 & 2.72 & -0.40 & 0.27 & 1.55 \\
\hline & 2 & 0.04 & -0.04 & -0.02 & 0.06 & 0.59 & -0.57 & -0.22 & 0.53 \\
\hline & 3 & -0.24 & 0.01 & 0.06 & -0.31 & -2.89 & 0.09 & 0.68 & -2.23 \\
\hline \multirow[t]{2}{*}{ Avg. } & & -0.05 & -0.04 & 0.00 & -0.05 & -1.50 & -1.43 & 0.04 & -0.83 \\
\hline & & \multicolumn{4}{|c|}{ post-formation $b_{S M B}$} & \multicolumn{4}{|c|}{$t\left(b_{S M B}\right)$} \\
\hline \multirow[t]{3}{*}{1} & 1 & 0.92 & 1.13 & 1.37 & -0.45 & 36.73 & 43.64 & 39.77 & -10.48 \\
\hline & 2 & 0.40 & 0.64 & 0.91 & -0.50 & 18.50 & 28.46 & 34.28 & -15.71 \\
\hline & 3 & -0.25 & 0.04 & 0.28 & -0.53 & -17.30 & 2.34 & 11.35 & -15.86 \\
\hline \multirow[t]{3}{*}{2} & 1 & 0.68 & 1.00 & 1.38 & -0.70 & 32.61 & 52.84 & 52.09 & -19.40 \\
\hline & 2 & 0.28 & 0.52 & 0.79 & -0.51 & 12.17 & 24.24 & 33.04 & -16.04 \\
\hline & 3 & -0.31 & 0.01 & 0.27 & -0.58 & -12.01 & 0.33 & 10.04 & -15.28 \\
\hline \multirow[t]{3}{*}{3} & 1 & 0.71 & 0.97 & 1.34 & -0.63 & 32.03 & 51.76 & 54.41 & -18.31 \\
\hline & 2 & 0.31 & 0.58 & 0.87 & -0.56 & 12.54 & 24.51 & 31.21 & -14.33 \\
\hline & 3 & -0.20 & 0.01 & 0.29 & -0.49 & -6.78 & 0.24 & 8.86 & -10.17 \\
\hline Avg. & & 0.28 & 0.54 & 0.83 & -0.55 & 25.97 & 58.70 & 63.40 & -27.33 \\
\hline
\end{tabular}

Panel H: SMB $(\mathrm{ME} \times \mathrm{OP})$

\begin{tabular}{|c|c|c|c|c|c|c|c|c|c|}
\hline \multicolumn{2}{|c|}{ Char-Portfolio } & \multicolumn{8}{|c|}{ pre-formation $\hat{b}_{\mathrm{SMB}}$-sorted portfolios } \\
\hline \multirow[t]{2}{*}{$\mathrm{OP}$} & ME & 1 & 2 & 3 & $1-3$ & 1 & 2 & 3 & $1-3$ \\
\hline & & \multicolumn{4}{|c|}{$\alpha$} & \multicolumn{4}{|c|}{$t(\alpha)$} \\
\hline \multirow[t]{3}{*}{1} & 1 & -0.07 & -0.06 & -0.04 & -0.04 & -1.20 & -0.97 & -0.41 & -0.33 \\
\hline & 2 & 0.07 & 0.08 & 0.00 & 0.06 & 0.93 & 1.10 & 0.04 & 0.56 \\
\hline & 3 & -0.13 & 0.01 & 0.25 & -0.38 & -1.95 & 0.22 & 2.63 & -2.90 \\
\hline \multirow[t]{3}{*}{2} & 1 & 0.04 & -0.02 & -0.11 & 0.15 & 0.69 & -0.34 & -1.56 & 1.61 \\
\hline & 2 & -0.06 & -0.05 & -0.03 & -0.03 & -1.02 & -0.83 & -0.42 & -0.36 \\
\hline & 3 & -0.07 & 0.06 & -0.01 & -0.06 & -1.36 & 1.06 & -0.20 & -0.61 \\
\hline \multirow[t]{3}{*}{3} & 1 & 0.07 & 0.04 & -0.14 & 0.22 & 1.10 & 0.62 & -1.67 & 1.98 \\
\hline & 2 & -0.09 & -0.10 & -0.07 & -0.01 & -1.43 & -1.52 & -0.98 & -0.16 \\
\hline & 3 & 0.09 & 0.02 & -0.03 & 0.11 & 2.00 & 0.37 & -0.33 & 1.10 \\
\hline \multirow[t]{2}{*}{ Avg. } & & -0.02 & -0.00 & -0.02 & 0.00 & -0.59 & -0.01 & -0.55 & 0.05 \\
\hline & & \multicolumn{4}{|c|}{ post-formation $b_{S M B}$} & \multicolumn{4}{|c|}{$t\left(b_{S M B}\right)$} \\
\hline \multirow[t]{3}{*}{1} & 1 & 0.83 & 1.17 & 1.42 & -0.59 & 39.03 & 56.41 & 44.94 & -15.24 \\
\hline & 2 & 0.27 & 0.63 & 0.83 & -0.56 & 10.63 & 25.39 & 26.88 & -14.03 \\
\hline & 3 & -0.34 & -0.02 & 0.19 & -0.52 & -14.47 & -0.68 & 5.69 & -11.54 \\
\hline \multirow[t]{3}{*}{2} & 1 & 0.63 & 0.94 & 1.25 & -0.61 & 28.64 & 45.48 & 50.60 & -18.41 \\
\hline & 2 & 0.30 & 0.56 & 0.83 & -0.54 & 13.68 & 28.62 & 33.21 & -16.69 \\
\hline & 3 & -0.32 & 0.00 & 0.22 & -0.54 & -16.44 & 0.03 & 9.12 & -15.39 \\
\hline \multirow[t]{3}{*}{3} & 1 & 0.81 & 1.02 & 1.24 & -0.43 & 34.91 & 45.46 & 40.83 & -11.07 \\
\hline & 2 & 0.41 & 0.62 & 0.91 & -0.50 & 18.91 & 27.86 & 34.70 & -16.01 \\
\hline & 3 & -0.24 & 0.03 & 0.34 & -0.59 & -15.87 & 1.33 & 12.84 & -16.33 \\
\hline Avg. & & 0.26 & 0.55 & 0.80 & -0.54 & 25.27 & 60.09 & 61.23 & -27.80 \\
\hline
\end{tabular}


Panel I: SMB $(\mathrm{ME} \times \mathrm{INV})$

\begin{tabular}{|c|c|c|c|c|c|c|c|c|c|}
\hline \multicolumn{2}{|c|}{ Char-Portfolio } & \multicolumn{8}{|c|}{ pre-formation $\hat{b}_{\mathrm{SMB}}$-sorted portfolios } \\
\hline \multirow[t]{2}{*}{ INV } & $\mathrm{ME}$ & 1 & 2 & 3 & $1-3$ & 1 & 2 & 3 & $1-3$ \\
\hline & & \multicolumn{4}{|c|}{$\alpha$} & \multicolumn{4}{|c|}{$t(\alpha)$} \\
\hline \multirow[t]{3}{*}{1} & 1 & 0.08 & 0.01 & 0.09 & -0.01 & 1.32 & 0.22 & 0.88 & -0.04 \\
\hline & 2 & -0.08 & -0.09 & 0.02 & -0.11 & -1.17 & -1.28 & 0.28 & -0.94 \\
\hline & 3 & -0.13 & -0.05 & -0.04 & -0.10 & -2.05 & -0.80 & -0.45 & -0.83 \\
\hline \multirow[t]{3}{*}{2} & 1 & 0.13 & 0.07 & 0.07 & 0.06 & 1.93 & 1.14 & 0.96 & 0.53 \\
\hline & 2 & 0.07 & -0.01 & 0.12 & -0.05 & 0.97 & -0.12 & 1.87 & -0.58 \\
\hline & 3 & -0.07 & 0.01 & 0.07 & -0.15 & -1.52 & 0.10 & 1.03 & -1.52 \\
\hline \multirow[t]{3}{*}{3} & 1 & -0.14 & -0.16 & -0.21 & 0.07 & -2.15 & -2.65 & -2.95 & 0.72 \\
\hline & 2 & -0.04 & -0.04 & -0.05 & 0.01 & -0.59 & -0.61 & -0.61 & 0.13 \\
\hline & 3 & 0.10 & 0.17 & 0.09 & 0.00 & 1.99 & 2.83 & 1.13 & 0.04 \\
\hline \multirow[t]{2}{*}{ Avg. } & & -0.01 & -0.01 & 0.02 & -0.03 & -0.32 & -0.37 & 0.54 & -0.51 \\
\hline & & \multicolumn{4}{|c|}{ post-formation $b_{S M B}$} & \multicolumn{4}{|c|}{$t\left(b_{S M B}\right)$} \\
\hline \multirow[t]{3}{*}{1} & 1 & 0.79 & 1.16 & 1.46 & -0.67 & 36.05 & 58.97 & 41.57 & -15.91 \\
\hline & 2 & 0.29 & 0.59 & 0.92 & -0.63 & 11.53 & 25.33 & 32.49 & -16.10 \\
\hline & 3 & -0.25 & -0.01 & 0.20 & -0.45 & -11.40 & -0.34 & 7.18 & -11.25 \\
\hline \multirow[t]{3}{*}{2} & 1 & 0.65 & 0.91 & 1.32 & -0.66 & 28.20 & 44.57 & 49.97 & -18.21 \\
\hline & 2 & 0.26 & 0.51 & 0.77 & -0.51 & 10.80 & 25.63 & 33.85 & -15.48 \\
\hline & 3 & -0.29 & 0.00 & 0.25 & -0.54 & -17.21 & 0.01 & 10.27 & -16.17 \\
\hline \multirow[t]{3}{*}{3} & 1 & 0.85 & 1.04 & 1.30 & -0.45 & 37.21 & 49.98 & 51.65 & -12.89 \\
\hline & 2 & 0.43 & 0.64 & 0.94 & -0.51 & 20.13 & 28.55 & 34.80 & -15.84 \\
\hline & 3 & -0.27 & 0.09 & 0.35 & -0.63 & -15.74 & 4.24 & 12.13 & -15.97 \\
\hline Avg. & & 0.27 & 0.55 & 0.83 & -0.56 & 26.07 & 62.87 & 65.73 & -28.02 \\
\hline
\end{tabular}


Table 4: Results of time-series regressions of hedge-portfolios.

Stocks are first sorted based on size and one of book-to-market, profitability or investment into $3 \times 3$ portfolios. Conditional on those sorts, they are subsequently sorted into 3 portfolios based on the respective loading, i.e., on HML, RMW or CMA. For MktRF and SMB we use the average of three hedge portfolios, which are based on a 3x3 sort on size and book-to-market, profitability or investment. The hedge portfolio then goes long the low loading and short the high loading portfolios. On the bottom, we form combination-portfolios that put equal weight on three (HML, RMW, CMA), four (HML, RMW, CMA, MktRF) or five (HML, RMW, CMA, MktRF, SMB) hedge portfolios. Monthly returns of these portfolios are then regressed on the 5 Fama and French (2015) characteristic portfolios in the sample period from 1963/07 - 2019/06.

\begin{tabular}{lrrrrrrrr}
\hline Hedge-Portfolio & Avg. & $\alpha$ & $b_{M k t-R F}$ & $b_{S M B}$ & $b_{H M L}$ & $b_{R M W}$ & $b_{C M A}$ & $R^{2}$ \\
\hline$r_{h, M k t R F}$ & -0.10 & 0.18 & -0.41 & -0.39 & -0.05 & 0.17 & 0.07 & 0.66 \\
& $(-0.80)$ & $(2.37)$ & $(-22.33)$ & $(-15.05)$ & $(-1.37)$ & $(4.72)$ & $(1.25)$ & \\
$r_{h, S M B}$ & -0.17 & -0.02 & -0.17 & -0.55 & 0.01 & 0.15 & 0.16 & 0.72 \\
& $(-1.72)$ & $(-0.45)$ & $(-12.37)$ & $(-28.33)$ & $(0.34)$ & $(5.55)$ & $(4.00)$ & \\
$r_{h, H M L}$ & -0.08 & 0.11 & -0.03 & 0.05 & -0.79 & -0.20 & 0.53 & 0.61 \\
& $(-0.83)$ & $(1.80)$ & $(-1.86)$ & $(2.42)$ & $(-27.80)$ & $(-6.85)$ & $(11.71)$ & \\
$r_{h, R M W}$ & -0.07 & 0.22 & 0.05 & -0.04 & -0.31 & -0.69 & -0.11 & 0.66 \\
& $(-0.73)$ & $(3.91)$ & $(3.26)$ & $(-1.96)$ & $(-11.66)$ & $(-24.90)$ & $(-2.63)$ & \\
$r_{h, C M A}$ & 0.04 & 0.20 & -0.04 & -0.02 & 0.31 & -0.09 & -0.96 & 0.43 \\
& $(0.52)$ & $(3.33)$ & $(-2.48)$ & $(-0.86)$ & $(10.72)$ & $(-2.96)$ & $(-21.01)$ & \\
\hline \multirow{2}{*}{ EW3 } & -0.03 & 0.18 & -0.01 & -0.00 & -0.26 & -0.33 & -0.18 & 0.70 \\
HML,RMW,CMA & $(-0.61)$ & $(5.48)$ & $(-0.82)$ & $(-0.18)$ & $(-17.29)$ & $(-20.59)$ & $(-7.46)$ & \\
EW4 & -0.05 & 0.18 & -0.11 & -0.10 & -0.21 & -0.20 & -0.12 & 0.58 \\
EW3+MktRF & $(-1.15)$ & $(5.93)$ & $(-14.51)$ & $(-9.47)$ & $(-14.91)$ & $(-13.82)$ & $(-5.30)$ & \\
EW5 & -0.07 & 0.15 & -0.10 & -0.15 & -0.19 & -0.17 & -0.09 & 0.56 \\
EW4+SMB & $(-1.54)$ & $(5.06)$ & $(-14.04)$ & $(-14.58)$ & $(-13.50)$ & $(-11.82)$ & $(-3.96)$ & \\
\hline
\end{tabular}


Table 5: Sharpe Ratio improvement.

We report the average return and return volatility (annualized, and in percent) and the corresponding annualized squared Sharpe-ratio for different versions of each of the five characteristic and characteristic efficient portfolios. $r_{c}$ are the returns of the characteristic portfolios. $r_{c}^{*}$ are the returns of the characteristic efficient portfolios calculated as in equation $(32) \cdot r_{c}^{i n d}$ are the returns of the industry-neutral characteristic portfolios, where, for the first four characteristic portfolios, we ex-ante hedge out $12 \mathrm{FF}$ industries exposure. As the industry portfolios explain almost $100 \%$ of the market portfolio, we do not calculate an industryneutral version of the market. The last three columns depict tests of differences between two portfolios, i.e., CPs to CEPs, CPs to industry-neutral CPs, and industry-neutral CPs to CEPs. For the mean, we report the $p$-value from a $t$-test of equal means. For the volatility, we report the $p$-value from Levene's test of equal variances. In the Sharpe ratio row, we report the $p$-value of the $\alpha$ from regressing the second on the first portfolio. If the $\alpha$ is negative, we report a "-" for the $p$-value. The second to last panel reports the statistics for the in-sample Markowitz optimal combination of the five original CPs, the CEPs, and the industry-neutral portfolios. The last panel repeats the exercise, excluding the MktRF portfolio. The sample period is $1963 / 07-2019 / 06$.

\begin{tabular}{|c|c|c|c|c|c|c|}
\hline & $r_{c}$ & $r_{c}^{*}$ & $r_{c-i n d}$ & $\left(r_{c}\right.$ to $\left.r_{c}^{*}\right)$ & $\begin{array}{c}p \text {-values } \\
\left(r_{c} \text { to } r_{c-i n d}\right)\end{array}$ & $\left(r_{c}^{*}\right.$ to $\left.r_{c-i n d}\right)$ \\
\hline \multicolumn{7}{|l|}{ HML } \\
\hline Mean & 3.68 & 2.43 & 2.61 & 0.18 & 0.30 & 0.79 \\
\hline Vol & 9.60 & 5.87 & 5.15 & $<0.01$ & $<0.01$ & $<0.01$ \\
\hline$S R^{2}$ & 0.15 & 0.17 & 0.26 & 0.13 & 0.01 & - \\
\hline \multicolumn{7}{|l|}{ RMW } \\
\hline Mean & 3.22 & 2.65 & 2.29 & 0.46 & 0.24 & 0.50 \\
\hline Vol & 7.79 & 5.06 & 5.80 & $<0.01$ & $<0.01$ & 0.88 \\
\hline$S R^{2}$ & 0.17 & 0.27 & 0.16 & 0.01 & - & 0.01 \\
\hline \multicolumn{7}{|l|}{ CMA } \\
\hline Mean & 2.63 & 2.33 & 2.12 & 0.64 & 0.49 & 0.63 \\
\hline Vol & 6.51 & 4.31 & 3.97 & $<0.01$ & $<0.01$ & 0.02 \\
\hline$S R^{2}$ & 0.16 & 0.29 & 0.28 & 0.01 & 0.01 & 0.07 \\
\hline \multicolumn{7}{|l|}{ SMB } \\
\hline Mean & 2.89 & 2.00 & 2.90 & 0.30 & 0.99 & 0.24 \\
\hline Vol & 10.27 & 6.52 & 8.29 & $<0.01$ & $<0.01$ & $<0.01$ \\
\hline$S R^{2}$ & 0.08 & 0.09 & 0.12 & 0.31 & 0.12 & - \\
\hline \multicolumn{7}{|c|}{ MktRF } \\
\hline Mean & 6.52 & 5.96 & - & 0.74 & - & - \\
\hline Vol & 15.14 & 10.51 & - & $<0.01$ & - & - \\
\hline$S R^{2}$ & 0.19 & 0.32 & - & $<0.01$ & - & - \\
\hline \multicolumn{7}{|c|}{ In-sample optimal combination } \\
\hline Mean & 3.49 & 2.82 & 2.57 & 0.05 & 0.01 & 0.26 \\
\hline Vol & 3.23 & 1.92 & 2.20 & $<0.01$ & $<0.01$ & 0.01 \\
\hline$S R^{2}$ & 1.16 & 2.16 & 1.37 & $<0.01$ & $<0.01$ & $<0.01$ \\
\hline \multicolumn{7}{|c|}{ In-sample optimal combination (without MktRF) } \\
\hline Mean & 2.94 & 2.44 & 2.35 & 0.22 & 0.16 & 0.64 \\
\hline Vol & 3.68 & 2.05 & 2.18 & $<0.01$ & $<0.01$ & 0.08 \\
\hline$S R^{2}$ & 0.64 & 1.43 & 1.15 & $<0.01$ & $<0.01$ & $<0.01$ \\
\hline
\end{tabular}


Table 6: Ex-post optimal Markowitz weights.

We report the weights on each of the five characteristic portfolios from a full-sample ex-post Markowitz optimization. The first column reports results for the original five characteristic portfolios, and the second column for the five characteristic efficient portfolios. The sample period is 1963/07 - 2019/06.

\begin{tabular}{lrr}
\hline & $r_{c}$ & $r_{c}^{*}$ \\
\hline CMA & 0.39 & 0.33 \\
HML & -0.01 & 0.08 \\
MktRF & 0.16 & 0.11 \\
RMW & 0.34 & 0.34 \\
SMB & 0.12 & 0.13 \\
\hline
\end{tabular}

Table 7: Spanning tests for HML.

We regress the returns of the original HML characteristic portfolio, $r_{c, H M L}$, (first 2 columns) as well the returns on the HML characteristic efficient portfolio, $r_{c, H M L}^{*}$, (columns 3 and 4 ) on the returns of the remaining four characteristic and characteristic efficient portfolios. The sample period is 1963/07 - 2019/06.

\begin{tabular}{lrlllllll}
\hline Portfolio & \multicolumn{2}{c}{$H M L$} & \multicolumn{2}{c}{$H M L$} & \multicolumn{2}{c}{$H M L^{*}$} & \multicolumn{2}{c}{$H M L^{*}$} \\
\hline$\alpha$ & -0.01 & $(-0.17)$ & 0.02 & $(0.18)$ & 0.15 & $(2.60)$ & 0.09 & $(1.85)$ \\
$b_{M k t R F}$ & 0.03 & $(1.45)$ & & & -0.01 & $(-0.97)$ & & \\
$b_{S M B}$ & 0.04 & $(1.27)$ & & & 0.03 & $(1.61)$ & & \\
$b_{R M W}$ & 0.25 & $(6.53)$ & & & -0.15 & $(-5.58)$ & & \\
$b_{C M A}$ & 1.04 & $(22.62)$ & & & 0.43 & $(13.52)$ & & \\
$b_{M k t R F^{*}}$ & & & 0.11 & $(3.09)$ & & & 0.02 & $(1.26)$ \\
$b_{S M B^{*}}$ & & & 0.08 & $(1.41)$ & & & 0.04 & $(1.54)$ \\
$b_{R M W^{*}}$ & & & 0.11 & $(1.35)$ & & & -0.26 & $(-6.94)$ \\
$b_{C M A^{*}}$ & & & 1.02 & $(10.92)$ & & & 0.77 & $(17.46)$ \\
\hline$R^{2}$ & 0.47 & & 0.18 & & 0.31 & & 0.50 & \\
\hline
\end{tabular}


Table 8: Correlations.

The table shows the correlations of monthly excess returns among the CPs (Panel A) and CEPs (Panel B). The sample period is 1963/07 - 2019/06.

Panel A: CPs

\begin{tabular}{lrrrrr}
\hline & $M k t R F$ & \multicolumn{1}{c}{$S M B$} & $H M L$ & $R M W$ & $C M A$ \\
\hline$M k t R F$ & 1.00 & 0.26 & -0.24 & -0.24 & -0.35 \\
$S M B$ & 0.26 & 1.00 & -0.05 & -0.35 & -0.04 \\
$H M L$ & -0.24 & -0.05 & 1.00 & 0.09 & 0.66 \\
$R M W$ & -0.24 & -0.35 & 0.09 & 1.00 & -0.13 \\
$C M A$ & -0.35 & -0.04 & 0.66 & -0.13 & 1.00 \\
\hline
\end{tabular}

Panel B: CEPs

\begin{tabular}{lrrrrr}
\hline & $M k t R F^{*}$ & $S M B^{*}$ & $H M L^{*}$ & $R M W^{*}$ & $C M A^{*}$ \\
\hline$M k t R F^{*}$ & 1.00 & -0.27 & -0.17 & 0.16 & -0.29 \\
$S M B^{*}$ & -0.27 & 1.00 & 0.18 & -0.26 & 0.15 \\
$H M L^{*}$ & -0.17 & 0.18 & 1.00 & -0.52 & 0.68 \\
$R M W^{*}$ & 0.16 & -0.26 & -0.52 & 1.00 & -0.50 \\
$C M A^{*}$ & -0.29 & 0.15 & 0.68 & -0.50 & 1.00 \\
\hline
\end{tabular}




\section{Appendix}

\section{A Notation}

1. Asset specifics

$N$ : Number of assets

$M:$ Number of characteristics

$\boldsymbol{r}:$ Vector of excess returns $(N \times 1)$

$\boldsymbol{\mu}$ : Vector of expected excess returns $(N \times 1)$

$\Sigma$ : Variance-covariance matrix $(N \times N)$

$X$ : Matrix of characteristics $(N \times M)$

$\lambda_{c}$ : Vector of characteristic premia $(M \times 1)$

2. Factor model

$f$ : Priced factor

$\lambda:$ Premium on priced factor

$\beta$ : Vector of individual firms' loadings $\left(\beta_{i}\right)$ on $f(N \times 1)$

$g$ : Vector of unpriced factors $((K-1) \times 1)$

$\gamma_{i}$ : Vector of asset $i$ 's loadings on the unpriced factors $\boldsymbol{g}(1 \times(K-1))$

$\epsilon_{i}$ : Idiosyncratic shocks for asset $i$

3. Characteristic portfolios (CPs)

$W_{c}$ : Matrix of CPs' weights $(N \times M)$

$\boldsymbol{w}_{c, m}: m$-th column of matrix $W_{c}(N \times 1)$

$\boldsymbol{r}_{c} \equiv W_{c}^{\top} \boldsymbol{r}:$ Vector of CPs' excess returns $(M \times 1)$

$\boldsymbol{\mu}_{c} \equiv \mathbb{E} \boldsymbol{r}_{c}:$ Vector of CPs' expected excess returns $(M \times 1)$

$\Sigma_{c} \equiv \operatorname{var}\left(W_{c}^{\top} \boldsymbol{r}\right):$ Covariance matrix of CPs' returns $(M \times M)$

$B$ : Matrix of the projection coefficients of $\boldsymbol{r}$ on $\boldsymbol{r}_{c}(N \times M)$

$\boldsymbol{b}_{m}: m$-th column of matrix $B(N \times 1)$

4. Characteristic efficient portfolios (CEPs) 
$W_{c}^{*}$ : Matrix of CEPs' weights $(N \times M)$

$\boldsymbol{w}_{c, m}^{*}: m$-th column of matrix $W_{c}^{*}(N \times 1)$

$\boldsymbol{r}_{c}^{*} \equiv W_{c}^{* \top} \boldsymbol{r}$ : Vector of CEPs' excess returns $(M \times 1)$

$\boldsymbol{\mu}_{c}^{*} \equiv \mathbb{E} \boldsymbol{r}_{c}^{*}$ : Vector of CEPs' expected excess returns $(M \times 1)$

$\Sigma_{c}^{*} \equiv \operatorname{var}\left(W_{c}^{* \top} r\right):$ Covariance matrix of CEPs' returns $(M \times M)$

$B^{*}$ : Matrix of the projection coefficients of $\boldsymbol{r}$ on $\boldsymbol{r}_{c}^{*}(N \times M)$

$\boldsymbol{b}_{m}^{\star}: m$-th column of matrix $B^{*}(N \times 1)$

5. Hedge portfolios

$W_{h}$ : Matrix of hedge portfolios' weights $(N \times M)$

$\boldsymbol{w}_{h, m}: m$-th column of matrix $W_{h}(N \times 1)$

$\Delta:$ Matrix of hedge ratios $(M \times M)$

\section{B Proofs}

\section{B.1 The characteristic efficient portfolios}

For each characteristic $m$, let the characteristic efficient portfolio (CEP) be the solution of the problem:

$$
\begin{array}{r}
\min _{\boldsymbol{w}_{c, m}} \boldsymbol{w}_{c, m}^{\top} \Sigma \boldsymbol{w}_{c, m} \\
\text { s.t. } \quad \boldsymbol{w}_{c, m}^{\top} X=\boldsymbol{e}_{m}^{\top}
\end{array}
$$

Where $\boldsymbol{w}_{c, m}$ is an $(N \times 1)$ vector of portfolio weights, $\Sigma$ is the $(N \times N)$ covariance matrix, $X$ an $(N \times M)$ characteristic matrix and $\boldsymbol{e}_{m}$ an $(M \times 1)$ vector with the $m^{\text {th }}$ entry equal to 1 and all others equal to 0 .

The Lagrangian is:

$$
\mathscr{L}=\boldsymbol{w}_{c, m}^{\top} \Sigma \boldsymbol{w}_{c, m}+\boldsymbol{\kappa}_{m}\left(\boldsymbol{e}_{m}-X^{\top} \boldsymbol{w}_{c, m}\right)
$$


The FOC with respect to $\boldsymbol{w}_{c, m}^{\top}$ is given as:

$$
\begin{gathered}
\Sigma \boldsymbol{w}_{c, m}-X \boldsymbol{\kappa}_{m}^{\top}=\mathbf{0} \\
\boldsymbol{w}_{c, m}=\Sigma^{-1} X \boldsymbol{\kappa}_{m}^{\top}
\end{gathered}
$$

The FOC with respect to $\boldsymbol{\kappa}_{m}$ is given as:

$$
\begin{aligned}
X^{\top} \boldsymbol{w}_{c, m} & =\boldsymbol{e}_{m} \\
\boldsymbol{\kappa}_{m}^{\top} & =\left(X^{\top} \Sigma^{-1} X\right)^{-1} \boldsymbol{e}_{m}
\end{aligned}
$$

Hence,

$$
\boldsymbol{w}_{c, m}^{*}=\Sigma^{-1} X\left(X^{\top} \Sigma^{-1} X\right)^{-1} \boldsymbol{e}_{m}
$$

The set of CEP weights, $W_{c}^{*}$, an $(N \times M)$ matrix, of which the $m$ th column is the vector of weights of the $m$ th CEP, can be written as

$$
W_{c}^{*}=\Sigma^{-1} X\left(X^{\top} \Sigma^{-1} X\right)^{-1}
$$

\section{B.2 Proof of Proposition 2.2}

Part 1: Let $\Sigma_{c}^{*}$ be the covariance matrix of CEP returns and $\boldsymbol{\mu}_{c}^{*}$ be the expected excess returns of the CEPs. Notice that under Assumption A1, we have that

$$
\Sigma_{c}^{*}=\left(X^{\top} \Sigma^{-1} X\right)^{-1} \text { and } \quad \mu_{c}^{*}=\lambda_{c}
$$

Hence, the maximum squared Sharpe ratio in the space spanned by $W_{c}^{*}$ is:

$$
S R^{\star 2}=\boldsymbol{\mu}_{c}^{\star \top} \Sigma_{c}^{\star-1} \boldsymbol{\mu}_{c}^{\star}=\boldsymbol{\lambda}_{c}^{\top} X^{\top} \Sigma^{-1} X \boldsymbol{\lambda}_{c}=\boldsymbol{\mu}^{\top} \Sigma^{-1} \boldsymbol{\mu}
$$

Hence, the CEPs span the MVE portfolio. 
Part 2: Let $B^{*}$ be the $(N \times M)$ matrix of loadings from a projection of assets' excess returns on the the CEPs' excess returns. Then:

$$
B^{*}=\Sigma W_{c}^{*}\left(W_{c}^{* \top} \Sigma W_{c}^{*}\right)^{-1}=X
$$

\section{B.3 Proof of Proposition 2.4}

Part 1: For each characteristic portfolio, the weight vector of the optimal hedge portfolio, $\boldsymbol{w}_{h, m}$, solves

$$
\begin{aligned}
\max _{\boldsymbol{w}_{h, m}} & \boldsymbol{w}_{h, m}^{\top} \boldsymbol{b}_{m} \\
\text { s.t. } & \boldsymbol{w}_{h, m}^{\top} X=\mathbf{0} \\
& \frac{1}{2} \boldsymbol{w}_{h, m}^{\top} \sum \boldsymbol{w}_{h, m}=\overline{\sigma^{2}}
\end{aligned}
$$

Where $\boldsymbol{b}_{m}$ is the $m^{\text {th }}$ multivariate regression coefficient of $\boldsymbol{r}$ on $\boldsymbol{r}_{c}$.

The Lagrangian is:

$$
\mathscr{L}=\boldsymbol{w}_{h, m}^{\top} \boldsymbol{b}_{m}-\boldsymbol{\kappa}_{1, m} X^{\top} \boldsymbol{w}_{h, m}+\kappa_{2, m}\left(\overline{\sigma^{2}}-\frac{1}{2} \boldsymbol{w}_{h, m}^{\top} \Sigma \boldsymbol{w}_{h, m}\right)
$$

The FOC with respect to $\boldsymbol{w}_{h, m}^{\top}$ is given as:

$$
\begin{array}{r}
\boldsymbol{b}_{m}-X \boldsymbol{\kappa}_{1, m}^{\top}-\kappa_{2, m} \Sigma \boldsymbol{w}_{h, m}=\mathbf{0} \\
\boldsymbol{w}_{h, m}=\frac{1}{\kappa_{2, m}} \Sigma^{-1}\left(\boldsymbol{b}_{m}-X \boldsymbol{\kappa}_{1, m}^{\top}\right)
\end{array}
$$

Solving the FOC with respect to $\boldsymbol{\kappa}_{1, m}$ for $\boldsymbol{\kappa}_{1, m}$ gives:

$$
\begin{gathered}
\left(\boldsymbol{b}_{m}^{\top}-\boldsymbol{\kappa}_{1, m} X^{\top}\right) \Sigma^{-1} X=\mathbf{0} \Longrightarrow \\
\boldsymbol{\kappa}_{1, m}=b_{m}^{\top} \Sigma^{-1} X\left(X^{\top} \Sigma^{-1} X\right)^{-1}
\end{gathered}
$$


Replacing $\boldsymbol{\kappa}_{1, m}$ we have:

$$
\boldsymbol{w}_{h, m}^{\star}=\Sigma^{-1}\left(B-X\left(X^{\top} \Sigma^{-1} X\right)^{-1} X^{\top} \Sigma^{-1} B\right) e_{\frac{1}{\kappa_{2, m}}}
$$

where $e_{\frac{1}{\kappa_{2, m}}}$ is an $(M \times 1)$ vector with the $m^{\text {th }}$ entry equal to $\frac{1}{\kappa_{2, m}}$ and all others equal to 0 . Substituting $B$ we have:

$$
\boldsymbol{w}_{h, m}^{*}=\left(W_{c} \Sigma_{c}^{-1}-\Sigma^{-1} X\left(X^{\top} \Sigma^{-1} X\right)^{-1} X^{\top} W_{c} \Sigma_{c}^{-1}\right) e_{\frac{1}{\kappa_{2}, m}}
$$

By solving the problem for all characteristics $m$ and substituting $W_{c}^{*}$, we have:

$$
W_{h}^{*}=\left(W_{c}-W_{c}^{*} X^{\top} W_{c}\right) \Sigma_{c}^{-1} E^{-1}
$$

where $E$ is an $(M \times M)$ diagonal matrix, with columns $e_{\kappa_{2, m}}$.

Part 2: Rearranging Equation B.22 we have

$$
W_{c}^{*} X^{\top} W_{c}=W_{c}-W_{h} E \Sigma_{c}
$$

Define $\Delta^{*}=E \Sigma_{c}$ and $A=X^{\top} W_{c}$. Hence,

$$
W_{c}^{*} A=W_{c}-W_{h}^{*} \Delta^{*}
$$

\section{B.4 The optimal hedge ratio}

The last step is to find the optimal hedge ratio $\Delta^{*}$

Let

$$
\widetilde{W_{c}^{*}}=W_{c}^{\star} X^{\top} W_{c}
$$


And

$$
\widetilde{\Sigma}_{c}^{*}=\operatorname{Var}\left[\widetilde{W}_{c}^{* \top} R\right]=W_{c}^{\top} X\left(X^{\top} \Sigma^{-1} X\right)^{-1} X^{\top} W_{c}
$$

From Equation (B.24) we have:

$$
\begin{gathered}
W_{h} E_{\kappa_{2}} \Sigma_{c}=W_{c}-\widetilde{W}_{c}^{*} \\
\operatorname{Var}\left[\Sigma_{c} E_{\kappa_{2}} W_{h}^{\top} R\right]=\operatorname{Var}\left[\left(W_{c}-\widetilde{W}_{c}^{*}\right)^{\top} R\right] \\
\Longrightarrow \Sigma_{c} E_{\kappa_{2}} \Sigma_{h} E_{\kappa_{2}} \Sigma_{c}=\Sigma_{c}-\widetilde{\Sigma}_{c}^{*}
\end{gathered}
$$

But,

$$
\widetilde{\Sigma}_{c}^{*}=\Sigma_{c}+\Sigma_{c} E_{\kappa_{2}} \Sigma_{h} E_{\kappa_{2}} \Sigma_{c}-2 W_{c}^{\top} \Sigma W_{h} E_{\kappa_{2}} \Sigma_{c}
$$

Substituting, we have:

$$
\begin{aligned}
\Sigma_{c} E_{\kappa_{2}} \Sigma_{h} E_{\kappa_{2}} \Sigma_{c} & =W_{c}^{\top} \Sigma W_{h} E_{\kappa_{2}} \Sigma_{c} \Longrightarrow \\
\Delta^{*} & =\Sigma_{c} E_{\kappa_{2}}=W_{c}^{\top} \Sigma W_{h} \Sigma_{h}^{-1}
\end{aligned}
$$

\section{Empirical details}

\section{C.1 Empirical definition of main variables}

We use data from Compustat and CRSP, downloaded directly from the WRDS data service. 


\begin{tabular}{|c|c|}
\hline Book Equity (BE) & $\begin{array}{l}\text { Stockholders book equity, minus the book value of preferred } \\
\text { stock, plus balance sheet deferred taxes (if available and fiscal } \\
\text { year is < 1993), minus investment tax credit (if available), mi- } \\
\text { nus post-retirement benefit assets (PRBA) if available. Stock- } \\
\text { holders book equity is shareholder equity (SEQ), common eq- } \\
\text { uity (CEQ) plus preferred stock (PSTK) or total assets (AT) } \\
\text { minus liabilities (LT) plus minority interest (MIB, if available) } \\
\text { (depending on availability, in that order). Book value of pre- } \\
\text { ferred stock is redemption (PSTKRV), liquidation (PSTKL), } \\
\text { or par value (PSTK) (depending on availability, in that or- } \\
\text { der). Deferred taxes is deferred taxes and investment tax } \\
\text { credit (TXDITC) or deferred taxes and investment tax credit } \\
\text { (TXDB) plus investment tax credit (ITCB) (depending on } \\
\text { availability, in that order). }\end{array}$ \\
\hline Market Equity (ME) & $\begin{array}{l}\text { Total firm market value }(|P R C| * S H R O U T) \text { summed over } \\
\text { all securities belonging to a firm, identified by GVKEY, and } \\
\text { if missing, by PERMCO, as of June. We give preference to } \\
\text { GVKEY to correctly account for tracking stocks. To be valid, } \\
\text { ME must be greater than zero. }\end{array}$ \\
\hline Book to Market (BEME) & $\begin{array}{l}\text { Book equity as of December divided by market equity as of } \\
\text { December }\left(\frac{B E}{M E}\right) \text {. }\end{array}$ \\
\hline Investment (INV) & $\begin{array}{l}\text { Total asset (AT) growth }\left(\frac{A T_{t}}{A T_{t-1}}-1\right) \text {. We consider PERMCO } \\
\text { as the identification key. AT must be greater than zero to be } \\
\text { considered. }\end{array}$ \\
\hline Operating Profitability (OP) & $\begin{array}{l}\text { Operating profitability to book equity (BE) ratio. Operating } \\
\text { profitability is sales (SALE) minus cost of goods sold (COGS), } \\
\text { minus selling, general, and administrative expenses (XSGA), } \\
\text { minus interest expense (XINT). In order to be non-missing, } \\
\text { SALE must be non-missing, at least one of the other entries } \\
\text { must be non-missing and BE must be greater than zero. }\end{array}$ \\
\hline
\end{tabular}




\section{C.2 Loading estimation}

We calculate ex-ante forecasts of loadings for $b$ 's, i.e., loadings on the benchmark characteristic portfolios; and for $\delta$ 's, i.e., the optimal hedge ratio.

To calculate ex-ante forecasts of loadings we follow Frazzini and Pedersen (2014) and use two different data windows of individual stock returns: 12-months of daily returns for volatility and 60 months of overlapping 3-day-cumulated returns for correlation. For this estimation, we only consider returns where $P_{t}$ and $P_{t-1}$ are non-missing.

For the estimation of correlations and factor volatilities, we calculate Daniel and Titman (1997) style pre-formation factor returns. Following their procedure, we use portfolio allocations and weights as of June 30 (portfolio formation date), and calculate portfolio returns for the preceding 5 years, holding the allocation and weights constant for each day.

Finally, we consider the observation that returns of stocks that will be allocated to a particular portfolio at the end of June, experience a level-shift in average returns starting already in January, as described in Daniel and Titman (1997). To account for this, when we calculate $b$ 's, we include a dummy variable for the rank-year, i.e., a variable that is equal to 1 if the return observation belongs to the year of portfolio formation.

\section{C.3 Dealing with missing prices}

CRSP stock files report missing values for returns (RET) if a stock does not have a valid price for 10 periods or more. The price tolerance period represents 10 months for monthly returns and 10 days for daily returns. For calculating traded portfolio returns, we instead follow Ken French's website and allow for a 200 days price tolerance period. This choice makes daily and monthly returns comparable. For pre-formation factors as described above, where all returns can be observed before formation, we exclude any observation with a missing price (as described above). 


\section{Supplemental results}

\section{D.1 Portfolio bin population}

Table D.1: Time-series minimum/mean/maximum number of firms for which loading forecast could be calculated, within each size-characteristic sorted portfolio.

Panel A: ME × BEME

\begin{tabular}{llrrr}
\hline \multicolumn{3}{l}{ Portfolio } & \multicolumn{3}{l}{ No. of firms } \\
\hline ME & BEME & min & mean & max \\
\hline 1 & 1 & 27 & 565 & 1042 \\
1 & 2 & 86 & 554 & 968 \\
1 & 3 & 189 & 963 & 1818 \\
2 & 1 & 78 & 255 & 427 \\
2 & 2 & 119 & 220 & 323 \\
2 & 3 & 88 & 152 & 198 \\
3 & 1 & 140 & 256 & 468 \\
3 & 2 & 101 & 158 & 221 \\
3 & 3 & 45 & 95 & 163 \\
\hline
\end{tabular}

Panel B: $\mathrm{ME} \times \mathrm{OP}$

\begin{tabular}{llrrr}
\hline \multicolumn{4}{l}{ Portfolio } & \multicolumn{3}{l}{ No. of firms } \\
\hline ME & OP & min & mean & max \\
\hline 1 & 1 & 100 & 1177 & 2142 \\
1 & 2 & 30 & 499 & 797 \\
1 & 3 & 24 & 381 & 784 \\
2 & 1 & 75 & 189 & 348 \\
2 & 2 & 68 & 217 & 319 \\
2 & 3 & 60 & 208 & 303 \\
3 & 1 & 52 & 112 & 199 \\
3 & 2 & 114 & 174 & 245 \\
3 & 3 & 121 & 219 & 311 \\
\hline
\end{tabular}

Panel C: ME × INV

\begin{tabular}{llrrr}
\hline \multicolumn{3}{l}{ Portfolio } & \multicolumn{3}{l}{ No. of firms } \\
\hline ME & INV & min & mean & max \\
\hline 1 & 1 & 65 & 914 & 1462 \\
1 & 2 & 29 & 517 & 967 \\
1 & 3 & 44 & 701 & 1297 \\
2 & 1 & 68 & 161 & 268 \\
2 & 2 & 38 & 201 & 309 \\
2 & 3 & 52 & 262 & 388 \\
3 & 1 & 51 & 122 & 210 \\
3 & 2 & 116 & 192 & 236 \\
3 & 3 & 86 & 195 & 323 \\
\hline
\end{tabular}

Table D.1 displays the minimum, mean and maximum population of the $3 \times 3$ independently sorted ME $\times$ BEME, ME $\times \mathrm{OP}$, and $\mathrm{ME} \times \mathrm{INV}$ portfolios, counting only firms for which a forecast loading is available. Within each of these, stocks are sorted within a characteristic bucket, on the respective forecast loadings, i.e., when we divide the displayed numbers by three, we have the minimum/mean/maximum number of firms of any of the 27 portfolios that the hedge portfolios are based on.

It turns out that the resulting portfolios end up well-populated. The lowest number of firms occurs in the small/high-OP portfolio, in 1964, when the small/high-OP portfolio contains 24 firms. In general, even portfolios of big/value stocks contain 95 stocks, on average, resulting in loading-sorted portfolios with more than 30 stocks.

\section{D.2 High power vs. low power}

The achievable improvement on a set of CPs intimately depends on the post-formation loadings of the hedge portfolios. Since the hedge portfolios have roughly zero expected returns, more negative loadings means that we are capturing variation in loadings that is 
not related to returns, which is translated in positive $\alpha$ s. Therefore, once we add these portfolios to the original CPs we should expect large Sharpe ratio improvements.

Maximizing the variation in loadings that is not related to returns relates to the power of the test that has as null hypothesis that the CPs form a valid asset pricing model (Daniel and Titman, 2012).

We show how the use of the methodology to forecast loadings advanced in this paper, which we refer to as the "high power" methodology, increases the power of standard asset pricing tests. We illustrate how a standard "low power" methodology used to estimate the loadings (see, e.g., Daniel and Titman, 1997; Davis et al., 2000) leads to a failure to reject asset pricing models and thus imposes too low a bound on the volatility of the stochastic discount factor. We do so by constructing characteristic balanced portfolios and showing that the ability of standard asset pricing models to properly account for their average returns depends critically on whether one uses the low or high power methodology.

The traditional low power approach uses as instruments for future loadings the result of regressing monthly stock excess returns on characteristic portfolio excess returns over a moving fixed-sized window based on, e.g., 36 or 60 monthly observations, skipping the most recent 6 months.

We first compare the low and high power methodology by looking at the post-formation loadings. We estimate the post-formation loadings by running a full-sample time series regression of the monthly excess returns on the five FF CPs (see equation (31)). To check whether our high power methodology results in larger dispersion of the post-formation loadings when compared to the low power methodology, Figure D.1 shows the post-formation loadings on the $\mathrm{x}$-axis and the respective average characteristic on the $\mathrm{y}$-axis for each of the 27 portfolios. Panels A and B correspond to the low and high power methodology, respectively.

Consider, for example, the top panels in Figure D.1, which focus on the loadings on HML for each of the two estimation methodologies. There are $3 \times 3$ groups of estimates - connected by lines - each corresponding to a particular BEME $\times$ ME bin. Each of those lines have three points corresponding to the three portfolios from the conditional sort on ex-ante estimated loadings.

The ideal output would be to find variation in the loadings that is not associated with variations in characteristics, our proxy for expected returns. Hence, the ideal equivalent 
of Figure D.1 would be one in which the spread from low betas (red dots) and high betas (green dots) is maximized, but conditional on belonging to a characteristic bucket, there is no additional correlation between the characteristic and the forecast loading, i.e., the dashed lines are perfectly horizontal.

As it is readily apparent from Figure D.1, the high power methodology generates substantially more cross-sectional dispersion in post-formation loadings than the low power methodology, which is key to generating hedge portfolios that are maximally correlated with the candidate characteristic portfolio. For example, focus on the loadings on HML for the large growth portfolios (portfolio $(1,3)$ ). The low power methodology generates post-formation loadings on HML, $b_{H M L}$, for each of the three portfolios of $-0.43,-0.22$ and 0.01 , respectively. The high power methodology instead generates post-formation HML loadings of $-0.48,-0.18$ and 0.16 , respectively. For the low power methodology, the loading of a portfolios that goes long on the low loading portfolio and short the high loading portfolios is -0.44 with a $t$-statistic of -8.76 . For the high power methodology the same post-formation loading is -0.64 with a $t$-statistic of -12.66 .

Notice that, reassuringly, both methodologies generate a positive correlation between preand post-formation loadings for each of the book-to-market and size groupings. This positive correlation between pre- and post extends to the case of CMA. But in the case of the loadings on RMW, the low power methodology does not produce a consistent positive association between pre- and post-formation loadings, whereas the high power methodology does.

The spreads in the loadings translate directly into the ability to reject the FF model. Table D.2 Panel A shows the results of time series regressions of the low power hedge portfolios on the FF CPs. First, notice that the average returns of the hedge portfolios are not statistically different from zero, as in the high power case (Panel B). Second, notice that the loadings of each hedge portfolio on the respective FF CP is much lower for the low power, compared to the high power methodology. For example, the $b_{H M L}$ for the high power methodology is -0.79 with a $t$-statistics of -27.8 , whereas for the low power it is -0.54 with a $t$-statistic of -19.55. Finally, we can look at the $\alpha$ 's. For the low power method we cannot reject the FF model using any of the hedge portfolios in isolation, since all $\alpha$ 's are not statistically different from zero. For the equal weighted combinations of hedge portfolios shown in the last rows of the table, we can see that the $t$-statistics of the $\alpha$ s are significantly positive even for the low 
power methodology. However, the equal weight combination $\alpha$ s are systematically bigger for the high power methodology.

In sum then our high power methodology forecasts future loadings better than the one used by Daniel and Titman (1997) or Davis et al. (2000) and, as a result, they translate into more efficient hedge portfolios as well as asset pricing tests with higher power. 
Figure D.1: Ex-post loading vs. characteristic. This figure shows the time-series average of post-formation characteristic portfolio loading on the $\mathrm{x}$-axis and the time-series average of the respective characteristic on the $y$-axis of each of the 27 portfolios formed on size, characteristic (book-to-market/operating profitability/investment) and characteristic portfolio loading. Panel A uses the low power methodology and B uses the high power methodology. The first row uses sorts on book-to-market and HML-loading, the second one operating profitability and RMW-loading and the last one investment and CMA-loading.

Panel A: Low power
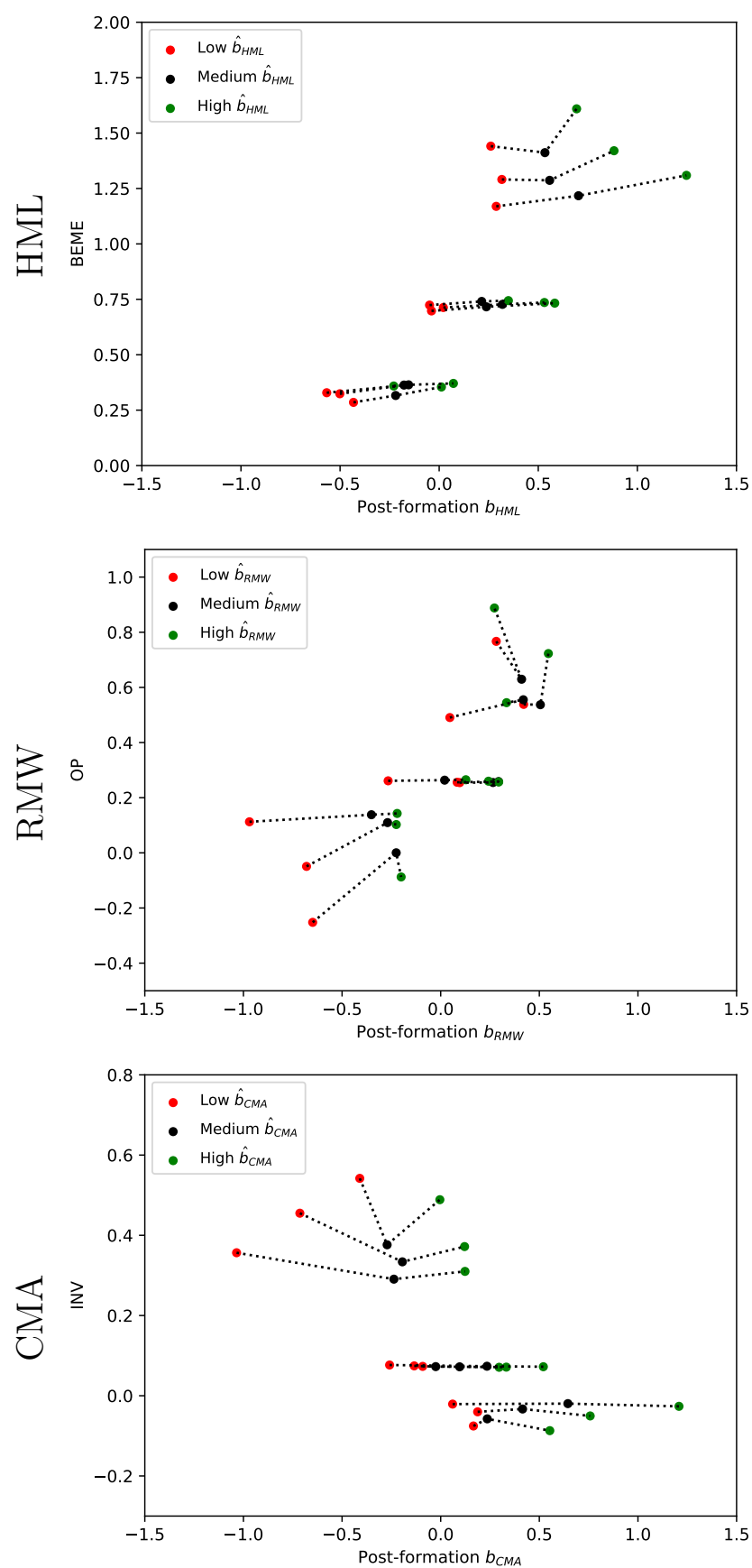

Panel B: High power
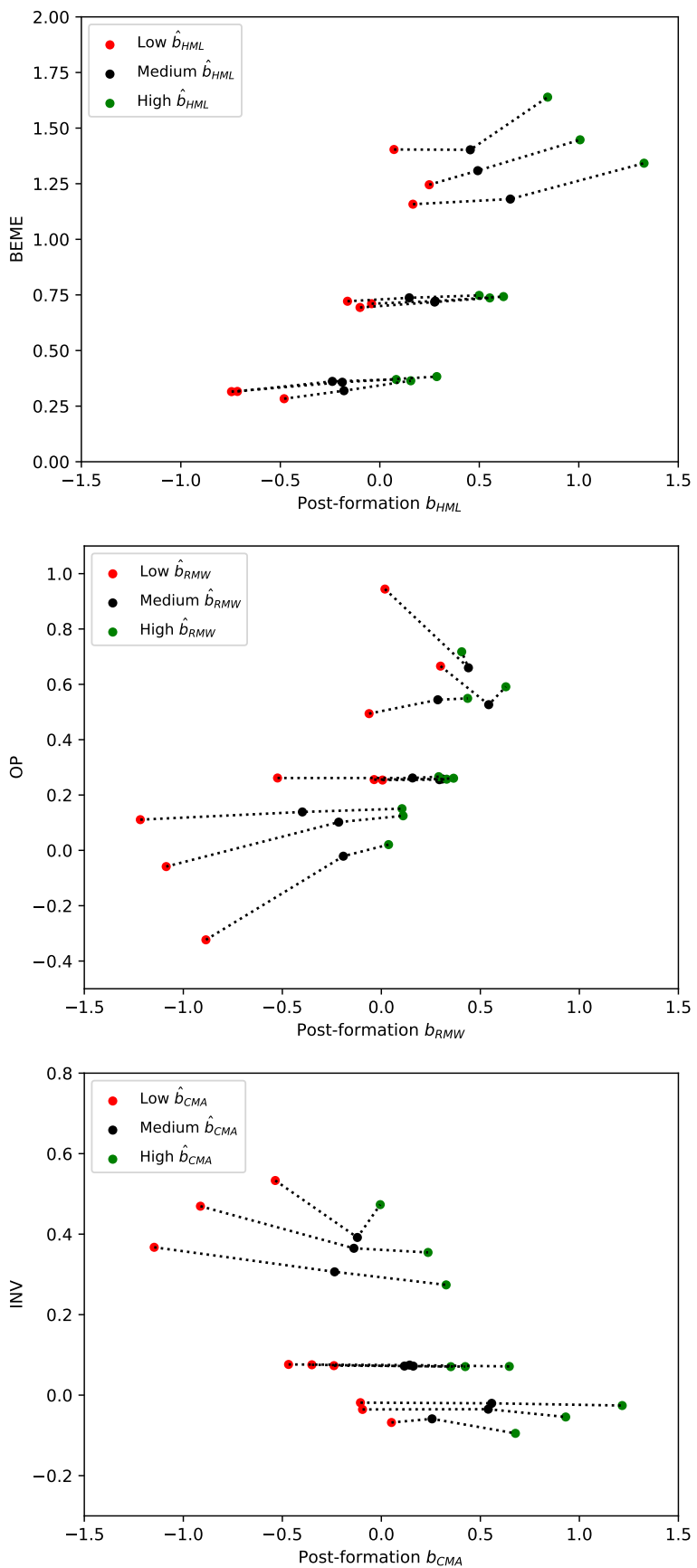


\section{Table D.2: Results of time-series regressions on characteristic-balanced hedge-}

portfolios.

Stocks are first sorted based on size and one of book-to-market, profitability or investment into $3 \times 3$ portfolios. Conditional on those sorts, they are subsequently sorted into 3 portfolios based on the respective loading, i.e., on HML, RMW or CMA. For MktRF and SMB we use the average of three hedge portfolios, which are based on a $3 \times 3$ sort on size and book-to-market, profitability or investment. The hedge portfolio then goes long the low loading and short the high loading portfolios. On the bottom, we form combination-portfolios that put equal weight on three (HML, RMW, CMA), four (HML, RMW, CMA, MktRF) or five (HML, RMW, CMA, MktRF, SMB) hedge portfolios. Monthly returns of these portfolios are then regressed on the 5 Fama and French (2015) characteristic portfolios in the sample period from 1963/07 - 2019/06. In Panel A we use the low power and in Panel B we use the high power methodology for forecasting loadings.

Panel A: Low power

\begin{tabular}{lrrrrrrrr}
\hline Hedge-Portfolio & Avg. & $\alpha$ & $b_{M k t-R F}$ & $b_{S M B}$ & $b_{H M L}$ & $b_{R M W}$ & $b_{C M A}$ & $R^{2}$ \\
\hline$r_{h, M k t R F}$ & -0.13 & 0.01 & -0.29 & -0.22 & 0.07 & 0.16 & 0.02 & 0.57 \\
& $(-1.42)$ & $(0.22)$ & $(-18.39)$ & $(-10.17)$ & $(2.36)$ & $(5.12)$ & $(0.42)$ & \\
$r_{h, S M B}$ & -0.11 & -0.02 & -0.14 & -0.38 & 0.04 & 0.09 & 0.17 & 0.59 \\
& $(-1.40)$ & $(-0.32)$ & $(-10.37)$ & $(-19.67)$ & $(1.44)$ & $(3.38)$ & $(4.06)$ & \\
$r_{h, H M L}$ & -0.04 & 0.05 & -0.00 & -0.00 & -0.54 & -0.05 & 0.44 & 0.39 \\
& $(-0.51)$ & $(0.82)$ & $(-0.32)$ & $(-0.18)$ & $(-19.55)$ & $(-1.66)$ & $(10.24)$ & \\
$r_{h, R M W}$ & -0.04 & 0.09 & 0.03 & -0.01 & -0.19 & -0.31 & -0.00 & 0.33 \\
& $(-0.61)$ & $(1.59)$ & $(2.47)$ & $(-0.74)$ & $(-7.26)$ & $(-11.51)$ & $(-0.11)$ & \\
$r_{h, C M A}$ & 0.02 & 0.10 & -0.04 & 0.01 & 0.28 & 0.00 & -0.68 & 0.31 \\
& $(0.28)$ & $(1.74)$ & $(-2.57)$ & $(0.36)$ & $(10.35)$ & $(0.10)$ & $(-16.04)$ & \\
\hline \multirow{2}{*}{ EW3 } & -0.02 & 0.08 & -0.00 & -0.00 & -0.15 & -0.12 & -0.08 & 0.41 \\
HML,RMW,CMA & $(-0.53)$ & $(2.71)$ & $(-0.33)$ & $(-0.35)$ & $(-10.93)$ & $(-8.38)$ & $(-3.74)$ & \\
EW4 & -0.05 & 0.06 & -0.07 & -0.06 & -0.09 & -0.05 & -0.06 & 0.28 \\
EW3+MktRF & $(-1.46)$ & $(2.18)$ & $(-10.37)$ & $(-5.86)$ & $(-7.00)$ & $(-3.55)$ & $(-2.61)$ & \\
EW5 & -0.05 & 0.05 & -0.07 & -0.10 & -0.08 & -0.04 & -0.03 & 0.32 \\
EW4+SMB & $(-1.61)$ & $(1.88)$ & $(-10.43)$ & $(-9.76)$ & $(-6.27)$ & $(-2.86)$ & $(-1.31)$ & \\
\hline
\end{tabular}

Panel B: High power

\begin{tabular}{lrrrrrrrr}
\hline Hedge-Portfolio & Avg. & $\alpha$ & $b_{M k t-R F}$ & $b_{S M B}$ & $b_{H M L}$ & $b_{R M W}$ & $b_{C M A}$ & $R^{2}$ \\
\hline$r_{h, M k t R F}$ & -0.10 & 0.18 & -0.41 & -0.39 & -0.05 & 0.17 & 0.07 & 0.66 \\
& $(-0.80)$ & $(2.37)$ & $(-22.33)$ & $(-15.05)$ & $(-1.37)$ & $(4.72)$ & $(1.25)$ & \\
$r_{h, S M B}$ & -0.17 & -0.02 & -0.17 & -0.55 & 0.01 & 0.15 & 0.16 & 0.72 \\
& $(-1.72)$ & $(-0.45)$ & $(-12.37)$ & $(-28.33)$ & $(0.34)$ & $(5.55)$ & $(4.00)$ & \\
$r_{h, H M L}$ & -0.08 & 0.11 & -0.03 & 0.05 & -0.79 & -0.20 & 0.53 & 0.61 \\
& $(-0.83)$ & $(1.80)$ & $(-1.86)$ & $(2.42)$ & $(-27.80)$ & $(-6.85)$ & $(11.71)$ & \\
$r_{h, R M W}$ & -0.07 & 0.22 & 0.05 & -0.04 & -0.31 & -0.69 & -0.11 & 0.66 \\
& $(-0.73)$ & $(3.91)$ & $(3.26)$ & $(-1.96)$ & $(-11.66)$ & $(-24.90)$ & $(-2.63)$ & \\
$r_{h, C M A}$ & 0.04 & 0.20 & -0.04 & -0.02 & 0.31 & -0.09 & -0.96 & 0.43 \\
& $(0.52)$ & $(3.33)$ & $(-2.48)$ & $(-0.86)$ & $(10.72)$ & $(-2.96)$ & $(-21.01)$ & \\
\hline \multirow{2}{*}{ EW3 } & -0.03 & 0.18 & -0.01 & -0.00 & -0.26 & -0.33 & -0.18 & 0.70 \\
HML,RMW,CMA & $(-0.61)$ & $(5.48)$ & $(-0.82)$ & $(-0.18)$ & $(-17.29)$ & $(-20.59)$ & $(-7.46)$ & \\
EW4 & -0.05 & 0.18 & -0.11 & -0.10 & -0.21 & -0.20 & -0.12 & 0.58 \\
EW3+MktRF & $(-1.15)$ & $(5.93)$ & $(-14.51)$ & $(-9.47)$ & $(-14.91)$ & $(-13.82)$ & $(-5.30)$ & \\
EW5 & -0.07 & 0.15 & -0.10 & -0.15 & -0.19 & -0.17 & -0.09 & 0.56 \\
EW4+SMB & $(-1.54)$ & $(5.06)$ & $(-14.04)$ & $(-14.58)$ & $(-13.50)$ & $(-11.82)$ & $(-3.96)$ & \\
\hline
\end{tabular}

